NBER WORKING PAPER SERIES

ALCOHOL EXPOSURE IN UTERO AND CHILD ACADEMIC ACHIEVEMENT

\author{
Stephanie von Hinke Kessler Scholder \\ George L. Wehby \\ Sarah Lewis \\ Luisa Zuccolo \\ Working Paper 19839 \\ http://www.nber.org/papers/w19839
}

\author{
NATIONAL BUREAU OF ECONOMIC RESEARCH \\ 1050 Massachusetts Avenue \\ Cambridge, MA 02138 \\ January 2014
}

We thank Neil Davies, Jason Fletcher, Steve Lehrer, Debbie Lawlor, Maarten Lindeboom, Owen O'Donnell, Christine Valente, Frank Windmeijer, conference participants at the Integrating Genetics and Social Science Conference, the 20th Workshop on Health Economics and Econometrics, the 2013 Royal Economic Society conference, and seminar participants at the University of Sheffield and University College Dublin for helpful comments on earlier version of this paper. We are extremely grateful to all the families who took part in this study, the midwives for their help in recruiting them, and the whole ALSPAC team, which includes interviewers, computer and laboratory technicians, clerical workers, research scientists, volunteers, managers, receptionists and nurses. The UK Medical Research Council (MRC), the Wellcome Trust and the University of Bristol provide core support for ALSPAC. This publication is the work of the authors, who will serve as guarantors for the contents of this paper. We gratefully acknowledge financial support from the UK Economic and Social Research Council (PTA026-27-2335), the UK Medical Research Council (G1002345, G0902144), and the NIH/NIDCR (R01 DE020895). The views expressed herein are those of the authors and do not necessarily reflect the views of the National Bureau of Economic Research.

NBER working papers are circulated for discussion and comment purposes. They have not been peerreviewed or been subject to the review by the NBER Board of Directors that accompanies official NBER publications.

(C) 2014 by Stephanie von Hinke Kessler Scholder, George L. Wehby, Sarah Lewis, and Luisa Zuccolo. All rights reserved. Short sections of text, not to exceed two paragraphs, may be quoted without explicit permission provided that full credit, including $(\mathbb{C}$ notice, is given to the source. 
Alcohol Exposure In Utero and Child Academic Achievement

Stephanie von Hinke Kessler Scholder, George L. Wehby, Sarah Lewis, and Luisa Zuccolo NBER Working Paper No. 19839

January 2014

JEL No. I12,J24

\begin{abstract}
We examine the effect of alcohol exposure in utero on child academic achievement. As well as studying the effect of any alcohol exposure, we investigate the effect of the dose, pattern, and duration of exposure. We use a genetic variant in the maternal alcohol-metabolism gene $A D H 1 B$ as an instrument for alcohol exposure, whilst controlling for the child's genotype on the same variant. We show that the instrument is unrelated to an extensive range of maternal and paternal characteristics and behaviours. OLS regressions suggest an ambiguous association between alcohol exposure in utero and children's academic attainment, but there is a strong social gradient in maternal drinking, with mothers in higher socio-economic groups more likely to drink. In stark contrast to the OLS, the IV estimates show negative effects of prenatal alcohol exposure on child educational attainment. These results are very robust to an extensive set of model specifications. In addition, we show that that the effects are solely driven by the maternal genotype, with no impact of the child's genotype.
\end{abstract}

Stephanie von Hinke Kessler Scholder

Department of Economics and Related Studies

University of York

Heslington, York, YO10 5DD

United Kingdom

Stephanie.Scholder@york.ac.uk

George L. Wehby

Department of Health Management and Policy

College of Public Health

University of Iowa

N248 CPHB, 105 River Street

Iowa City, IA 52242

and NBER

george-wehby@uiowa.edu
Sarah Lewis

MRC Integrative Epidemiology Unit

School of Social and Community

Medicine University

S.J.Lewis@bristol.ac.uk

Luisa Zuccolo

MRC Integrative Epidemiology Unit

School of Social and Community

Medicine University

L.Zuccolo@bristol.ac.uk 


\section{Introduction and Literature}

The first scientific study that examined the effects of excessive alcohol intake during pregnancy was published by a Liverpool prison physician in 1899 (Sullivan, 1899). He argued that alcohol consumption caused the higher rates of stillbirth observed among female alcoholic prisoners compared to their sober counterparts. The detrimental effects of excessive drinking during pregnancy are currently well-known. The effects of low-to-moderate drinking, however, are less conclusive. Indeed, there are conflicting recommendations regarding the 'threshold' for maternal prenatal alcohol consumption, ranging from total abstinence in most countries including the US to restricted consumption in the UK. Only in 1995 did the UK Department of Health issue guidelines for women who were (planning to become) pregnant, stating that "women should not drink more than 1 or 2 units of alcohol once or twice a week, and should avoid episodes of intoxication” (DH, 1995). Their most recent guidelines are very similar: despite advising pregnant women not to drink in the first three months of pregnancy, they mention that, if women choose to drink, they should not exceed 1 to 2 units once or twice a week, as "at this low level, there is no evidence of any harm to the unborn baby” (NICE, 2008).

These conflicting recommendations arise from inconsistent findings in observational studies of the correlation between low-to-moderate alcohol consumption and child development (including physical and mental health, cognitive and behavioural outcomes). Some find negative effects on child development, some do not find evidence of developmental differences, and others argue it improves child outcomes (for reviews of this literature, see e.g. Gray and Henderson, 2006; Polygenis et al., 1998; Abel and Hannigan, 1995). One of the major problems in estimating the causal effects of prenatal alcohol consumption is that it is a choice; as such, it may be related to other unobserved characteristics that also affect the outcome of interest, biasing the estimates.

This paper examines the impact of alcohol exposure in utero, as proxied by whether the mother consumed any alcohol during pregnancy, on child academic achievement. We also investigate the effect of the dose, pattern, and duration of exposure. We deal with unobserved residual confounding using 'Mendelian randomization', referring to the random allocation of an individual's genotype at conception (Davey Smith and Ebrahim, 2003). Although this allocation is random at the family trio level (i.e. from parents to children), at a population level it has been shown that genetic variants are largely unrelated to the many socioeconomic and behavioural characteristics that are closely linked with each other and that 
confound conventional observational studies. This has been shown using a wide range of genetic variants ${ }^{1}$, different data sources $^{2}$, and for an extensive set of background characteristics $^{3}$ (see e.g. Bhatti et al., 2005; WTCCC, 2007; Davey Smith et al., 2008; Kivimäki et al., 2008; von Hinke Kessler Scholder et al., 2011; Lawlor et al., 2013). ${ }^{4}$ Hence, we employ a carefully validated genetic variant that is associated with decreased alcohol exposure as an instrumental variable (IV) for exposure to alcohol in utero (Zuccolo et al., 2009). Under assumptions discussed in detail below, genetic variants are independent of unobservable confounders, including those that occur in utero. As such, Mendelian randomization can be exploited to make causal inferences about the effects of behavioural or health conditions that have (at least partly) a genetic aetiology on certain outcomes of interest. For a brief introduction to some of the genetic terms referred to in this study, see Appendix A.

Our contribution to the literature is, first, to examine the causal effects of prenatal alcohol exposure on child development. As suggested by the relatively few studies attempting to investigate the causal effects (see below), it is particularly difficult to estimate these due to unobserved residual confounding. Second, as it is obviously unethical to design a randomized controlled trial, we show that quasi-experimental designs, such as Mendelian randomization, may provide a powerful and useful alternative for causal inference. We also present a thorough discussion of the assumptions required in Mendelian randomization experiments,

\footnotetext{
${ }^{1}$ Including, for example, $L A C 1$ (rs4988235), CETP (rs708272), TNF- $\alpha$ (rs1800629), GPX4 (rs1007), MTHFR (rs1801133), FTO (rs9939609), as well as the variant used here (ADH1B, rs1229984).

${ }^{2}$ Such as the British Women Heart and Health Study, the Young Finns Study, the Copenhagen General Population Study, the Avon Longitudinal Study of Parents and Children, as well as different case-control samples.

${ }^{3}$ These include more 'medical' characteristics (e.g. pulse, lung function, vitamin levels, haemoglobin, fasting insulin, fasting glucose, fibrinogen, C-reactive protein, plasma viscosity, etc.) as well as socioeconomic or behavioural characteristics (e.g. area deprivation, SES, types of foods/drinks consumed, time use, walking speed, educational level, age when parents died, housing characteristics, nurse estimation of life expectancy, etc.)

${ }^{4}$ For example, Bhatti et al. (2005) explores differences in polymorphism frequencies by willingness to participate in studies. They examine three studies with different recruitment designs and different participation incentives. Conditional on having provided blood or saliva samples, they investigate whether genotype frequencies differ by the timing of non-response to questionnaires (early, late and never responders), finding no systematic correlations. Davey Smith et al. (2008) estimate pairwise correlations between non-genetic and genetic variables and compare the number of correlations that are statistically significant with the number expected by chance if all variables were uncorrelated. They show significant correlations between behavioural, socioeconomic and physiological factors, with $45 \%$ of the 4,560 pairwise correlations being significant at the $1 \%$ level. In contrast, genetic variants show no greater association with each other, nor with the behavioural, socioeconomic and physiological factors than what would be expected by chance. Consistent with these findings, the allele frequencies in British blood donors have been shown to be virtually identical to those in the British 1958 cohort study (WTCCC, 2007). The former are clearly a highly selected sample in the population, whereas the latter includes a nationally representative sample of all children born in one week in Britain. Taken together, this suggests that genetic variants are generally unrelated to potential confounders.
} 
and provide additional evidence on the validity of genetic variants as instrumental variables by testing its correlation with an unusually wide range of maternal and paternal characteristics and behaviours. Third, we add to the literature on the long-term effects of the early environment on later child outcomes (for a recent overview, see Almond and Currie, 2011), on potential differential investments by parents in response to child development (Almond and Mazumder, 2013), as well as on identifying important periods of parental investments per se (Cunha and Heckman, 2007). Finally, we provide advice to policy makers, distinguishing between the effects of low-to-moderate versus excessive alcohol exposure in utero.

We start by presenting some simple descriptive statistics about the prevalence of maternal prenatal alcohol consumption, as these are not well documented in the economics literature. We show that $63 \%$ of pregnant women drink at some point during pregnancy, with $17 \%$ reporting that they binged (defined as drinking four units of alcohol in a day). On average, women drink 1.5 units of alcohol per week. OLS regressions show an ambiguous association between alcohol exposure in utero and children's educational attainment, with exposure to wine having a positive association, but exposure to beer being negative. Binge drinking is bad for the child, but a longer exposure to alcohol (in terms of the number of trimesters) is positively associated with the child's outcomes.

We then present evidence of a strong social gradient in alcohol exposure, with older mothers, and those of higher socio-economic position being more likely to drink during pregnancy, and particularly drink wine. Beer consumption on the other hand, is associated with smoking, lower education, and worse mental health. We use a genetic variant in the maternal Alcohol Dehydrogenase 1B gene, an alcohol-metabolizing gene, as an instrument for prenatal alcohol exposure. We show that the SNP is associated with alcohol exposure in utero. In addition, we demonstrate that it is not related to any of the background characteristics that we show to be associated with prenatal drinking. To provide additional evidence on the validity of our IV approach, we exploit the richness of our data and correlate the SNP to an unusually extensive range of maternal and paternal prenatal characteristics and behaviours; we find no evidence of any systematic associations that would suggest the instrument is invalid. In stark contrast to the OLS, our IV estimates show strong negative effects of alcohol exposure in utero on child educational achievement, which are robust to a large set of model specifications. In addition, the reduced form regressions show that the effects are solely driven by the maternal SNP, with no impact of the child's SNP on the child's academic attainment. The results also 
suggest that low-to-moderate (as opposed to excessive) exposure may have similar negative effects on child outcomes. Yet, despite the large negative effects, we find little evidence of differential parental responsive investments to child development, exploring an unusually wide range of parental postnatal responses and behaviours.

The relatively few studies in the economics literature that have attempted to deal with unobserved confounding related to prenatal alcohol exposure generally find large negative effects on child development. ${ }^{5}$ Exploiting a Swedish alcohol policy experiment from the 1960s that increased alcohol availability in two Swedish counties by allowing grocery stores to sell strong beer, Nilsson (2008) investigates the effects of prenatal alcohol exposure on a set of adult outcomes. The policy experiment led to a sharp increase in alcohol consumption in the experimental regions, particularly among youths, causing the experiment to be discontinued prematurely. Using a difference-in-difference-in-differences design, he finds that children born to mothers under age 21, who have the longest prenatal exposure to the experiment at delivery, have a lower human capital attainment later in life: total years of schooling are reduced by 0.27 on average, with males being more affected ( 0.47 years) than females (0.10 years). Children exposed prenatally to alcohol are four percentage points less likely to have completed high school, and 2.5 percentage points less likely to have graduated. Their earnings at age 32 are 24 percent lower compared to those not exposed, and the proportion on welfare increased by five percentage points.

Wüst (2010) uses Danish survey and register data to examine the effect of maternal inputs on child birth outcomes (birth weight, foetal growth, and preterm birth). OLS analyses suggest an ambiguous association between prenatal alcohol consumption and birth outcomes. The sibling fixed effects however, shows clear negative effects, suggesting that each daily unit of alcohol decreases birth weight by 147 grams (4\%), and increases the probability of a preterm birth by 7.8 percentage points. ${ }^{6}$ Exploiting changes in the minimum legal drinking age over time across US states, similar adverse effects on birth outcomes are reported by Fertig and Watson (2009), whilst Barreca and Page (2012) find no effects. Finally, Zhang (2010) examines the relationship between state-level alcohol taxes, prenatal drinking, and infant health using the US Natality Files and the Behavioural Risk Surveillance System. The results suggest that an increase in taxes on beer relates to a decrease in the incidence of low birth

\footnotetext{
${ }^{5}$ Other studies in the epidemiology literature include Lewis et al. (2012) and Zuccolo et al. (2013).

${ }^{6}$ Although not the main research question in their study, Rosenzweig and Wolpin (1994) also do not find any effects of maternal prenatal alcohol consumption on child test scores in their GLS estimation, but the estimates become negative when using a within-mother specification.
} 
weight.

Our paper is structured as follows: the next section reviews the mechanisms through which alcohol can affect the foetus, and discusses the metabolism of alcohol. Sections three presents the methodological framework and discusses the validity of the instrument. The data is introduced in section four, followed by the results in section five. We conclude with a discussion of our findings.

\section{Mechanisms}

\subsection{In utero alcohol exposure and child development}

Excessive drinking during pregnancy is well-known to be detrimental to the foetus, potentially leading to Foetal Alcohol Spectrum Disorder (FASD, a pattern of mental and physical defects). The effects of low-to-moderate drinking are less clear, and there is no consensus as to what level of exposure is toxic to the foetus.

Numerous mechanisms have been suggested to contribute to alcohol-induced foetal damage. Its effects on the developing brain are particularly complex, as - depending on the developmental stage of the cells - alcohol can affect cell division, the survival of migrating cells, the establishment of mature cell structures/functions, as well as interfere with the brain's cellular functions. For example, after multiplication through cell division, nerve cells in the foetal brain migrate to an appropriate location where they mature to their full form and function. Alcohol exposure during cell division may decrease the cell division rate, whilst exposure during later stages may deplete cells due to alcohol-induced cell death (Goodlett and Horn, 2001). Hence, the timing of alcohol exposure may be important for different aspects of brain development. However, because the brain is one of the first organs to begin and the last to complete development, it is susceptible to damage throughout pregnancy (Guerri, 2002). Furthermore, as it is the blood alcohol level, rather than the amount of alcohol consumed, that can cause foetal damage, binge drinking is generally regarded as more damaging than drinking the same amount of alcohol over a longer period (Guerri, 2002).

Any damage due to prenatal alcohol exposure however, does not necessarily show at birth or in infancy, but may only manifest later in childhood, adolescence or even adulthood. Hence, affected children may go undetected until problems arise in the academic environment (Coles et al., 1991), with neurodevelopmental problems potentially persisting into adult life (Gray and Henderson, 2006). The most prominent dysfunctions include deficits in verbal learning 
and in integrating visual information, alterations in spatial memory and in reaction time, impaired attention, reduced academic achievement and other cognitive and motor skills (Guerri, 2002; Russell, 1991).

\subsection{The metabolism of alcohol}

Figure 1 graphically presents the first two steps in the metabolism of ethanol. ${ }^{7}$ The alcohol dehydrogenase (ADH) family of enzymes, which includes ADH1B, catalyses its first step: oxidizing ethanol to acetaldehyde, a mutagenic and carcinogenic metabolite. With that, the ADH1B enzyme plays a major role in the breakdown of ethanol. The rare variant of rs1229984, a single nucleotide polymorphism, or SNP, in the ADH1B gene, greatly increases ADH1B enzymatic activity, resulting in a quicker reduction of blood alcohol levels, and sharper rises of acetaldehyde in blood and organs (see Appendix A for a brief introduction to some of the genetic terms used here). The latter in turn leads to symptoms such as increased heart rate and nausea. Individuals with the rare variant of $A D H 1 B$ therefore consume less alcohol, as found in numerous studies across many populations (see below). Hence, foetuses of mothers who carry the rare variant of $A D H 1 B$ have a reduced exposure to alcohol compared to foetuses of mothers who carry the common variant. Note that the effects of $A D H 1 B$ on alcohol consumption are subtle: it does not make an individual an alcoholic or in other ways alcohol-dependent. Instead, it only reduces alcohol intake by a small amount. ${ }^{8}$

\section{Methodological framework}

We use a SNP in the alcohol dehydrogenase 1B (ADH1B) gene rs1229984 to explain variation in alcohol exposure in utero. The vast majority of individuals of European ancestry are homozygous for the common allele. In fact, there are very few individuals who are homozygous for the rare allele $(<1 \%)$. We therefore specify a binary instrument, equalling 1 when the individual carries either one or two copies of the rare allele (A), assuming a

\footnotetext{
${ }^{7}$ Ethanol is also known as pure alcohol or drinking alcohol. It is the type of alcohol found in alcoholic beverages.

${ }^{8}$ The second step in the metabolism of ethanol is mainly driven by aldehyde dehydrogenase enzymes. Some individuals carry a polymorphism in the $A L D H 2$ gene which encodes an enzyme that is unable to clear acetaldehyde, leading to severe symptoms of facial flushing, increased heart rate, and nausea, causing these individuals to abstain from alcohol or drink very little. This $A L D H 2$ variant has been used in Mendelian randomization studies to explore the causal effects of alcohol consumption on blood pressure (Chen et al., 2008), drug use and anti-social behavior (Irons et al., 2007), and upper aerodigestive and stomach cancers (Hashibe et al., 2008; Zhang et al., 2007). However, its relevance is limited to East-Asian populations as the variant is absent in populations of European ancestry.
} 
dominant genetic model (as in Zuccolo et al., 2009, 2010); i.e. we compare individuals with genotype GA or AA to those with genotype GG.

\subsection{Potential outcomes framework}

Let $Z$ denote this binary genetic variant, with $Z_{i}=1$ indicating that the mother of child $i$ carries the rare variant, and $Z_{i}=0$ implying that the mother of child $i$ does not carry the rare variant. Let $A$ and $S$ denote random variables representing, respectively, alcohol intake and the educational outcome. Let $A_{i}(z)$ be the potential alcohol exposure for child $i$ when the instrument is set to $z$. Similarly, let $S_{i}(z, a)$ be the potential outcome for child $i$ that would be obtained if the instrument was set to $z$, and alcohol exposure, the treatment variable, was set to $a$. Only one of the two potential exposures or treatments $\left(A_{i}(0)\right.$ and $\left.A_{i}(1)\right)$, and only one of the two potential outcomes $\left(S_{i}\left(0, A_{i}(0)\right)\right.$ and $\left.S_{i}\left(1, A_{i}(1)\right)\right)$ are ever observed for any one child.

As implicit in our notation, we assume that there is no interference between units (the Stable Unit Treatment Value Assumption, see Rubin, 1980). Given the set of potential outcomes, we can define the causal effect for child $i$ of $Z$ on $A$ as $\left(A_{i}(1)-A_{i}(0)\right)$, and the causal effect for

child $i$ of $Z$ on $S$ as $\left(S_{i}\left(1, A_{i}(1)\right)-S_{i}\left(0, A_{i}(0)\right)\right)$. These are also known as the intention-totreat effects. Our framework follows the work by, among others, Imbens and Angrist (1994) and Angrist, Imbens and Rubin (1996). We briefly lay out our structural assumptions, and discuss more specifically how these apply to our research question.

Assumption 1: (Conditional) Independence

$$
Z_{i} \perp\left\{S_{i}(z, a), A_{i}(z)\right\}_{z, a}
$$

Independence assumes that the instrument is as good as randomly assigned. Conditional independence implies that independence holds conditional on some (vector of) covariate(s) $X_{i}$, which would be denoted by $Z_{i} \perp\left\{S_{i}(z, a), A_{i}(z)\right\}_{z, a} \mid X_{i}$.

Although genetic variants are randomly assigned at conception, the independence assumption can be violated when a systematic relationship exists between the allele frequency and the outcome of interest in different sub-populations; this is also known as population 
stratification. The most common example, and one that is important in the case of $A D H 1 B$, is ancestry. The $A D H 1 B$ variant is one of the most ethnically stratified: the Minor Allele Frequency (MAF; the frequency with which the rare allele occurs in the population) ranges from 2-5\% in Western European populations to 60-70\% in North-East Asia (Borinskaya et al., 2009). However, population stratification is likely to be less important in our study, as our data is collected in a small geographically defined region with a predominantly white population. In addition, we only include a child if the mother describes herself and the child's father as white, and we adjust for ten ancestry-informative principal components derived from analysis of the genome wide association data (Bouaziz et al., 2011). In section 4.4, we evaluate the independence assumption by exploring the distribution of an extensive range of background characteristics by the value of the instrument. If the instrument is randomized, there should be no systematic differences in such characteristics.

Assumption 2: Exclusion

$$
S_{i}(1, a)=S_{i}(0, a), \text { for all } a \text {. }
$$

Exclusion implies that the instrument can only affect the outcome via its effect on $A$. Hence, we can write $S_{i}(a, z)=S_{i}(a)$. If the exclusion restriction only holds conditional on $X_{i}$, we may specify the exclusion restriction conditional on these covariate(s).

The exclusion restriction can in principle be violated in different situations. First, we need to consider the mechanism through which the variant affects alcohol exposure. This mechanism is relatively well understood, as discussed in section 2.2. Furthermore, we know that the $A D H 1 B$ gene is predominantly expressed in the liver and (less so) in the lining of the stomach (Lee et al., 2006). The liver functions as the main organ in ethanol clearance; the stomach and small intestine are the principal absorption sites of ingested alcohol (Cortot et al., 1986).

Second, the exclusion restriction may be violated by pleiotropy, referring to the possibility that a SNP has multiple phenotypic associations. The gene expression and the well understood mechanisms of $A D H 1 B$ decrease the likelihood that $A D H 1 B$ directly influences behaviours other than alcohol consumption. However, we cannot rule this out. It may be possible, for example, that carriers of the $A D H 1 B$ rare allele are more likely to become anxious due to, or take medication to counter, any negative side-effects of their alcohol intake, which in turn could directly affect foetal development, violating the exclusion restriction. We directly investigate this in Section 4.4, examining the distribution of an 
extensive set of maternal characteristics during pregnancy by genotype, including maternal diet, health and health conditions, physical activity, the use of medication, substance use, mental health, and the use of chemicals.

Third, Linkage Disequilibrium (LD) refers to certain genetic variants potentially being coinherited with other variants. Whether this violates the exclusion restriction depends on the function(s) of any co-inherited variants. $A D H 1 B$ is in weak LD with other variants on the Alcohol Dehydrogenase genes, such as $A D H 1 A$ and $A D H 1 C$, but these have all been shown to relate to alcohol metabolism, rather than to behaviours other than drinking (Birley et al., 2009).

More generally, we investigate the potential violation of the exclusion restriction by searching the medical literature on the relationships between $A D H 1 B$ and other variables. In addition to consistent evidence of an association between $A D H 1 B$ and alcohol intake (see also below), the SNP is consistently associated with conditions such as liver cirrhosis (see e.g. Lorenzo et al., 2006), head and neck cancer (see e.g. Brennan et al., 2004; McKay et al., 2011), upper aerodigestive tract cancer (see e.g. Canova et al., 2009) and oesophageal cancer (see e.g. Zhang et al., 2006). These are all associated with alcohol consumption, strongly suggesting that the SNP affects the outcomes through its effect on alcohol intake.

Assumption 3: Nonzero effect of instrument on treatment

$$
E\left[A_{i}(1)-A_{i}(0)\right] \neq 0
$$

This implies that the instrument has some effect on treatment. It is essential for this association to be replicated in a large number of independent studies, as it has been shown that many initial genetic associations fail to replicate in independent samples (Colhoun et al., 2003; see also Beauchamp et al., 2011). Individuals with the rare variant of $A D H 1 B$ are predicted to consume less alcohol than those with two common alleles. With that, foetuses of mothers who carry the rare variant have a reduced exposure to alcohol compared to foetuses of mothers who carry the common variant. This negative association is very robust and has been replicated in numerous independent genetic studies (see e.g. Reich et al. (1998); Whitfield et al. (1998); Saccone et al. (2000, 2005); Loew et al. (2003); Wall et al. (2005); Duranceaux et al. (2006); Zintzaras et al. (2006); Luo et al. (2006); Zhang et al. (2007); Ghosh et al. (2008); Tolstrup et al. (2008); Zuccolo et al. (2009); MacGregor et al. (2009); 
Sherva et al. (2009)), confirming Assumption 3; we show the standard statistical tests below.

Assumption 4: Monotonicity

$$
P\left[A_{i}(1) \leq A_{i}(0)\right]=1 \quad \text { for all } i \text {. }
$$

This means that the potential exposure or treatment for child $i$ whose mother does not carry the rare variant is at least as high as the potential treatment for the same child whose mother does carry the rare variant, for all $i$. As discussed above, $A D H 1 B$ does not make individuals alcoholics, nor does it stop people from drinking altogether; it only affects intake by a small amount. As such, individuals will not be aware of their genotype, and it is therefore very unlikely that they would engage in any potential 'compensatory responses', such as drinking less because they may be genetically less 'protected' against drinking. Hence, we assume that the foetus is less exposed to alcohol if the mother carries the risk allele than if she does not.

We use assumptions 1 to 4 to interpret differences in average outcomes and treatments at different values of the instrument. Under these assumptions, the instrumental variables (Wald) estimand, defined as the ratio of the difference in average outcomes at two values of the instrument to the difference in average treatment at the same two values of the instrument, can be written as:

$$
\hat{\beta}_{I V}=\frac{E\left[S_{i} \mid Z_{i}=1\right]-E\left[S_{i} \mid Z_{i}=0\right]}{E\left[A_{i} \mid Z_{i}=1\right]-E\left[A_{i} \mid Z_{i}=0\right]}
$$

This is a Local Average Treatment Effect: the effect of in utero alcohol exposure on child academic achievement for children whose mother was induced by the instrument to reduce her alcohol intake. Our instrument picks up differences in children's exposure for mothers with and without the rare variant. Mothers who carry the rare variant are more likely to abstain in pregnancy, less likely to binge, and on average consume less if they drink at all. We therefore start by exploring the effects of any alcohol exposure on academic achievement, but we are also interested in the effects of the dose, pattern and duration of exposure. However, estimating the effects of these additional treatments has implications for our IV approach. Indeed, with only one instrument, as we can only estimate the effect of one treatment at a time. When estimating the effect of an increase in the duration, for example, the exclusion restriction implies that our instrument $Z$ only affects the outcome through its 
effect on the duration. However, $Z$ may also affect the outcome through its effect on the dose and pattern of exposure. As such, specifying separate models for each treatment may violate our assumptions. In an attempt to deal with this, we start the analyses by defining treatment as a binary indicator equal to one if the foetus was exposed to any alcohol during the course of the pregnancy, and equal to zero otherwise. This measure picks up a combined effect of any alcohol exposure in utero, ranging from light to heavy exposure, and including shorter as well as longer exposures.

We then estimate the effects of the dose, pattern and duration of exposure, but recognize the potential limitation of this approach with respect to the IV assumptions. The pattern variable (binge drinking) is binary; the dose and duration are count variables. Using a variable treatment intensity for the dose and duration, the Wald estimand becomes

$$
\hat{\beta}_{I V}=\sum_{a=1}^{\bar{a}} \omega_{a} E\left[S_{i}(a)-S_{i}(a-1) \mid A_{i}(1) \leq a<A_{i}(0)\right],
$$

where $\bar{a}$ is the maximum of $a$, and the weights $\omega_{a}=\frac{P\left[A_{i}(1) \leq a<A_{i}(0)\right]}{\sum_{j=1}^{\bar{a}} P\left[A_{i}(1) \leq j<A_{i}(0)\right]}$ are non-negative and sum to one (Angrist and Imbens, 1995; Angrist and Pischke, 2009). Hence, the IV estimate with variable treatment intensity is a weighted average of the causal responses to a unit change in treatment, for those whose treatment status is affected by the instrument. The weight attached to the average of $S_{i}(a)-S_{i}(a-1)$ is proportional to the number of people who, because of the instrument, change their treatment intensity from more than $a$ units to $a$ or less (Angrist and Imbens, 1995). We show these weight functions in section 4.4.

\subsection{Interpretation of the estimates}

The interpretation of our estimates is not straightforward, but rather depends on two important issues. First, we note that we identify an 'overall' or 'total' effect of alcohol exposure, which includes any effects that alcohol has on other substance use that in turn may affect child development. Indeed, if we were interested in the effects of alcohol exposure per $s e$, our estimates may be either upward or downward biased, depending on whether alcohol and other substances are compliments or substitutes. For example, if alcohol and e.g. cannabis are substitutes (DiNardo and Lemieux, 2001) and prenatal exposure to cannabis negatively affects the child academic attainment $S$, the positive numerator of (1) will be reduced by the negative effect of cannabis. As the denominator is unchanged, the IV estimate 
would underestimate the effect of alcohol per se. Conversely, if alcohol and e.g. smoking are complements (Dee, 1999), and prenatal exposure to smoking negatively affects child development, the IV estimate would overestimate the effect of alcohol.

We directly explore any potential complements and substitutes of alcohol below, where we test whether there are any systematic differences by genotype in the use of a wide range of substances, including caffeine, smoking, cannabis, amphetamine, barbiturate, cocaine, heroin, methadone and ecstasy. We also examine whether maternal prenatal alcohol consumption affects her substance use using IV regressions. Our results show no systematic patterns, suggesting that the 'overall' effect we identify is similar to the 'alcohol-effect' per se.

The second issue to note regarding the interpretation of the estimates is that our treatment of interest is prenatal alcohol exposure. Foetal exposure to alcohol consists of three components: maternal consumption, maternal metabolism, and foetal metabolism. The rare allele of maternal $A D H 1 B$ rs1229984 is negatively associated with exposure through maternal consumption and metabolism: it is associated with a reduction in intake and an increase in the metabolic rate. Hence, the numerator of the Wald estimand (1) captures this total, or combined, 'exposure effect'.

Ideally, therefore, we would like our treatment variable in the denominator of (1) to be a direct measure of exposure, such as foetal blood alcohol levels. For obvious practical and ethical reasons, however, we do not observe this. As we discuss below, we only observe one component of alcohol exposure: maternal alcohol consumption. This could be problematic, as, holding alcohol intake constant, blood alcohol levels may be lower in rare allele carriers of $A D H 1 B$ due to the increased speed with which ethanol is broken down.

We search the literature to investigate the relative importance of the three components through which $A D H 1 B$ may affect foetal alcohol exposure. As we discuss above, this shows clear evidence that $A D H 1 B$ is an important determinant of the first component: alcohol intake. We also find this in our data: as we show below, those who carry the rare allele drink around 0.8 units a week less compared to those not carrying the rare allele; a difference similar to a 53\% decrease relative to the mean. In addition, as alcohol consumed by the mother can cross the placenta without delay, it may immediately affect the foetus. Although there is no evidence on the importance of the effect of $A D H 1 B$ on foetal metabolism, there is some - albeit little - evidence on adult metabolism. Neumark (2004) finds that $A D H 1 B$ explains $8.5 \%$ of the variance in alcohol elimination rate in a sample of 109 (Jewish) male 
students. Hence, although the evidence is limited, this would suggest that maternal metabolic rates do play a role, which we are not able to account for. In other words, as we only observe one of the three components of alcohol exposure in the denominator of (1), and since the numerator captures the full 'exposure effect', the IV estimate based on consumption alone is likely to be overestimated. Hence, although the sign of our estimates is correct, we cannot identify the exact magnitude, and we argue that our analysis provides an upper bound of the causal effect of alcohol exposure in utero.

\section{Data}

Our data are from a cohort of children born in one geographic area (Avon) of England. Women eligible for enrolment in the population-based Avon Longitudinal Study of Parents and Children (ALSPAC) had an expected delivery date between 1 April 1991 and 31 December 1992. Note that the first official guidelines on prenatal alcohol consumption, mentioning that pregnant women should not drink more than 1-2 units of alcohol once or twice a week, were only issued by the UK Department of Health in 1995; after this cohort was born. Despite this, the US Surgeon General advised women not to drink in pregnancy as early as 1981 (Office of the US Surgeon General, 1981), and it is unlikely that UK women were completely insulated from this information. Approximately 85\% of eligible mothers enrolled, leading to about 14,000 pregnancies (ALSPAC is a cohort; there is no systematic data collection on siblings). ${ }^{9}$ The Avon area has approximately 1 million inhabitants and is broadly representative of the UK as a whole, although slightly more affluent than the general population (Boyd et al., 2012; Fraser et al., 2012; see www.bristol.ac.uk/alspac for more a detailed description of the data).

Just over 12,000 children had at least one completed questionnaire. Our sample selection process is as follows. First, we exclude children whose mother or father is of non-white ethnic origin to reduce the risk of population stratification. Second, we select mothers for whom we observe both their and their child's genotype, leaving us with 5,531 observations. ${ }^{10}$

\footnotetext{
${ }^{9}$ Of the 14,676 foetuses with a known birth outcome, 14,062 were live births and 13,988 were alive at 1 year. As we do not observe the genotype of mothers whose children did not survive, we cannot directly explore whether alcohol exposure in utero affects survival rates. However, if the genotype affects the survival of foetuses, it would not be in Hardy-Weinberg equilibrium (which states that allele and genotype frequencies in a population remain constant from generation to generation in the absence of other evolutionary influences, such as non-random mating and selection). We checked this and $A D H 1 B$ is in equilibrium.

${ }^{10}$ For our sample of mother-child pairs, we observe a total of 7,088 maternal genotypes, and 8,886 child genotypes at rs1229984. As we require both genotypes in the analyses, we can only use those observations for
} 
Third, we drop observations with missing data on all measures of prenatal alcohol exposure ( $n=134$ ), resulting in 5,397 observations. We further restrict the sample to children for whom we observe their academic achievement at least once. Depending on the measure of alcohol exposure and on the outcome of interest, the final sample includes between 1,922 and 4,088 mother-child matches. ${ }^{11}$

\subsection{Measures of academic achievement}

We specify different measures of academic achievement. First, we use an entry assessment test, taken by all pupils about to start primary school (ages 4-5). Although there were no compulsory national assessment tests at this time, the Local Education Authorities covering the ALSPAC area used the same tests, which is available for $80 \%$ of (not privately owned) schools. In addition, we use four nationally set exams taken at ages 7, 11, 14 and 16 (also known as the Key Stage 1 (KS1), Key Stage 2 (KS2), Key Stage 3 (KS3) and Key Stage 4 (KS4, or GCSE) exam respectively). These measures of children's performance are objective and comparable across all children. Children's scores are obtained from the National Pupil Database, a census of all pupils in England within the state school system, which is matched into ALSPAC. For each of the Key Stage tests (1 to 4), we use an average score for the child's mandatory subjects, standardized on the full sample of children for whom data is available, with mean 0 and standard deviation $1 .^{12}$

\subsection{In Utero exposure and the genetic marker}

which we observe the two: $n=5,513$. It is unlikely that missing genotype data introduces selection bias. First, empirical evidence on other data suggests that genotype frequencies are the same for general-population versus selected samples (e.g. the British 1958 birth cohort versus British blood donors from the Wellcome Trust CaseControl Consortium; see WTCCC, 2007). Second, empirical evidence shows that genotype frequencies do not differ by the timing of non-response to questionnaires (see Bhatti et al., 2005). And third, we examine potential bias in our data due to missing genotypes by investigating whether, conditional on observing genetic information, the probability of being in the final sample differs by maternal and child genotypes. In other words, we test whether the genotype frequencies for mother and child differ, comparing the sample where we observe both genotypes (i.e. our estimation sample) to the sample where we only observe just the mother's or just the child genotype. We find no evidence that mother or child genotype frequencies differ between the two samples ( $p=0.12$ and $p=0.58$ respectively), suggesting that the missingness is unrelated to the instrument.

${ }^{11}$ The low sample sizes are mainly driven by third trimester alcohol intake for which an additional 35\% (of the maximum of 5,397 observations) is missing. Lower educated women are more likely to be missing in the third trimester. However, this does not affect our results, which are robust the use of different samples. More generally, Boyd et al. (2012) and Fraser et al. (2012) show that the lower socio-economic groups are more likely to attrite.

${ }^{12}$ For KS1, this is an average of the child's reading, writing, spelling and maths scores; KS2 includes reading, writing, science and maths. For KS3 and KS4, the final score is an average of the child's English, maths and science. 
We use the binary genetic instrument $A D H 1 B$, comparing those with genotype GA or AA to those with genotype GG (A being the rare allele, where the effect is dominant; i.e. carrying one rare allele, GA, has a similar effect on alcohol consumption as carrying two, AA). Depending on the specification of interest, between 4.7 and $5.2 \%$ of our sample carry as least one rare allele. ${ }^{13}$

As discussed above, we would ideally use a direct measure of alcohol exposure in utero, such as foetal blood alcohol levels. As this is not available in the data, we proxy alcohol exposure in utero by maternal alcohol consumption during pregnancy. We start the analyses using a binary variable indicating whether the foetus was exposed to alcohol in utero. This equals one if the woman reports drinking any amount at any point during pregnancy, and equals zero if the woman reports not to drink in the first, second, as well as third trimester, and reports not to have binged (i.e. has non-missing values for alcohol intake in each trimester). ${ }^{14}$ We then examine the effect of the dose of alcohol exposure, measured by the number of units consumed per week, averaged over the first, second, and third trimester. In addition, we examine the pattern and duration of alcohol exposure. We proxy the pattern by investigating the effects of bingeing, defined by drinking the equivalent of two pints of beer, four glasses of wine, or four pub measures of spirit in one day, measured in the second trimester. The duration is measured by a count variable ranging from 0 to 3 , representing the number of trimesters during which the foetus was exposed to alcohol.

Several epidemiological studies distinguish between the effects of different types of beverages, noting increases in preterm births or decreases in birth weight primarily among beer drinkers (e.g. Kline et al., 1987). To investigate potential differences in the type of drink, we separately examine the effects of beer or wine consumption. This explores differences in (e.g.) wine consumption among those who report not consuming other alcoholic drinks. We do not use information on the consumption of spirits, as too few mothers report drinking spirits during pregnancy. The questionnaire explained that half a pint of ordinary strength beer, lager or cider, and a small glass of ordinary strength wine contains one (UK) unit of

\footnotetext{
${ }^{13}$ With our sample sizes, this corresponds to 106 to 267 mothers (presented in Table 1 below); a relatively low number.

${ }^{14}$ Alcohol consumption in the first, second, and third trimesters are obtained from questionnaires at 8,18 , and 32 weeks gestation respectively. Note that the first trimester questionnaire was only sent out to mothers who enrolled before 14 weeks gestation; this is almost half of all mothers in our data. The other half were asked about their first trimester alcohol consumption at a later date. For ease of description and discussion however, we refer to this as the week 8, or first trimester, questionnaire. In the first and third trimester, women were directly asked to report the number of alcoholic units consumed per week. In the second trimester, women were asked to report the number of units of beer, wine, spirits and other alcohol per week, which we sum to obtain the total number of units.
} 
alcohol (similar to $10 \mathrm{ml}$ or 8 grams of ethanol).

Note that all measures of alcohol exposure may be subject to substantial measurement error. First, the concentration of alcohol in different types of beers and wines varies considerably. Second, the size of a glass of wine in a bar or restaurant can vary anywhere between $125 \mathrm{ml}$ to $250 \mathrm{ml}$. Third, these standard measures of 125 or $250 \mathrm{ml}$ are only used in bars and restaurants; measures at home are likely to differ. Fourth, women may under-report their consumption during pregnancy (e.g. Gray and Henderson, 2006). Combining the measurement error with the imprecision and bias related to the reporting of alcohol consumption, this can lead to considerable underestimation of the amount of alcohol actually consumed (Stockwell et al., 2004), which may drive OLS estimates towards the null, though the IV may partially correct for this, assuming that the instrument is unrelated to the measurement error. We explore this assumption indirectly in Section 4.4, showing no systematic correlation between the instrument and a wide range of covariates.

\subsection{Covariates}

Conditioning on covariates is not necessary to obtain unbiased estimates in Mendelian randomization studies, as the covariates do not enter the assignment (randomization) mechanism. In fact, it is unclear which covariates to include in a Mendelian randomization

study, as any characteristic is measured post-randomization, and - with that - may be affected by the instrument (von Hinke Kessler Scholder et al., 2011, 2013). For this reason, we do not control for covariates in our main analysis, though we discuss and report the estimates that adjust for a wide variety of different sets of covariates in Section 5.9 and Appendix D.

The exception however, is that we include ten ancestry-informative principal components to account for any remaining population stratification, and we control for the child's genotype. We include the latter for two reasons. First, when alcohol consumed by the mother crosses the placenta, the child's $A D H 1 B$ may also start oxidizing the ethanol (depending on whether the enzyme is expressed in utero). Second, the child's genotype is likely to be related to the child's alcohol consumption later in life, and may -through that- affect the child's academic achievement, although this is not likely for academic outcomes measured at younger ages. Including the child's $A D H 1 B$ will account for these potential biases. However, the results are not sensitive to the inclusion or exclusion of the child's $A D H 1 B$. 


\subsection{Descriptive Statistics}

As discussed in Section 3, the IV estimate for the dose and duration of alcohol exposure is a weighted average of the unit causal response. Figure 2 presents the weight function, plotting the differences (between those carrying no risk alleles and those carrying at least one risk allele for $A D H 1 B$ ) in the probability that alcohol intake is at or exceeds the level on the $\mathrm{x}$ axis. This shows that those who carry no risk allele of $A D H 1 B$ are between two and 13 percentage points more likely to drink, depending on the number of units examined. The intensity of the shift is highest around 2 to 3 units per week, declines thereafter, but remains positive throughout.

Table 1 presents descriptive statistics of the average alcohol consumption during pregnancy. We show these for the full sample (column 1), as well as by genotype (columns 2 and 3). Panel A shows that, on average, 62.7\% of the sample drank any alcohol during pregnancy, but this varies by genotype, with $63.3 \%$ of mothers who are homozygous for the common allele drinking alcohol, and $50.7 \%$ of those who carry at least one rare allele. Furthermore, we find that $17.0 \%$ of mothers who have two common alleles binged at least once in the second trimester, compared to $11.2 \%$ among those carrying at least one rare allele. Similarly, using the number of trimesters in which the mother drinks as a proxy for the duration or length of exposure, we find the average to be 0.99 for those carrying two common alleles, compared to 0.59 for those carrying at least one rare allele.

The average number of units of alcohol per week is just over 1.5. However, there is much variation around this: the average number across pregnancy ranges from 0-35, with the variation in the number of beers being larger than that for wine. There are again large differences by maternal genotype, as shown in columns 2 and 3. Mothers who are homozygous for the common allele, for example, drink an average of 1.55 units a week. This is 0.65 units a week among those carrying at least one rare allele.

The second part of the table shows the between and within standard deviations for the number of units of alcohol, wine and beer consumed for the full sample and the two genotypes separately. This shows that most of the variation lies between mothers, though there remains considerable variation within mothers. This suggests that mothers do alter their alcohol intake; it is not the case that mothers' alcohol consumption remains stable over the course of her pregnancy. In other words, our results are not based on one particular group of 
mothers who do not change their behaviour during pregnancy.

To provide evidence on the validity of our IV approach, we exploit the richness of our data and correlate the instrument to an unusually extensive range of maternal and paternal prenatal background characteristics (we explore activities after birth - i.e. those that may be affected by child development - in Section 5.5). This is presented in Appendix B, showing the mean and standard deviation of a wide range of variables by the value of the instrument. With random assignment of genetic variants, there should be no systematic variation in covariates by genotype.

We start by testing covariates that are related to the (potential) alcohol intake of the mother's genetically-related family. With each maternal allele having a 50\% chance of being inherited by the child, children are more likely to carry the rare allele if their mother does. Similarly, we find that, among mothers who carry the rare allele, her mother and father are slightly less likely to have an alcohol problem. The mother's partner, however, is equally likely to drink during and after birth (at 8 months) for mothers with or without the rare allele, suggesting that potential assortative mating based on alcohol consumption is not an important issue.

Our further extensive range of covariates includes (i) a set of 'standard' covariates, (ii) maternal tea/coffee/milk consumption, (iii) parental diet and nutrition, (iv) parental attitudes to breastfeeding and other parenting issues, (v) religious beliefs, (vi) household and family characteristics, (vii) previous/current pregnancies and conditions during labour and delivery, (viii) mother's and partner's physical health, including a wide range of conditions measured both in the first and second trimester of pregnancy, (ix) mother's physical activity, (x) measures of parental mental health, (xi) maternal use of medication in the first and second trimester as well as after pregnancy, (xii) parental substance use, (xiii) mother's use of chemicals during pregnancy, (xiv) the extent of social support available to the mother and partner, and (xv) neighbourhood characteristics.

All tests are reported in Table B1, showing no systematic differences in the wide range of covariates by maternal genotype. We compare the number of correlations that are statistically significant with the number expected by chance if all variables were uncorrelated (excluding the characteristics of genetically-related family). We find no greater association between the genetic variant and the covariates than what would be expected by chance ( $p=0.32$ at the $10 \%$ level, $p=0.46$ at $5 \%$, and $p=0.48$ at $1 \%$ ), suggesting that the SNP is independent of behavioural or environmental factors that may affect the outcome of interest. Indeed, in the 
robustness checks in Appendix D, we test the sensitivity of our analysis by controlling for these covariates in the IV specification, leaving our findings unaffected.

\section{Results}

\subsection{OLS results}

Table 2 presents the OLS estimates of the associations between prenatal alcohol exposure and child educational attainment, controlling for the ancestry-informative principal components and the child's $A D H 1 B$. Panel A reports the estimates for any alcohol exposure, showing an insignificant relationship with the different measures of child educational attainment, presented in the columns. Panel B shows a clear negative association between maternal binge drinking and educational achievement, whilst a longer exposure to alcohol is positively correlated with children's academic attainment.

Examining the (average) number of units of alcohol in Panel $\mathrm{C}$ shows an ambiguous association; OLS coefficients are sometimes positive, sometimes negative, but most estimates cannot be distinguished from zero. In contrast, the table shows strong positive correlations for exposure to wine, but negative associations for exposure to beer. Although this could reflect differential effects of wine and beer, it is more likely to simply reflect other characteristics of mothers who drink wine as opposed to beer during pregnancy.

Indeed, column 1 and 2 in Table 3 present the results from separate regressions of any alcohol and binge drinking respectively on the 'standard' covariates presented in Appendix $\mathrm{B}$, showing a strong socio-economic gradient in prenatal alcohol exposure. Mothers of higher socio-economic position are more likely to drink alcohol, and less likely to binge, whereas length of exposure (column 3) is positively associated with socio-economic position. The positive gradient is stronger for wine consumption (column 5), than for mothers who drink beer or other alcoholic beverages (column 6): older, better educated, higher social class, employed mothers, and those with higher family income and a better educated, employed partner are more likely to consume wine, whilst smoking, lower educated mothers with worse mental health are more likely to drink beer. This social gradient in alcohol consumption and the inverse gradient for binge drinking is consistent with that observed in other US and UK 
surveys. $^{15}$

\section{$5.2 \mathrm{IV}$ results}

Table 4 presents the first stage IV results, regressing prenatal alcohol exposure on the genetic instrument whilst controlling for the child's $A D H 1 B$. As expected, we find a negative correlation between maternal $A D H 1 B$ and in utero alcohol exposure: mothers who carry at least one rare allele of $A D H 1 B$ are less likely to drink any alcohol (column 1), less likely to binge (column 2), have a shorter duration of alcohol consumption (column 3), and drink fewer units of alcohol compared to those carrying two common alleles (columns 4-6). Hence, children born to these mothers have a reduced alcohol exposure during pregnancy. The $F$ statistic depends on the specification and sample size used, and is strongest when we consider the number of units of alcohol, ranging between 16 and 23. If we do not control for the child's genotype, this increases to 28-43, with similar point estimates and slightly smaller standard errors, suggesting that $A D H 1 B$ predicts alcohol exposure well, but that the inclusion of child $A D H 1 B$ reduces its precision. The coefficients suggest that those who carry the rare allele are between 11 and 15 percentage points less likely to consume any alcohol during pregnancy. They drink between 0.77 and 0.86 units a week less compared to those not carrying the rare allele. The wine and beer-specific effects are smaller, though in the same direction. As discussed above, alcohol intake is only one of the three components through which the foetus may be exposed to alcohol, and hence, this is likely to be an underestimate of the effect of $A D H 1 B$ on actual exposure.

The second stage IV results are presented in Table 5. To deal with potential weak instruments, we report the weak-instrument robust 95\% confidence bounds, based on the Anderson Rubin statistic (Andrews et al., 2006). This shows consistent negative effects of any prenatal alcohol exposure, bingeing, the duration, and the dose of alcohol exposure on all measures of child educational attainment, though due to the sometimes large standard errors, not all are significant. The magnitude of the estimates is considerable, though as we discuss above, we argue these are upper bounds of the causal effect of alcohol exposure.

Increasing the number of units of alcohol in utero lowers child academic attainment, with

\footnotetext{
${ }^{15}$ Although the majority of these explore the social gradient in alcohol consumption in general (see e.g. Cutler and Lleras-Muney (2010), using the National Health and Interview Survey, the Health and Retirement Study, the National Longitudinal Survey of Youth 1979, and the National Child Development Study), others explore alcohol intake during or just after pregnancy (e.g. Bartley et al. (2005) and Dezateux et al. (2005) using the UK Millennium Cohort Study).
} 
similar effect-sizes when examining the different educational outcomes. The estimates suggest that exposure to an additional unit of alcohol reduces academic achievement by up to 0.2 to 0.3 standard deviations. There is a slight suggestion that the negative effects of alcohol exposure increase as the child ages, with larger effects for the KS4 exam compared to the entry assessment or KS1 exams, indicating possible accumulation of educational gaps and complementarity of educational achievement over time.

Examining the two types of alcoholic beverages, we find similar negative effects to the 'average alcohol' specification, though they are less well defined due to the smaller sample sizes, and larger due to the weaker first stage association (and therefore smaller denominator in (1)). Note, however, that the instrument is not specific to wine or beer consumption, but to alcohol intake more generally. The estimates can therefore not be interpreted as the specific effect of wine or beer intake, but rather indicate that the OLS associations, suggesting that wine improves and beer worsens child development, are likely to be biased due to unobserved confounding.

Although we argue that our IV estimates are an upper bound of the true causal effect, we are not the first to estimate such large effects, or to see a different association from the OLS after attempting to account for residual confounding. Indeed, Nilsson (2008) finds substantially large effects of prenatal alcohol exposure on human capital outcomes in Sweden. Similarly, Rosenzweig and Wolpin (1994) and Wüst (2010) obtain considerably larger negative effects in within-mother specifications compared to more ambiguous results in the OLS or GLS. Furthermore, it is consistent with the literature on the long-term effects of early life conditions on later-life outcomes. This literature generally finds that foetal shocks have large impacts on later outcomes, including on test scores, educational attainment, and other developmental outcomes (see e.g. Currie, 2009; Almond and Currie, 2011). In addition and as discussed above, our measures of exposure are likely to be subject to considerable measurement error, which may drive OLS estimates towards the null. The IV, however, is not affected by this, resulting in larger estimates (in absolute value).

\subsection{Reduced forms}

Table 6 presents the reduced form estimates from separate regressions of the test scores on the maternal genotype, and regressions of the test scores on the child's genotype (Panel A); Panel B includes both genotypes simultaneously. All analyses control for the ancestry- 
informative principal components. Recall that exposure to alcohol in utero results from a combination of three components: maternal consumption, maternal metabolism, and foetal metabolism. These analyses therefore shed light on whether the effect we find is likely to come via the combined consumption and metabolism through the mother, or via the foetal metabolism. We find a strong positive estimate for the maternal genotype, with much smaller and close-to-zero estimates for the child's genotype, suggesting that the alcohol effect runs through maternal intake and metabolism, rather than via the child metabolizing its mother's alcohol.

\subsection{The prenatal period}

We are interested in the effect of prenatal alcohol exposure on child academic achievement. For mothers who carry a rare allele of $A D H 1 B$, however, their mother may also have been a carrier. As such, the mother's mother may have drunk less during her pregnancy, affecting the mother's cognitive abilities. This implies that we may not be able to attribute the entire observed effect to prenatal drinking by this generation of women alone, as there may also be indirect effects of drinking by the child's female ancestors. However, that does not provide evidence against a detrimental effect of prenatal alcohol exposure on child academic outcomes.

Furthermore, one may argue that our instrument does not solely explain prenatal drinking. In other words, mothers who carry the rare variant of $A D H 1 B$ are likely to have had lower alcohol consumption throughout life. Hence, if the difference in alcohol exposure over the mother's lifetime changes her preferences or attitudes towards her child's education, the estimated effects are not necessarily solely due to prenatal alcohol consumption, but may partly reflect a more general alcohol intake.

Similarly, as alcohol consumption is correlated over the life cycle, our estimated negative effects may reflect the combined effects of alcohol consumption in different periods, rather than that specific to the prenatal period. For example, mothers who drink more may - perhaps because of that - spend less time with their children or pay less attention to their children's school performance. Or children whose mothers drink more may change their behaviour in response, affecting their outcomes. ${ }^{16}$ To examine these potential pathways, Table B1

\footnotetext{
${ }^{16}$ Although we observe some variables for maternal alcohol intake post-pregnancy, these are categorical variables and therefore the magnitude of any OLS or IV estimates are not comparable to those reported above.
} 
(Appendix B), explores whether $A D H 1 B$ rare allele carriers have systematically different behaviours compared to those who carry two common alleles. We find no evidence of systematic differences by genotype.

Another possibility to explicitly examine the effects of prenatal alcohol exposure is by using SNPs that only affect exposure during pregnancy. Although the $A D H 1 B$ effect is not specific to the pregnancy period, there is evidence that $A D H 1 B$ is a stronger predictor of alcohol intake and quitting during pregnancy, compared to that in other periods (Jacobson et al., 2006; Zuccolo et al., 2009; Wehby and von Hinke Kessler Scholder, 2013). ${ }^{17}$ Hence, we can examine the effect of quitting during pregnancy. If prenatal alcohol exposure negatively affects child academic achievement, we would expect to find a positive effect on child academic attainment for those children whose mother's $A D H 1 B$ induced them to quit drinking during pregnancy. To investigate this, we restrict the sample to women who drank prior to pregnancy and define quitters as those reporting not to drink at any point during pregnancy. ${ }^{18}$ The findings (available from the authors upon request) show consistent positive effects of quitting during pregnancy on child educational attainment, with estimates of very similar (absolute) magnitude to those in Panel A, Table 5. As above, the results are likely to be an overestimate due to not being able to measure actual exposure to alcohol. Nevertheless, the direction of effect is as expected. Hence, although we are not able to fully deal with the specificity of the prenatal period, our results are at least suggestive that alcohol exposure during the intrauterine period affects the foetus.

\subsection{Parental responsive investments}

The large estimates of the effect of prenatal alcohol exposure on child educational attainment call for an investigation into the potentially differential investments that parents make in response to their child's development. The literature on parental responsive investments tends to explore whether they reinforce or compensate for initial endowment differences (for a recent overview of the literature, see Almond and Mazumder, 2013). Understanding these responses is of broad interest and can provide interesting insights into parental responsive

\footnotetext{
${ }^{17}$ This could suggest an interaction between $A D H 1 B$ and the environment; the latter being pregnancy. With women facing similar environments during pregnancy, those who carry $A D H 1 B$ may find it easier to quit. Alternatively, it could mean that $A D H 1 B$ causes other (physical) changes in pregnancy that lead these women to women quit drinking. Although there is no evidence of the latter, and we find no evidence of this in Table B1, it could violate the IV assumption depending on such other effects of the variant.

${ }^{18}$ In other words, this definition is perfectly negatively correlated with our definition of 'any alcohol' exposure, but the analysis is conditional on the sample of women who drank before pregnancy.
} 
investment behaviours.

To explore this in detail, we estimate IV regressions to examine whether alcohol exposure in utero leads to differential parental responses, considering a wide range of post-birth characteristics and behaviours that parents have control over. These include (i) child diet and nutrition, (ii) immunisations and other health treatments (such as fluoride treatment and the use of vitamins), (iii) interactions between the parents and child, (iv) doctor and dentist visits, (v) parenting and teaching scores of both the mother and her partner, (vi) time use, (vii) maternal worries and concerns about her child, (viii) a set of post-birth household characteristics, (ix) the use of child care, and (x) the level of social support and social network available to the mother and her partner. In addition, many of these variables are observed multiple times after birth, allowing us to also explore whether any differences are systematic over time.

The results are presented in Table C1, Appendix C. These show some significant effects of alcohol exposure in utero. For example, consuming alcohol during pregnancy increases (decreases) the likelihood of having given the baby formula (a herbal drink) at age 6 months. However, we find little evidence of any systematic patterns in the data that would suggest that prenatal alcohol consumption leads to differential parental choices and behaviours. For example, parents are more likely (at age 6 months) to change nappies at night of babies exposed to alcohol in utero, but there is no difference in night-time nappy changing at age four weeks. Similarly, we find that parents of children who are exposed to alcohol in utero are less likely to take their child to the dentist or use a toothbrush/toothpaste at 38 month, but they are more likely to have a doctor visit at 18 and 30 months. The only finding that is consistent over time is that exposure to alcohol increases the likelihood that babies are regularly looked after by their grandparents at age 15, 24, and 38 months. Considering the wide range of parental choices explored, however, there seems to be little evidence of any systematic differences in parental responsive investments for children exposed to alcohol in utero compared to those not exposed, suggesting that most of the effect we find from prenatal alcohol consumption on academic achievement in foetal in origin.

\subsection{Subgroup analysis}

To examine whether the effects of alcohol exposure are different for different groups of children, we distinguish between child's gender, mother's age at birth, partner's social class 
at birth, maternal education, and family income. The results are reported in Table 7. Consistent with Nilsson (2009), the estimates are slightly larger for children of lower educated and lower income mothers. In contrast to previous findings that show boys to be more vulnerable to alcohol exposure in utero than girls (e.g. Nilsson, 2009; Barreca and Page, 2012), however, we find no clear patterns by gender or social class.

\subsection{Low-to-moderate drinking}

The UK Department of Health suggests that, if women choose to drink during pregnancy, they should not exceed 1-2 units once or twice a week, as "at this low level, there is no evidence of any harm to the unborn baby”. If there truly are non-linearities in the effects of alcohol exposure in utero, we cannot directly investigate this with only one instrument. To shed some more light on this however, Figure 3 plots the IV point estimates for mothers drinking 1-5, 6-10, 11-15, and 16 or more units a week, comparing each of them to mothers who do not drink. This shows that all estimates are negative, including the indicators for lowto-moderate consumption, though not all are very precisely estimated. Nevertheless, this does suggest that low-to-moderate alcohol exposure also harms the foetus.

\subsection{The timing of exposure}

For policy purposes, whether there is any differential effect in the timing of exposure to alcohol in utero is of substantial interest. Although we observe the number of drinks in each trimester and we can run the analyses separately by trimester, the interpretation of the estimates is limited by the fact that the instrument is not specific to a particular trimester. In other words, since the reduced form (the numerator in (1)) is similar in all analysis for a specific outcome variable (apart from differences due to the sample size), changes in the IV estimates are mainly driven by differences in the first stage (the denominator in (1)). Indeed, unsurprisingly, our results (available upon request) suggest the estimates are similar throughout pregnancy.

\subsection{Robustness checks}

We perform a range of checks to verify that our results are robust to different specifications, shown in Appendix D. We present the estimates of the average number of units per week 
during her pregnancy on Key Stage 1 scores, though the findings are robust to the use of the Entry Assessment test, or later Key Stage exams. The different model specifications control for different sets of covariates. We start by controlling for a set of alcohol-related variables (Panel A): specification 1 repeats the KS1 results from Table 5 for comparison; specification 2 includes an indicator for maternal smoking during pregnancy; specification 3 does not include the child's $A D H 1 B$ (i.e. only including the principal components); specification 4 includes (binary) indicators for maternal post-natal alcohol intake when the child was 8, 21, 33, and 47 months old; specification 5 includes binary indicators for the child's own alcohol consumption at 157, 166, and 185 months; specification 6 accounts for the mother's partner's alcohol consumption in the second trimester, the partner's alcohol intake and bingeing at 8 months, and whether the mother's parent's ever had an alcohol problem.

We next run multiple IV analyses, each time controlling for the different sets of characteristics and behaviours listed in table B1, Appendix B. For these analyses, we only control for the mother's characteristics, as sample sizes reduce substantially when controlling for partner's characteristics due to missing values. However, as most variables relate to the mother, this still controls for an extensive set of covariates that are generally not observed in survey data. Panel B shows that the use of different sets of control variables leads to different sample sizes due to missing values on some covariates. However, our results are very robust, with coefficients of similar magnitudes in all specifications.

\section{Discussion and conclusion}

This paper examines the effect of alcohol exposure in utero on child academic achievement. Simple correlations between alcohol exposure and child academic achievement show somewhat ambiguous results, with exposure to wine having a positive association, but exposure to beer being negative. Binge drinking is bad for the child, but a longer duration of

exposure is positively associated with the child's academic performance. However, we present clear evidence of the endogeneity of alcohol intake, showing a strong social gradient in maternal alcohol consumption, with mothers of higher socio-economic status more likely to drink, and in particular, drink wine. In contrast, beer consumption is associated with lower education and worse mental health. To deal with the confounding, we use a genetic variant in the alcohol metabolism gene $A D H 1 B$ as an instrument for alcohol exposure, and show that in contrast to alcohol consumption - the genetic instrument is unrelated to potential 
confounders, examining an unusually wide range of maternal and paternal characteristics and behaviours. We include a detailed discussion of the IV assumptions that are required to estimate the causal effect of alcohol exposure. In stark contrast to the OLS, our IV estimates show large negative effects of prenatal alcohol exposure on child educational achievement, which are robust to a large set of model specifications. In addition, the reduced form regressions show that the effects are solely driven by the maternal genotype, with no impact of the child's genotype. Yet, despite the large negative effects, we find little evidence of differential parental responses to child development, exploring a wide range of parental postnatal investments and behaviours.

Our estimates are Local Average Treatment Effects, capturing the effect on children whose mother was induced by her genotype to reduce her alcohol intake. Although we obviously cannot alter individuals' genotypes, we believe that our estimates remain policy relevant. As argued in Imbens (2010), if randomized experiments are unethical or infeasible, credible evaluations can be based on instrumental variable strategies. Although they are second best to randomized experiments, as they rely on additional assumptions and have less external validity, they are often all we have. The relatively small number of studies attempting to deal with the endogeneity of prenatal alcohol exposure indeed suggest that it is particularly difficult due to unobserved residual confounding. Using different methodological approaches, these studies find negative effects of prenatal alcohol exposure on child development (see e.g. Nilsson, 2008; Rosenzweig and Wolpin, 1994; Wüst, 2010; Zhang, 2010; Fertig and Watson, 2009). There is no evidence a priori to suggest that different sources of variation in alcohol exposure lead to different effects of exposure on academic achievement. In addition, if there is a biological effect of alcohol exposure (damaging the developing brain), any reduction in exposure should improve child outcomes. Hence, despite estimating a LATE, we believe that our estimates have some external validity and are relevant to policy.

Although the mothers in our sample were pregnant before the official UK guidelines on prenatal alcohol consumption were released, we believe our results are still likely to be relevant in today's context for three reasons. First, the US Surgeon General advised women not to drink during pregnancy as early as 1981, and it is unlikely that UK women were completely insulated from this information. Second, with the UK's most recent guidelines on alcohol consumption during pregnancy being very similar to their first guidelines, we assume that differences in the information available between the early 1990s and today are modest. Third, it is unlikely that the biological effects of alcohol exposure on child development have 
changed over time, suggesting that the results are also relevant for today's society.

Although we argue that our estimates may be an upper-bound, they are very robust to different model specifications. In addition, we are not the first to find such large effects: the few papers that attempt to deal with unobserved confounding in alcohol exposure also find large negative effects on child development (see e.g. Nilsson, 2008; Wüst, 2010; Zhang, 2010).

Nevertheless, the paper has several limitations. First, we are not able to fully deal with the specificity of the prenatal period. Second, we cannot make any strong statements about the specific effects of low-to-moderate versus excessive prenatal alcohol intake, though the analyses suggest that both negatively affect child academic attainment. Third, although the results suggest the effects are similar for alcohol intake throughout pregnancy, we cannot rule out differential effects of the timing of exposure. Fourth, as with any other IV analyses, the validity of independence and exclusion will never be known with complete certainty. However, the well-known mechanism of $A D H 1 B$, its location on the chromosome, the literature search on the effects of $A D H 1 B$, and our extensive tests examining the distribution of child and family characteristics by genotype all suggest that the SNP is independent of behavioural or environmental factors that may affect the outcome of interest.

Hence, by examining the link between prenatal alcohol exposure and child educational outcomes, this paper contributes to the economic literature on the long-term effects of the early environment on later child outcomes (e.g. van den Berg et al., 2006; Almond, 2006; Currie, 2009; Almond and Currie, 2011; Almond and Mazumber, 2011), on potential differential investments by parents in response to child development (Almond and Mazumder, 2013), and on identifying critical and sensitive periods of parental investments per se (e.g. Cunha and Heckman, 2007). We also provide advice to policy makers, showing that low-to-moderate alcohol exposure in utero may have similar negative effects on the foetus that may be carried into childhood and adolescence. In addition, since it is unethical to design a randomized controlled trial to study foetal alcohol exposure, we show that quasiexperimental designs such as Mendelian randomization can provide powerful alternatives for causal inference. 


\section{References}

Abel, E. and Hannigan, J. (1995). J-Shaped Relationship between Drinking During Pregnancy and birth Weight: Reanalysis of prospective Epidemiological Data, Alcohol and Alcoholism, vol. 30(3), pp. 345-355.

Almond, D. (2006). Is the 1918 Inuenza Pandemic over? Long-term Effects of in utero Influenza Exposure in the Post-1940 U.S. Population, Journal of Political Economy, vol. 114(4), pp. 672-712.

Almond, D, and Currie, J. (2011). Killing me Softly: The Fetal Origins Hypothesis, Journal of Economic Perspectives, vol. 25(3), pp. 153-72.

Almond, D, and Mazumder, B. (2011). Health Capital and the Prenatal Environment: The Effect of Ramadan Observance During Pregnancy, American Economic Journal: Applied Economics, vol. 4: pp. 56-85.

Almond, D, and Mazumder, B. (2013). Fetal Origins and Parental Responses, Annual Review of Economics, vol. 5: pp. 37-56.

Andrews, D, Moreira, M. and Stock, J. (2006). Optimal two-sided invariant similar tests for instrumental variables regression, Econometrica, vol. 74(3), pp. 715-752.

Angrist, J, Imbens, G. and Rubin, D. (1996). Identification of Causal Effects using Instrumental Variables, Journal of the American Statistical Association, vol. 91(434), pp. 444-472.

Angrist, J. and Imbens G. (1995). Two-Stage least Squares Estimation of Average Causal Effects in Models with Variable Treatment Intensity. Journal of the American Statistical Association, vol. 90(430), pp. 431-442.

Angrist, J. and Pischke, J-S. (2009). Mostly Harmless Econometrics: An Empiricist's Companion, Princeton: Princeton University Press.

Barreca, A., Page, E. 2012. A Pint for a Pound? Reevaluating the Relationship between Minimum Drinking Age Laws and Birth Outcomes. Tulane Economics Working Paper Series, no. 1220

Bartley M. et al. (2005) Children's origins. In: (S. Dex and H. Joshi, Eds.) Children of the $21^{\text {st }}$ Century: From birth to nine months. Bristol: The Policy Press.

Beauchamp, J. Cesarini, D., Johannesson, M., van der Loos, M., Koellinger, P., Groenen, P., Fowler, J., Rosenquist, N., Thurik, R. and Christakis, N. (2011). Molecular Genetics and Economics, Journal of Economic Perspectives, vol. 24(4), pp.57-82.

van den Berg, G., Portrait, F. and Lindeboom, M. (2006). Economic conditions early in life and individual mortality, American Economic Review, vol. 96, pp. 290-302.

Bhatti, P., Sigurdson, A., Wang, S., et al. (2005). Genetic Variation and Willingness to Participate in Epidemiologic Research: Data from Three Studies, Cancer Epidemiology Biomarkers and Prevention, vol. 14, pp. 2449-2453.

Birley, A., James, M., Dickson, P. et al. (2009). ADH single nucleotide polymorphism associations with alcohol metabolism in vivo, Human Molecular Genetics, vol. 18(22), pp. 1533-1542.

Borinskaya, S., Kal'ina, N., Marusin, A., et al. (2009). Distribution of the Alcohol Dehydrogenase ADH1B*47His Allele in Eurasia, American Journal of Human Genetics, vol. 84, pp. 89-92.

Bouaziz M. et al. (2011). Accounting for population stratification in practice: a comparison of the main strategies dedicated to genome-wide association studies. PLoS One, 6: e28845.

Boyd, A., Golding, J., Macleod, J., Lawlor, D., Fraser A., Henderson, J., Molloy, L., Ness, A., Ring S. and Davey Smith, G. (2012). Cohort Profile: The 'Children of the 90s' - the Index Offspring of the Avon Longitudinal Study of Parents and Children, International Journal of Epidemiology, doi: 10.1093/ije/dys064 
Brennan, P. et al. (2004). Pooled analysis of alcohol dehydrogenase genotypes and head and neck cancer: a HuGE review, American journal of epidemiology, vol. 159(1), 1-16.

Canova, C. et al. (2009). Genetic associations of 115 polymorphisms with cancers of the upper aerodigestive tract across 10 European countries: the ARCAGE project. Cancer research, vol. 69, pp. 2956-65

Chen, L, Davey Smith, G., Harbord, R. and Lewis, S. (2008). Alcohol Intake and Blood Pressure: A Systematic Review Implementing a Mendelian Randomization Approach, PLoS Medicine,vol.5,pp.461-71.

Coles, C., Brown, R., Smith I., et al. (1991). Effects of Prenatal Alcohol Exposure at School Age. I. Physical and Cognitive Development, Neurotoxicology and Teratology, vol. 13, pp. 357-367.

Colhoun, H., McKeigue, P. and Davey Smith, G. (2003). Problems of Reporting Genetic Associations with Complex Outcomes, The Lancet, vol. 361, pp. 865-72.

Cortot, A., Jobin, G., Ducrot, F., et al. (1986). Gastric emptying and gastrointestinal absorption of alcohol ingested with a meal, Dig Dis Sci vol. 31, pp. 343-348.

Cunha, F., and Heckman, J. (2007). The Technology of Skill Formation. American Economic Review, vol, 97(2), pp. 31-48.

Currie, J. (2009). Healthy, wealthy, and wise: Is there a causal relationship between child health and human capital development? Journal of Economic Literature, vol. XLVII(1), pp. 87-122.

Cutler, D. and Lleras-Muney, A. (2010). Understanding differences in health behaviors by education. Journal of Health Economics, vol. 29, pp. 1-28.

Davey Smith, G. and Ebrahim, S. (2003). 'Mendelian Randomization': Can Genetic Epidemiology Contribute to Understanding Environmental Determinants of Disease? International Journal of Epidemiology, vol. 32, pp. 1-22.

Davey Smith, G, Lawlor, D., Harbord, R., Timpson, N., Day, I. and Ebrahim, S. (2008). Clustered Environments and Randomized Genes: A Fundamental Distinction between Conventional and Genetic Epidemiology, PLoS Medicine vol. 4, pp. 1985-1992.

Dee, T.S. 1999. The complementarity of teen smoking and drinking. Journal of Health Economics, 18(6), 769-793.

Department of Health. 1995. Sensible drinking: Report of an Interdepartmental Working Group. London: Department of Health. [Accessed 5 December 2012] available at: www.dh.gov.uk/en/

Publicationsandstatistics/Publications/PublicationsPolicyAndGuidance/DH_4084701

Dezateux C. et al. (2005) Children's health. In: (S. Dex and H. Joshi, Eds.) Children of the $21^{\text {st }}$ Century: From birth to nine months. Bristol: The Policy Press.

DiNardo, J.E, Lemieux, T. 2001. Alcohol, marijuana, and American youth: The unintended consequences of government regulation. Journal of Health Economics, 20, 991-1010.

Duranceaux, N.C.E., Schuckit, M.A., Eng, M.Y., Robinson, S.K., Carr, L.G. and Wall, T.L. 2006. Associations of variations in alcohol dehydrogenase genes with the level of response to alcohol in non-Asians, Alcoholism: Clinical and Experimental Research, vol. 30, pp. 1470-1478.

Fertig, A. Watson, T. 2009. Minimum drinking age laws and infant health outcomes. Journal of Health Economics, vol. 28, pp. 737-747.

Fraser, A., Macdonald-Wallis, C., Tilling, K., Boyd, A., Golding, J., Davey Smith, G., Henderson, J., Macleod, J., Molloy, L., Ness, A., Ring, S., Nelson, S. and Lawlor, D. (2012). Cohort Profile: The Avon Longitudinal Study of Parents and Children: ALSPAC Mothers Cohort, International Journal of Epidemiology, doi: 10.1093/ije/dys066 
Ghosh, S., Bierut, L., Porjesz, B., et al. (2008). A novel non-parametric regression reveals linkage on chromosome 4 for the number of externalizing symptoms in Sib-Pairs, American Journal of Medical Genetics Part B (Neuropsychiatric Genetics), vol. 147B, pp. 13011305.

Golding, J., Pembrey, M., Jones, R. and the ALSPAC Study Team (2001). ALSPAC - The Avon Longitudinal Study of Parents and Children: I. Study Methodology, Pediatric and Perinatal Epidemiology, vol. 15, pp. 74-87.

Goodlett, C. and Horn, K. (2001). Mechanisms of Alcohol-Induced Damage to the Developing Nervous System, Alcohol Research and Health: the Journal of the National Institute on Alcohol Abuse and Alcoholism, vol. 25(3), pp. 175-84.

Gray, R. and Henderson, J. (2006). Review of the Fetal Effects of Prenatal Alcohol Exposure.

Report to the Department of Health; National Perinatal Epidemiology Unit.

Guerri, C. (2002). Mechanisms Involved in Central Nervous System Dysfunctions Induced by Prenatal Ethanol Exposure, Neurotoxicity Research, vol. 4(4), pp. 327-335.

Hashibe, M., McKay, J., Curado, M., et al. (2008). Multiple ADH Genes are Associated with Upper Aerodigestive Cancers, Nature Genetics, vol. 40, pp. 707-709.

von Hinke Kessler Scholder, S., Davey Smith, G., Lawlor, D., Propper, C., Windmeijer, F. (2011). Genetic Markers as Instrumental Variables, CMPO Working Paper 11/274.

von Hinke Kessler Scholder, S., Davey Smith, G., Lawlor, D., Propper, C., Windmeijer, F. (2013). Child Height, Health and Human Capital: Evidence using Genetic Markers, European Economic Review, vol. 57, pp. 1-22.

Imbens, G. and Angrist, J. (1994). Identification and Estimation of Local Average Treatment Effects, Econometrica, vol. 62(2), pp. 467-475.

Imbens, G. (2010). Better LATE than nothing: Some comments on Deaton (2009) and Heckman and Urzua (2009). Journal of Economic Literature, 48, 399-423.

Irons, D.E., McGue, M., Iacono, W., and Oetting, W. (2007). Mendelian Randomization: A Novel Test of the Gateway Hypothesis and Models of Gene-Environment Interplay, Development and Psychopathology, vol. 19, pp. 1181-1195.

Jacobson, S., Carr, L., Croxford, J. et al. (2006). Protective Effects of the Alcohol Dehydrogenase-ADH1B Allele in Children Exposed to Alcohol During Pregnancy, The Journal of Pediatrics, vol. 148, pp.30-37.

Kivimäki, M, Davey Smith, G., Timpson, N., Lawlor, D., et al., (2008). Lifetime Body Mass Index and Later Atherosclerosis Risk in Young Adults: Examining Causal Links using Mendelian Randomization in the Cardiovascular Risk in Young Finns Study, European Heart Journal, vol. 29 (20), pp. 2552-2560.

Kline, J., Stein, Z., and Hutzler, M. (1987). Cigarettes, Alcohol and Marijuana: Varying Associations with Birthweight, International Journal of Epidemiology, vol. 16(1), pp. 4451.

Lawlor, D., Harbord, R., Sterne, J., Timpson, N. and Davey Smith, G. (2008). Mendelian Randomization: Using Genes as Instruments for Making Causal Inferences in Epidemiology, Statistics in Medicine, vol. 27, pp. 1133-1163.

Lawlor, D., Nordestgaard, B., Benn, M., Zuccolo, L., Tybjaerg-Hansen, A. and Davey Smith, G. (2013). Exploring Causal Associations between Alcohol and Coronary Heart Disease Risk Factors: Findings from a Mendelian Randomization Study in the Copenhagen General Population Study, European Heart Journal, vol. 34, pp. 2519-2528.

Lee, S-L., Chau, G-Y., Yao, C-T. et al. (2006). Functional Assessment of Human Alcohol Dehydrogenase Family in Ethanol Metabolism: Significance of First-Pass Metabolism, Alcoholism: Clinical and Experimental Research, vol. 30(7), 1132-1142. 
Lewis, S. et al. (2012). Fetal Alcohol Exposure and IQ at Age 8: Evidence from a PopulationBased Birth-Cohort Study. PLoS ONE, vol. 7(11), pp. e49407.

Loew, M. Boeing, H. Sturmer, T. and Brenner, H. (2003). Relation among alcohol dehydrogenase 2 polymorphism, alcohol consumption, and levels of gammaglutamyltransferase, Alcohol, vol. 29, pp. 131-135.

Lorenzo, A. et al. (2006). Polymorphisms of alcohol-metabolizing enzymes and the risk for alcoholism and alcoholic liver disease in Caucasian Spanish women, Drug and alcohol dependence, vol.84(2),pp.195-200.

Luo, X., Kranzler, H., Zuo, L., et al. (2006). Diplotype trend regression analysis of the ADH gene cluster and the ALDH2 gene: multiple significant associations with alcohol dependence, The American Journal of Human Genetics, vol. 78, pp. 973-987.

Macgregor, S., Lind, P., Bucholz, K., et al. (2009). Associations of ADH and ALDH2 gene variation with self report alcohol reactions, consumption and dependence: an integrated analysis, Human Molecular Genetics, vol. 18(3), pp. 580-593.

McKay J.D., Truong, T., Gaborieau, V., Chabrier, A., Chuang, S-C. et al. (2011). A GenomeWide Association Study of Upper Aerodigestive Tract Cancers Conducted within the INHANCE Consortium, PLoS Genetics, vol. 7(3), pp. e1001333.

Neumark, Y. Friedlander, Y. Durst, R., Leitersdorf, E., et al. (2004). Alcohol Dehydrogenase Polymorphisms Influence Alcohol-Elimination Rates in a Male Jewish Population, Alcoholism: Clinical and Experimental Research, vol. 28(1), pp. 10-14.

NICE, National Institute for Health and Clinical Excellence. (2008). "Understanding NICE Guidelines: Routine Antenatal Care for Healthy Pregnant Women.” [Accessed 5 December 2012] available at: www.nice.org.uk/nicemedia/pdf/CG062PublicInfo.pdf

Nilsson, P. (2008). Does a Pint a Day affect your Child's Pay? The Effect of Prenatal Alcohol Exposure on Adult Outcomes, Cemmap Working paper 22/08.

Office of the US Surgeon General. 1981. Surgeon General's advisory on alcohol and pregnancy. FDA Drug Bulletin, 11:9-10.

Polygenis, D., Wartona, S., Malmberg, C., et al., (1998). Moderate alcohol Consumption during Pregnancy and the Incidence of Fetal Malformations: A Meta-Analysis, Neurotoxicology and Teratology, 20, pp. 61-7.

Reich, T., Edenberg, H., Goate, A., et al. (1998). Genome-wide search for genes affecting the risk for alcohol dependence, American Journal of Medical Genetics Part B (Neuropsychiatric Genetics), 81, pp. 207-215.

Rosenzweig, M. and Wolpin, K. (1993). Are There Increasing Returns to the Intergenerational Production of Human Capital? Maternal Schooling and Child Intellectual Achievement, Journal of Human Resources, vol. 29, pp. 670-693.

Rubin, D. (1980). Comment on 'Randomization Analysis of Experimental Data: The Fisher Randomization Test’ by D. Basu, Journal of the American Statistical Association, vol. 75, pp. 591-593.

Russell, M. (1991). Clinical Implications of Recent Research on the Fetal Alcohol Syndrome, Bulletin of the New York Academy of Medicine, vol. 67(3), pp. 207-222.

Saccone, N., Kwon, J., Corbett, J., et al. (2000). A genome screen of maximum number of drinks as an alcoholism phenotype, American Journal of Medical Genetics Part B (Neuropsychiatric Genetics), vol. 96, 632-637.

Stockwell, T., Dnoath, S., Cooper-Stanbury, M., et al. (2004). Under-reporting of Alcohol Consumption in Household Surveys: A Comparison of Quantity-Frequency, GraduatedFrequency and Recent Recall, Addiction, vol. 99(8), pp. 1024-1033.

Saccone, S.F., Saccone, N.L., Neuman, R.J. and Rice, J.P. (2005). Genetic analysis of the maximum drinks phenotype, BMC Genetics, vol. 6, pp. S124. 
Sherva, R., Rice, J.P., Neuman, R.J., Rochberg, N., Saccone, N.L. and Bierut, L.J. (2009). Associations and interactions between SNPs in the alcohol metabolizing genes and alcoholism phenotypes in European Americans, Alcoholism: Clinical and Experimental Research, vol. 33, pp. 848-857.

Sullivan, W.C. (1899). A Note on the Influence of Maternal Inebriety on the Offspring, Journal of Mental Science, vol. 45, pp. 489-503.

Tolstrup, J.S., Nordestgaard, B.G., Rasmussen, S., Tybjaerg-Hansen, A. and Gronbaek,M. (2008). Alcoholism and alcohol drinking habits predicted from alcohol dehydrogenase genes, The Pharmacogenomics Journal, vol. 8, pp. 220-227.

Wall, T.L., Shea, S.H., Luczak, S.E., Cook, T.A.R. and Carr, L.G. (2005). Genetic associations of alcohol dehydrogenase with alcohol use disorders and endophenotypes in White college students, J. Abnorm. Psychol., vol. 114, pp. 456-465.

Wehby, G., and S. von Hinke Kessler Scholder. 2013. Genetic Instrumental Variables Studies of Effects of Prenatal Risk Factors. Biodemography and Social Biology, vol. 59, pp. 4-36.

Whitfield, J.B., Nightingale, B.N., Bucholz, K.K., Madden, P.A.F., Heath, A.C. and Martin, N.G. (1998). ADH Genotypes and Alcohol Use and Dependence in Europeans, Alcoholism: Clinical and Experimental Research, vol. 22, pp. 1463-1469.

WTCCC (Wellcome Trust Case Control Consortium). (2007). Genome-wide association study of 14,000 cases of seven common diseases and 3,000 shared controls, Nature, vol. 447, pp. 661-678.

Wüst, M. (2010). The Effect of Cigarette and Alcohol Consumption on Birth Outcomes, Aarhus School of Business, Department of Economics Working Paper 10-05.

Zhang G., Mai, R., Huang, B. (2010). ADH1B Arg47His Polymorphism Is Associated with Esophageal Cancer Risk in High-Incidence Asian Population: Evidence from a MetaAnalysis, PLoS ONE vol. 5(10), pp. e13679.

Zhang, F., Hou, L., Terry, M., et al. (2007). Genetic polymorphisms in alcohol metabolism, alcohol intake and the risk of stomach cancer in Warsaw, Poland, International Journal of Cancer, vol. 121, pp.2060-64.

Zhang, N. (2010). Alcohol Taxes and Birth Outcomes, International Journal of Environmental Research and Public Health, vol. 7, pp. 1901-1912.

Zintzaras, E., Stefanidis, I., Santos, M. Vidal, F. (2006). Do alcohol-metabolizing enzyme gene polymorphisms increase the risk of alcoholism and alcoholic liver disease? Hepatology, vol. 43:352-361.

Zuccolo L, Fitz-Simon, N., Gray, R., Ring, S., Sayal, K., Davey Smith, G. and Lewis, S. (2009). A non-synonymous variant in $A D H 1 B$ is strongly associated with prenatal alcohol use in a European sample of pregnant women, Human Molecular Genetics, vol. 18(22), pp. 4457-4466.

Zuccolo, L. (2010). Alcohol and Prostate Cancer: Identifying Potentially Modifiable Lifestyle-related Causes of Cancer by Means of Mendelian Randomization, PhD thesis, School of Social and Community Medicine, University of Bristol.

Zuccolo L. et al. (2013) Prenatal Alcohol Exposure and Offspring Cognition and School Performance: A 'Mendelian Randomization' Natural Experiment. International Journal of Epidemiology, doi:10.1093/ije/dyt172 


\section{Appendix A: A Brief Introduction to Genetics}

Each cell in the human body contains a nucleus in which most DNA (99.9995\%) is located. DNA forms structures called chromosomes, where each chromosome contains a single continuous piece of DNA. All cells in the human body apart from gametes (i.e. germ cells) contain 46 chromosomes, organized into 23 chromosome pairs: one copy of chromosome 122 from each parent, plus an X-chromosome from the mother and either an $\mathrm{X}$ or a $\mathrm{Y}$ chromosome from the father.

Sites within DNA which vary between people are called polymorphisms. The most commonly studied form of polymorphism is a Single Nucleotide Polymorphism (SNP): a single base-pair variation in a particular location on the DNA sequence. As chromosomes come in pairs, humans have two base-pairs at each location (locus). Where there are two or more forms of DNA at a specific locus, these different forms are called alleles. The term genotype is used to describe the specific set of alleles inherited at a particular location on the chromosome. For example, individuals can have one of two alleles on each chromosome at the rs1229984 locus (A or G), this will result in three genotypes: they can be homozygous for the common allele (having two of the same common/most prevalent alleles: GG), heterozygous (AG), and homozygous for the rare allele (AA). 


\section{Appendix B: Tests of Independence}

To provide evidence on the validity of our IV approach, Table B1 presents descriptives of the covariates presented in the first column by genotype. Column 3 shows the $p$-value of a test whether the mean among those homozygous for the common allele (column 1) equals the mean among those carrying at least one rare allele (column 2). With random assignment of genetic variants, there should be no systematic variation in covariates by genotype. Table B1 shows this for a wide range of maternal and paternal prenatal background characteristics and behaviours (we investigate activities after birth - i.e. those that may be affected by child development, exploring potential parental responsive investments - in section 5.5).

We compare the number of correlations that are statistically significant with the number expected by chance if all variables were uncorrelated (excluding the first set of covariates, which concern genetically-related family members). We find no greater association between the genetic variant and covariates than what would be expected by chance ( $p=0.32$ at the $10 \%$ level, $p=0.46$ at $5 \%$, and $p=0.48$ at $1 \%$ ), suggesting that the SNP is independent of behavioural or environmental factors that may affect the outcome of interest. 
Table B1: Descriptive statistics: mean and standard deviation of covariates

\begin{tabular}{|c|c|c|c|c|c|}
\hline \multirow{2}{*}{ Alcohol-related covariates of mother's family } & \multicolumn{2}{|c|}{$\begin{array}{c}\text { (1) } \\
\text { Mother is homozygous } \\
\text { for the common allele at } \\
\text { rs1229984 } \\
\text { Mean (std dev) }\end{array}$} & \multicolumn{2}{|c|}{$\begin{array}{c}(2) \\
\text { Mother carries at least } \\
\text { one rare allele at } \\
\text { rs1229984 } \\
\text { Mean (std dev) } \\
\end{array}$} & \multirow[t]{2}{*}{$\begin{array}{c}\text { (3) } \\
\text { t-test } \\
p \text {-value }\end{array}$} \\
\hline & & & & & \\
\hline Child's $A D H 1 B$ (rs1229984) & 0.029 & $(0.168)$ & 0.471 & $(0.500)$ & $<0.001$ \\
\hline Mother's mother has alcohol problem & 0.022 & $(0.147)$ & 0.008 & $(0.091)$ & 0.125 \\
\hline Mother's father has alcohol problem & 0.054 & $(0.226)$ & 0.034 & $(0.181)$ & 0.094 \\
\hline \multicolumn{6}{|l|}{ Alcohol-related covariates of mother's partner } \\
\hline Partner's drinks any alcohol (at 18 wks gestation) & 0.705 & $(0.456)$ & 0.728 & $(0.446)$ & 0.436 \\
\hline Partner's drinks any alcohol (at 8 months) & 0.749 & $(0.434)$ & 0.702 & $(0.457)$ & 0.573 \\
\hline Freq. partner drinks $>4$ units ( 8 month; $0=$ never, $5=$ daily) & 2.088 & (1.390) & 1.966 & (1.558) & 0.315 \\
\hline \multicolumn{6}{|l|}{ 'Standard' covariates ${ }^{1}$} \\
\hline$\overline{\text { Girl }}$ & 0.482 & $(0.500)$ & 0.505 & $(0.501)$ & 0.449 \\
\hline Child’s age at KS1 (in months) & 88.727 & (3.735) & 88.302 & $(3.673)$ & 0.096 \\
\hline Mother's age at child's birth (in years) & 28.543 & $(4.666)$ & 28.651 & $(4.555)$ & 0.709 \\
\hline Older siblings $(0,1$, or $2+)$ & 0.726 & $(0.748)$ & 0.727 & $(0.746)$ & 0.972 \\
\hline Younger siblings $(0,1$, or $2+)$ & 0.048 & $(0.220)$ & 0.075 & $(0.279)$ & 0.068 \\
\hline Father's education: O-level & 0.309 & $(0.462)$ & 0.293 & $(0.456)$ & 0.582 \\
\hline Father's education: A-level & 0.275 & $(0.447)$ & 0.293 & $(0.456)$ & 0.533 \\
\hline Father's education: University degree & 0.190 & $(0.392)$ & 0.202 & $(0.402)$ & 0.646 \\
\hline Mother's education: O-level & 0.444 & $(0.497)$ & 0.451 & $(0.499)$ & 0.809 \\
\hline Mother's education: A-level & 0.233 & $(0.423)$ & 0.257 & $(0.438)$ & 0.366 \\
\hline Mother's education: University degree & 0.146 & $(0.353)$ & 0.153 & $(0.361)$ & 0.749 \\
\hline Social class: Semi-skilled & 0.098 & $(0.297)$ & 0.070 & $(0.255)$ & 0.145 \\
\hline Social class: Skilled manual & 0.301 & $(0.459)$ & 0.332 & $(0.472)$ & 0.304 \\
\hline Social class: Skilled non-manual & 0.114 & $(0.318)$ & 0.082 & $(0.275)$ & 0.119 \\
\hline Social class: Managerial/Technical & 0.349 & $(0.477)$ & 0.361 & $(0.481)$ & 0.718 \\
\hline Social class: Professional & 0.114 & $(0.317)$ & 0.119 & $(0.324)$ & 0.798 \\
\hline Ln(income) & 5.331 & $(0.479)$ & 5.352 & $(0.452)$ & 0.510 \\
\hline Mother employed & 0.499 & $(0.500)$ & 0.444 & $(0.498)$ & 0.103 \\
\hline Father employed & 0.873 & $(0.333)$ & 0.897 & $(0.305)$ & 0.274 \\
\hline CCEI [score ranging from 0-44] & 13.009 & $(7.485)$ & 12.943 & $(7.222)$ & 0.894 \\
\hline EPDS [score ranging from $0-23$ ] & 6.629 & $(4.723)$ & 6.440 & $(4.760)$ & 0.538 \\
\hline Smoking (first trimester) & 0.172 & $(0.377)$ & 0.136 & $(0.343)$ & 0.131 \\
\hline \multicolumn{6}{|l|}{ Mother's tea, coffee \& milk, 8 weeks gestation } \\
\hline$\overline{\text { Drink tea }}$ & 0.799 & $(0.401)$ & 0.749 & $(0.434)$ & 0.050 \\
\hline Drink decaf tea & 0.035 & $(0.184)$ & 0.034 & $(0.182)$ & 0.951 \\
\hline Drink coffee & 0.511 & $(0.500)$ & 0.492 & $(0.501)$ & 0.556 \\
\hline Drink decaf coffee & 0.157 & $(0.364)$ & 0.130 & $(0.337)$ & 0.249 \\
\hline Drink cola & 0.347 & $(0.476)$ & 0.391 & $(0.489)$ & 0.149 \\
\hline Drink decaf cola & 0.090 & $(0.287)$ & 0.080 & $(0.272)$ & 0.576 \\
\hline Drink milk & 0.586 & $(0.493)$ & 0.604 & $(0.490)$ & 0.561 \\
\hline \multicolumn{6}{|l|}{ Parental diet and nutrition $^{2}$} \\
\hline Mother eats sausages/burgers & 0.608 & $(0.488)$ & 0.584 & $(0.494)$ & 0.448 \\
\hline Mother eats pies or pastries & 0.550 & $(0.498)$ & 0.506 & $(0.501)$ & 0.169 \\
\hline Mother eats meat & 0.913 & $(0.281)$ & 0.898 & $(0.303)$ & 0.400 \\
\hline Mother eats poultry & 0.906 & $(0.292)$ & 0.898 & $(0.303)$ & 0.665 \\
\hline Mother eats offal & 0.093 & $(0.290)$ & 0.075 & $(0.263)$ & 0.320 \\
\hline Mother eats white fish & 0.823 & $(0.382)$ & 0.843 & $(0.364)$ & 0.413 \\
\hline Mother eats oily fish & 0.593 & $(0.491)$ & 0.612 & $(0.488)$ & 0.543 \\
\hline Mother eats shellfish & 0.193 & $(0.394)$ & 0.196 & $(0.398)$ & 0.893 \\
\hline Mother eats eggs or quiche & 0.861 & $(0.346)$ & 0.859 & $(0.349)$ & 0.908 \\
\hline Mother eats cheese & 0.945 & $(0.227)$ & 0.953 & $(0.212)$ & 0.600 \\
\hline Mother eats pizza & 0.571 & $(0.495)$ & 0.643 & $(0.480)$ & 0.024 \\
\hline Mother eats chips & 0.819 & $(0.385)$ & 0.776 & $(0.417)$ & 0.085 \\
\hline Mother eats roast potatoes & 0.697 & $(0.460)$ & 0.702 & $(0.458)$ & 0.858 \\
\hline Mother eats boiled or baked potatoes & 0.975 & $(0.156)$ & 0.980 & $(0.139)$ & 0.587 \\
\hline Mother eats boiled rice & 0.767 & $(0.423)$ & 0.788 & $(0.409)$ & 0.432 \\
\hline Mother eats pasta & 0.811 & $(0.392)$ & 0.816 & $(0.389)$ & 0.843 \\
\hline
\end{tabular}




\begin{tabular}{|c|c|c|c|c|c|}
\hline Mother eats crisps & 0.792 & $(0.406)$ & 0.769 & $(0.423)$ & 0.372 \\
\hline Mother eats fried food & 0.486 & $(0.500)$ & 0.427 & $(0.496)$ & 0.067 \\
\hline Mother eats baked beans & 0.853 & $(0.354)$ & 0.859 & $(0.349)$ & 0.803 \\
\hline Mother eats peas or corn & 0.933 & $(0.251)$ & 0.941 & $(0.236)$ & 0.592 \\
\hline Mother eats cabbage & 0.904 & $(0.294)$ & 0.898 & $(0.303)$ & 0.745 \\
\hline Mother eats other green vegetables & 0.938 & $(0.242)$ & 0.925 & $(0.263)$ & 0.429 \\
\hline Mother eats carrots & 0.929 & $(0.257)$ & 0.929 & $(0.257)$ & 0.970 \\
\hline Mother eats root vegetables (not carrots) & 0.629 & $(0.483)$ & 0.580 & $(0.494)$ & 0.120 \\
\hline Mother eats salad & 0.916 & $(0.277)$ & 0.933 & $(0.250)$ & 0.339 \\
\hline Mother eats fresh fruit & 0.979 & $(0.143)$ & 0.988 & $(0.108)$ & 0.320 \\
\hline Mother drinks tinned juice & 0.188 & $(0.391)$ & 0.122 & $(0.327)$ & 0.008 \\
\hline Mother drinks pure non-tinned juice & 0.788 & $(0.408)$ & 0.831 & $(0.375)$ & 0.101 \\
\hline Mother eats pudding & 0.759 & $(0.428)$ & 0.780 & $(0.415)$ & 0.432 \\
\hline Mother eats oat cereals & 0.559 & $(0.497)$ & 0.537 & $(0.500)$ & 0.491 \\
\hline Mother eats bran cereals & 0.686 & $(0.464)$ & 0.722 & $(0.449)$ & 0.234 \\
\hline Mother eats other cereals & 0.677 & $(0.468)$ & 0.659 & $(0.475)$ & 0.544 \\
\hline Mother eats cakes or buns & 0.869 & $(0.338)$ & 0.890 & $(0.313)$ & 0.320 \\
\hline Mother eats crispbreads & 0.318 & $(0.466)$ & 0.322 & $(0.468)$ & 0.913 \\
\hline Mother eats biscuits & 0.913 & $(0.282)$ & 0.914 & $(0.281)$ & 0.969 \\
\hline Mother eats chocolate bars & 0.839 & $(0.367)$ & 0.820 & $(0.385)$ & 0.406 \\
\hline Mother eats pulses & 0.239 & $(0.427)$ & 0.294 & $(0.457)$ & 0.047 \\
\hline Mother eats nuts & 0.317 & $(0.465)$ & 0.310 & $(0.463)$ & 0.809 \\
\hline Mother eats bean curd & 0.024 & $(0.154)$ & 0.047 & $(0.212)$ & 0.025 \\
\hline Mother eats tahini & 0.024 & $(0.154)$ & 0.043 & $(0.204)$ & 0.059 \\
\hline Mother eats soya or similar non-meat & 0.080 & $(0.271)$ & 0.078 & $(0.269)$ & 0.945 \\
\hline Mother eats chocolate & 0.763 & $(0.426)$ & 0.780 & $(0.415)$ & 0.515 \\
\hline Mother eats sweets & 0.595 & $(0.491)$ & 0.533 & $(0.500)$ & 0.050 \\
\hline Mother drinks diet drinks & 0.755 & $(0.430)$ & 0.700 & $(0.459)$ & 0.056 \\
\hline Partner eats sausages or burgers & 0.738 & $(0.440)$ & 0.709 & $(0.455)$ & 0.341 \\
\hline Partner eats pies or pastries & 0.711 & $(0.454)$ & 0.644 & $(0.480)$ & 0.034 \\
\hline Partner eats meat & 0.949 & $(0.220)$ & 0.891 & $(0.312)$ & $<0.001$ \\
\hline Partner eats poultry & 0.925 & $(0.263)$ & 0.886 & $(0.318)$ & 0.036 \\
\hline Partner eats offal & 0.226 & $(0.418)$ & 0.177 & $(0.383)$ & 0.092 \\
\hline Partner eats white fish & 0.807 & $(0.394)$ & 0.814 & $(0.390)$ & 0.820 \\
\hline Partner eats oily fish & 0.533 & $(0.499)$ & 0.523 & $(0.501)$ & 0.775 \\
\hline Partner eats shellfish & 0.232 & $(0.422)$ & 0.183 & $(0.388)$ & 0.096 \\
\hline Partner eats fried food & 0.759 & $(0.428)$ & 0.714 & $(0.453)$ & 0.131 \\
\hline Partner eats cabbage & 0.888 & $(0.316)$ & 0.900 & $(0.301)$ & 0.579 \\
\hline Partner eats carrots & 0.918 & $(0.275)$ & 0.918 & $(0.275)$ & 0.979 \\
\hline Partner eats other vegetables & 0.969 & $(0.174)$ & 0.973 & $(0.163)$ & 0.736 \\
\hline Partner eats salad & 0.868 & $(0.339)$ & 0.923 & $(0.268)$ & 0.018 \\
\hline Partner eats fresh fruit & 0.881 & $(0.324)$ & 0.872 & $(0.335)$ & 0.687 \\
\hline Partner drinks tinned juice & 0.227 & $(0.419)$ & 0.191 & $(0.394)$ & 0.212 \\
\hline Partner drinks pure non-tinned juice & 0.714 & $(0.452)$ & 0.682 & $(0.467)$ & 0.298 \\
\hline Partner eats nuts & 0.363 & $(0.481)$ & 0.341 & $(0.475)$ & 0.507 \\
\hline Partner drinks diet drink & 0.566 & $(0.496)$ & 0.556 & $(0.498)$ & 0.777 \\
\hline Mother eats mostly white bread & 0.575 & $(0.494)$ & 0.549 & $(0.499)$ & 0.411 \\
\hline Partner eats mostly white bread & 0.780 & $(0.415)$ & 0.750 & $(0.434)$ & 0.384 \\
\hline Mother eats mostly brown/granary bread & 0.446 & $(0.497)$ & 0.475 & $(0.500)$ & 0.367 \\
\hline Partner eats mostly brown/granary bread & 0.641 & $(0.480)$ & 0.653 & $(0.478)$ & 0.770 \\
\hline Mothers eats mostly wholemeal bread & 0.506 & $(0.500)$ & 0.506 & $(0.501)$ & 1.000 \\
\hline Partner eats mostly wholemeal bread & 0.612 & $(0.487)$ & 0.580 & $(0.495)$ & 0.465 \\
\hline Mothers eats mostly chappati’s & 0.013 & $(0.114)$ & 0.008 & $(0.088)$ & 0.457 \\
\hline Partner eats mostly chappati’s & 0.055 & $(0.228)$ & 0.020 & $(0.140)$ & 0.124 \\
\hline Mother doesn't usually eat any bread & 0.021 & $(0.143)$ & 0.031 & $(0.175)$ & 0.257 \\
\hline Partner doesn't usually eat any bread & 0.075 & $(0.264)$ & 0.041 & $(0.199)$ & 0.264 \\
\hline Mother has takeaway meals & 0.704 & $(0.457)$ & 0.738 & $(0.440)$ & 0.242 \\
\hline Partner has takeaway meals & 0.689 & $(0.463)$ & 0.687 & $(0.465)$ & 0.954 \\
\hline Mother is vegetarian or vegan & 0.131 & $(0.338)$ & 0.157 & $(0.365)$ & 0.233 \\
\hline Partner is vegetarian or vegan & 0.033 & $(0.178)$ & 0.064 & $(0.246)$ & 0.013 \\
\hline Mother buys organic vegetables & 0.306 & $(0.461)$ & 0.296 & $(0.457)$ & 0.737 \\
\hline Mother buys organic meat & 0.143 & $(0.350)$ & 0.148 & $(0.356)$ & 0.831 \\
\hline Mother buys other organic foods & 0.038 & $(0.191)$ & 0.035 & $(0.184)$ & 0.809 \\
\hline \multicolumn{6}{|l|}{ Parental attitudes } \\
\hline Mother's attitude to breastfeeding[ranging from $4-23]^{3}$ & 16.204 & (3.279) & 16.458 & (3.198) & 0.228 \\
\hline Partner's attitude to breastfeeding[ranging from $6-22]^{3}$ & 15.591 & $(2.679)$ & 15.731 & $(2.951)$ & 0.461 \\
\hline
\end{tabular}




\begin{tabular}{|c|c|c|c|c|c|}
\hline \multicolumn{6}{|l|}{ Proportion agreeing (mother): } \\
\hline Should pick up crying baby & 0.483 & $(0.500)$ & 0.532 & $(0.500)$ & 0.129 \\
\hline Regular feed \& sleep pattern is important & 0.903 & $(0.296)$ & 0.900 & $(0.301)$ & 0.852 \\
\hline Should always be fed when they are hungry & 0.942 & $(0.233)$ & 0.933 & $(0.251)$ & 0.536 \\
\hline Babies need stimulation to develop well & 0.977 & $(0.150)$ & 0.984 & $(0.126)$ & 0.467 \\
\hline Babies should not be disturbed too much & 0.550 & $(0.498)$ & 0.560 & $(0.497)$ & 0.735 \\
\hline Parents should adapt lives to baby’s demands & 0.523 & $(0.500)$ & 0.552 & $(0.498)$ & 0.365 \\
\hline Baby should fit into parents’ routine & 0.576 & $(0.494)$ & 0.571 & $(0.496)$ & 0.884 \\
\hline Babies should develop naturally & 0.429 & $(0.495)$ & 0.417 & $(0.494)$ & 0.730 \\
\hline It is important to talk to a baby & 0.999 & $(0.025)$ & 0.996 & $(0.063)$ & 0.069 \\
\hline Cuddling baby is very important & 0.999 & $(0.032)$ & 0.996 & $(0.063)$ & 0.195 \\
\hline \multicolumn{6}{|l|}{ Proportion agreeing (partner): } \\
\hline Should pick up crying baby & 0.397 & $(0.489)$ & 0.427 & $(0.496)$ & 0.387 \\
\hline Regular feed \& sleep pattern is important & 0.918 & $(0.274)$ & 0.949 & $(0.221)$ & 0.113 \\
\hline Should always be fed when they are hungry & 0.870 & $(0.336)$ & 0.882 & $(0.323)$ & 0.618 \\
\hline Babies need stimulation to develop well & 0.978 & $(0.146)$ & 0.962 & $(0.191)$ & 0.125 \\
\hline Babies should not be disturbed too much & 0.590 & $(0.492)$ & 0.640 & $(0.481)$ & 0.147 \\
\hline Parents should adapt lives to baby’s demands & 0.635 & $(0.481)$ & 0.626 & $(0.485)$ & 0.787 \\
\hline Baby should fit into parents' routine & 0.502 & $(0.500)$ & 0.498 & $(0.501)$ & 0.900 \\
\hline Babies should develop naturally & 0.411 & $(0.492)$ & 0.500 & $(0.501)$ & 0.010 \\
\hline It is important to talk to a baby & 0.997 & $(0.051)$ & 1.000 & $(0.000)$ & 0.458 \\
\hline Cuddling baby is very important & 0.997 & $(0.053)$ & 1.000 & $(0.000)$ & 0.436 \\
\hline Attitude to fatherhood score [ranging from 8-45] & 38.477 & $(5.183)$ & 38.596 & $(5.788)$ & 0.758 \\
\hline Work and parenthood score [ranging from 1-12] & 8.751 & (2.029) & 8.675 & $(2.060)$ & 0.635 \\
\hline \multicolumn{6}{|l|}{$\underline{\text { Religious beliefs }}$} \\
\hline Mother believes in a divine power & 0.503 & $(0.500)$ & 0.539 & $(0.499)$ & 0.264 \\
\hline Partner believes in a divine power & 0.360 & $(0.480)$ & 0.408 & $(0.493)$ & 0.149 \\
\hline Mother feels helped by divine power & 0.339 & $(0.474)$ & 0.377 & $(0.486)$ & 0.209 \\
\hline Partner feels helped by divine power & 0.240 & $(0.427)$ & 0.271 & $(0.445)$ & 0.308 \\
\hline Mother appeals to God for help if in trouble & 0.474 & $(0.499)$ & 0.506 & $(0.501)$ & 0.323 \\
\hline Partner appeals to God for help if in trouble & 0.352 & $(0.478)$ & 0.426 & $(0.496)$ & 0.028 \\
\hline \multicolumn{6}{|l|}{ Household characteristics } \\
\hline Home is mortgaged/owned & 0.796 & $(0.403)$ & 0.829 & $(0.377)$ & 0.191 \\
\hline Total number of rooms [ranging from $0-18$ ] & 4.942 & $(1.507)$ & 4.879 & $(1.417)$ & 0.508 \\
\hline Use of garden or yard & 0.950 & $(0.218)$ & 0.973 & $(0.161)$ & 0.084 \\
\hline Working phone in home & 0.920 & $(0.271)$ & 0.933 & $(0.251)$ & 0.461 \\
\hline Use of car by mum or partner & 0.922 & $(0.268)$ & 0.963 & $(0.190)$ & 0.015 \\
\hline House has damp condensation or mould & 0.481 & $(0.500)$ & 0.448 & $(0.498)$ & 0.295 \\
\hline Partner is father of child & 0.994 & $(0.074)$ & 0.996 & $(0.061)$ & 0.699 \\
\hline Partner lives with mum & 0.952 & $(0.214)$ & 0.970 & $(0.171)$ & 0.178 \\
\hline Age of partner [ranging from 16-60] & 30.963 & $(5.602)$ & 30.643 & (5.349) & 0.378 \\
\hline Marital status (8 wks gestation) & 0.796 & $(0.403)$ & 0.841 & $(0.367)$ & 0.076 \\
\hline Total no. of persons (8 wks gestation) & 2.929 & $(1.093)$ & 2.901 & $(1.031)$ & 0.675 \\
\hline \multicolumn{6}{|l|}{ Pregnancy } \\
\hline Seen doctor for possible infertility & 0.131 & $(0.337)$ & 0.136 & $(0.343)$ & 0.815 \\
\hline Used treatments to help conceive & 0.033 & $(0.179)$ & 0.051 & $(0.220)$ & 0.128 \\
\hline Has previously been pregnant & 0.660 & $(0.474)$ & 0.655 & $(0.476)$ & 0.868 \\
\hline Has previously had a miscarriage & 0.206 & $(0.404)$ & 0.217 & $(0.413)$ & 0.663 \\
\hline Has previously had an abortion or termination & 0.134 & $(0.340)$ & 0.098 & $(0.299)$ & 0.099 \\
\hline Has previously had a stillbirth & 0.008 & $(0.088)$ & 0.011 & $(0.106)$ & 0.530 \\
\hline Previous child born alive but died later & 0.013 & $(0.111)$ & 0.011 & $(0.106)$ & 0.874 \\
\hline Mother's age when first pregnant [ranging from 12-42] & 24.986 & $(4.868)$ & 24.978 & $(4.719)$ & 0.977 \\
\hline This pregnancy was intentional & 0.730 & $(0.444)$ & 0.780 & $(0.415)$ & 0.074 \\
\hline Mother happy with pregnancy when first pregnant & 0.717 & $(0.450)$ & 0.756 & $(0.431)$ & 0.177 \\
\hline Motherhood means personal sacrifice & 0.705 & $(0.456)$ & 0.667 & $(0.472)$ & 0.184 \\
\hline Mother is currently happy with pregnancy & 0.888 & $(0.316)$ & 0.925 & $(0.265)$ & 0.062 \\
\hline Partner is happy about pregnancy & 0.869 & $(0.338)$ & 0.867 & $(0.340)$ & 0.928 \\
\hline Partner's first reaction was supportive & 0.838 & $(0.368)$ & 0.861 & $(0.347)$ & 0.332 \\
\hline Partner is currently supportive & 0.897 & $(0.304)$ & 0.911 & $(0.286)$ & 0.483 \\
\hline Mother already knew a lot about pregnancy & 0.617 & $(0.486)$ & 0.644 & $(0.480)$ & 0.388 \\
\hline Self-induced vomiting for weight loss prior to pregnancy & 0.053 & $(0.224)$ & 0.073 & $(0.261)$ & 0.156 \\
\hline Self-induced vomiting during this pregnancy & 0.010 & $(0.102)$ & 0.015 & $(0.124)$ & 0.453 \\
\hline Laxative use for weight loss prior to pregnancy & 0.042 & $(0.200)$ & 0.035 & $(0.183)$ & 0.593 \\
\hline Laxative use during this pregnancy & 0.003 & $(0.054)$ & 0.000 & $(0.000)$ & 0.381 \\
\hline
\end{tabular}




\begin{tabular}{|c|c|c|c|c|c|}
\hline Mother had pain relief during labour & 0.873 & $(0.333)$ & 0.867 & $(0.340)$ & 0.798 \\
\hline Mother had caesarean section & 0.103 & $(0.303)$ & 0.080 & $(0.272)$ & 0.259 \\
\hline Partner was with mother during labour & 0.882 & $(0.322)$ & 0.884 & $(0.320)$ & 0.912 \\
\hline Partner was with mother during delivery & 0.854 & $(0.353)$ & 0.873 & $(0.334)$ & 0.429 \\
\hline Mother intends to work after child's birth & 0.471 & $(0.499)$ & 0.464 & $(0.500)$ & 0.823 \\
\hline \multicolumn{6}{|l|}{ Mother's and partner's physical health } \\
\hline Partner is well (8 wks gestation) & 0.963 & $(0.190)$ & 0.955 & $(0.208)$ & 0.524 \\
\hline Mother is well prior to pregnancy & 0.926 & $(0.261)$ & 0.934 & $(0.249)$ & 0.659 \\
\hline Mother is well in first trimester & 0.407 & $(0.491)$ & 0.457 & $(0.499)$ & 0.114 \\
\hline Mother is well in second trimester & 0.754 & $(0.431)$ & 0.766 & $(0.424)$ & 0.668 \\
\hline Mother is well in third trimester & 0.766 & $(0.423)$ & 0.776 & $(0.417)$ & 0.697 \\
\hline Partner is well (8 month post birth) & 0.968 & $(0.176)$ & 0.962 & $(0.192)$ & 0.614 \\
\hline Height of mother (in cm) & 164.183 & $(6.767)$ & 164.057 & (6.960) & 0.772 \\
\hline Weight of mother pre-pregnancy (in kg) & 62.086 & $(11.030)$ & 60.483 & (9.620) & 0.025 \\
\hline Mother visited dentist in preg (measured post-preg) & 0.771 & $(0.420)$ & 0.842 & $(0.366)$ & 0.055 \\
\hline Mother: Nausea in first trimester & 0.706 & $(0.456)$ & 0.737 & $(0.441)$ & 0.272 \\
\hline Mother: Vomiting in first trimester & 0.417 & $(0.493)$ & 0.390 & (0.489) & 0.388 \\
\hline Mother: Diarrhoea in first trimester & 0.172 & $(0.378)$ & 0.170 & $(0.376)$ & 0.923 \\
\hline Mother: Vaginal Bleeding in first trimester & 0.158 & $(0.365)$ & 0.181 & $(0.386)$ & 0.314 \\
\hline Mother: Jaundice in first trimester & 0.001 & $(0.025)$ & 0.000 & $(0.000)$ & 0.687 \\
\hline Mother: Urinary infection in first trimester & 0.048 & $(0.213)$ & 0.062 & $(0.241)$ & 0.299 \\
\hline Mother: Influenza in first trimester & 0.084 & $(0.278)$ & 0.081 & $(0.273)$ & 0.850 \\
\hline Mother: Rubella in in first trimester & 0.000 & $(0.014)$ & 0.000 & $(0.000)$ & 0.816 \\
\hline Mother: Thrush in first trimester & 0.089 & $(0.284)$ & 0.108 & $(0.311)$ & 0.286 \\
\hline Mother: Genital herpes in first trimester & 0.001 & $(0.038)$ & 0.000 & $(0.000)$ & 0.537 \\
\hline Mother: Other infection in first trimester & 0.047 & $(0.212)$ & 0.062 & $(0.241)$ & 0.284 \\
\hline Mother: Any infection in first trimester & 0.232 & $(0.422)$ & 0.266 & $(0.443)$ & 0.202 \\
\hline Mother: Injury or shock in first trimester & 0.046 & $(0.211)$ & 0.078 & $(0.268)$ & 0.023 \\
\hline Mother: Sugar in urine in first trimester & 0.020 & $(0.139)$ & 0.039 & $(0.193)$ & 0.036 \\
\hline Mother: X-ray in first trimester & 0.018 & $(0.132)$ & 0.031 & $(0.174)$ & 0.125 \\
\hline Mother: Amniocentesis in in first trimester & 0.006 & $(0.078)$ & 0.004 & $(0.062)$ & 0.654 \\
\hline Mother: Chorionic Villus Sampling in first trimester & 0.009 & $(0.092)$ & 0.008 & $(0.088)$ & 0.886 \\
\hline Mother: Spina bifida test in first trimester & 0.125 & $(0.331)$ & 0.140 & $(0.347)$ & 0.505 \\
\hline Mother: Ultrasound scan in first trimester & 0.265 & $(0.441)$ & 0.310 & $(0.463)$ & 0.111 \\
\hline Mother: Admitted to hospital in first trimester & 0.037 & $(0.188)$ & 0.012 & $(0.107)$ & 0.034 \\
\hline Mother: Nausea in second trimester & 0.364 & $(0.481)$ & 0.391 & $(0.489)$ & 0.393 \\
\hline Mother: Vomiting in second trimester & 0.220 & $(0.414)$ & 0.234 & $(0.424)$ & 0.581 \\
\hline Mother: Diarrhoea in second trimester & 0.310 & $(0.462)$ & 0.246 & $(0.432)$ & 0.032 \\
\hline Mother: Vaginal bleeding in second trimester & 0.043 & $(0.202)$ & 0.039 & $(0.194)$ & 0.773 \\
\hline Mother: Jaundice in second trimester & 0.001 & $(0.029)$ & 0.000 & $(0.000)$ & 0.643 \\
\hline Mother: Urinary infection in second trimester & 0.057 & $(0.232)$ & 0.031 & $(0.174)$ & 0.081 \\
\hline Mother: Cold in second trimester & 0.401 & $(0.490)$ & 0.367 & $(0.483)$ & 0.277 \\
\hline Mother: Influenza in second trimester & 0.056 & $(0.229)$ & 0.039 & $(0.194)$ & 0.257 \\
\hline Mother: Rubella in second trimester & 0.000 & $(0.000)$ & 0.000 & $(0.000)$ & - \\
\hline Mother: Thrush in second trimester & 0.132 & $(0.338)$ & 0.102 & $(0.303)$ & 0.162 \\
\hline Mother: Genital herpes in second trimester & 0.003 & $(0.054)$ & 0.008 & $(0.088)$ & 0.178 \\
\hline Mother: Other infection in second trimester & 0.053 & $(0.224)$ & 0.055 & $(0.228)$ & 0.900 \\
\hline Mother: Any infection in second trimester & 0.253 & $(0.435)$ & 0.211 & $(0.409)$ & 0.132 \\
\hline Mother: Injury or shock in second trimester & 0.076 & $(0.265)$ & 0.070 & $(0.256)$ & 0.731 \\
\hline Mother: Sugar in urine in second trimester & 0.128 & $(0.335)$ & 0.117 & $(0.322)$ & 0.600 \\
\hline Mother: X-ray in second trimester & 0.009 & $(0.093)$ & 0.027 & $(0.163)$ & 0.003 \\
\hline Mother: Amniocentesis in second trimester & 0.018 & $(0.132)$ & 0.016 & $(0.124)$ & 0.812 \\
\hline Mother: Chorionic Villus Sampling in second trimester & 0.008 & $(0.087)$ & 0.004 & $(0.063)$ & 0.506 \\
\hline Mother: Spina bifida test in second trimester & 0.232 & $(0.422)$ & 0.293 & $(0.456)$ & 0.026 \\
\hline Mother: Ultrasound in second trimester & 0.427 & $(0.495)$ & 0.430 & $(0.496)$ & 0.937 \\
\hline Mother: Headache in second trimester & 0.604 & $(0.489)$ & 0.574 & $(0.495)$ & 0.335 \\
\hline Mother: Backache in second trimester & 0.789 & $(0.408)$ & 0.754 & $(0.432)$ & 0.185 \\
\hline Mother: Varicose veins in second trimester & 0.144 & $(0.351)$ & 0.148 & $(0.356)$ & 0.842 \\
\hline Mother: Admitted to hospital in second trimester & 0.066 & $(0.248)$ & 0.055 & $(0.228)$ & 0.490 \\
\hline \multicolumn{6}{|l|}{ Mother's physical activity } \\
\hline Mother exercises at least once a week & 0.693 & $(0.461)$ & 0.615 & $(0.488)$ & 0.008 \\
\hline Mother usually walks & 0.263 & $(0.440)$ & 0.206 & $(0.405)$ & 0.045 \\
\hline Mother usually cycles & 0.009 & $(0.096)$ & 0.012 & $(0.108)$ & 0.693 \\
\hline Mother usually uses public transport & 0.074 & $(0.262)$ & 0.054 & $(0.227)$ & 0.244 \\
\hline Mother usually uses the car & 0.721 & $(0.449)$ & 0.774 & $(0.419)$ & 0.063 \\
\hline
\end{tabular}




\begin{tabular}{|c|c|c|c|c|c|}
\hline Mother: Jogging & 0.019 & $(0.138)$ & 0.012 & $(0.108)$ & 0.395 \\
\hline Mother: Aerobics & 0.050 & $(0.217)$ & 0.051 & $(0.221)$ & 0.905 \\
\hline Mother: Ante-natal exercise & 0.242 & $(0.428)$ & 0.251 & $(0.434)$ & 0.732 \\
\hline Mother: Keep fit exercises & 0.136 & $(0.343)$ & 0.142 & $(0.349)$ & 0.790 \\
\hline Mother: Yoga & 0.030 & $(0.170)$ & 0.032 & $(0.175)$ & 0.868 \\
\hline Mother: Squash & 0.005 & $(0.069)$ & 0.004 & $(0.063)$ & 0.859 \\
\hline Mother: Tennis or badminton & 0.030 & $(0.170)$ & 0.032 & $(0.176)$ & 0.852 \\
\hline Mother: Swimming & 0.453 & $(0.498)$ & 0.420 & $(0.495)$ & 0.310 \\
\hline Mother: Brisk walking & 0.753 & $(0.431)$ & 0.719 & $(0.450)$ & 0.215 \\
\hline Mother: Weight training & 0.006 & $(0.079)$ & 0.008 & $(0.089)$ & 0.746 \\
\hline Mother: Cycling & 0.061 & $(0.239)$ & 0.071 & $(0.258)$ & 0.501 \\
\hline Mother: Other exercise & 0.083 & $(0.276)$ & 0.105 & $(0.307)$ & 0.219 \\
\hline \multicolumn{6}{|l|}{ Parental mental health } \\
\hline 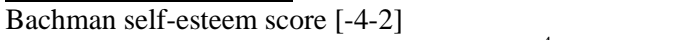 & 0.015 & $(0.987)$ & 0.035 & $(0.969)$ & 0.760 \\
\hline Mother's self-perceived change score [11-35] $]^{4}$ & 23.860 & $(2.734)$ & 24.206 & $(2.811)$ & 0.050 \\
\hline Mother's self-perceived feel good score [7-30] $]^{4}$ & 16.799 & (3.866) & 16.659 & (3.877) & 0.576 \\
\hline Mother's perception of partner's change score [9-35] ${ }^{4}$ & 20.938 & $(1.674)$ & 20.928 & $(1.853)$ & 0.930 \\
\hline Mother's perception of partner's feel good score [7-31] ${ }^{4}$ & 13.734 & $(4.026)$ & 13.498 & (3.863) & 0.373 \\
\hline Partner's self-perceived change score $[9-35]^{4}$ & 20.647 & $(2.309)$ & 20.832 & $(2.069)$ & 0.251 \\
\hline Partner's self-perceived feel good score $[7-30]^{4}$ & 15.791 & $(3.806)$ & 15.690 & $(3.786)$ & 0.705 \\
\hline Partner's perception of mother's change score [10-35 $]^{4}$ & 20.368 & $(1.538)$ & 20.257 & (1.538) & 0.309 \\
\hline Partner's perception of mother's feel good score [7-32] ${ }^{4}$ & 14.901 & (3.839) & 14.557 & $(4.082)$ & 0.208 \\
\hline Mother: Interpersonal awareness score [7-28] & 18.324 & (4.659) & 18.835 & $(4.866)$ & 0.085 \\
\hline Mother: Need for approval score [8-32] & 25.836 & (3.581) & 26.073 & (3.122) & 0.296 \\
\hline Mother: Separation anxiety score [8-32] & 16.211 & $(4.612)$ & 16.275 & (4.939) & 0.827 \\
\hline Mother: Timidity score [8-32] & 20.644 & (4.503) & 21.111 & $(4.362)$ & 0.101 \\
\hline Mother: Fragile inner-self score [5-20] & 8.701 & (2.919) & 8.748 & $(2.954)$ & 0.799 \\
\hline Mother: Total interpersonal sensitivity score [36-140] & 89.704 & 15.828) & 91.034 & (15.818) & 0.185 \\
\hline Partner: Interpersonal awareness score [7-28] & 16.229 & $(4.854)$ & 16.467 & $(4.683)$ & 0.487 \\
\hline Partner: Need for approval score [0-32] & 24.540 & (4.319) & 24.507 & $(4.344)$ & 0.914 \\
\hline Partner: Separation anxiety score $[0-32]$ & 14.692 & (4.386) & 14.519 & (4.567) & 0.577 \\
\hline Partner: Timidity score [3-32] & 18.896 & (4.697) & 18.877 & (4.794) & 0.955 \\
\hline Partner: Fragile inner-self score [5-20] & 8.187 & $(2.725)$ & 8.267 & $(2.635)$ & 0.680 \\
\hline Partner: Total interpersonal sensitivity score [29-138] & 82.456 & 16.270) & 82.519 & $(15.482)$ & 0.956 \\
\hline Mother: Pre-17 life event score [0-63] & 8.751 & $(8.324)$ & 8.685 & $(8.096)$ & 0.901 \\
\hline Partner: Pre-17 life event score [0-74] & 9.890 & $(8.700)$ & 10.552 & $(9.027)$ & 0.272 \\
\hline Partner's affection score (mother reported) $[6-30]^{5}$ & 11.340 & $(4.087)$ & 11.363 & $(3.913)$ & 0.930 \\
\hline Partner's affection score (partner reported) $[6-30]^{5}$ & 10.929 & $(3.905)$ & 10.970 & $(4.033)$ & 0.886 \\
\hline Partner's aggression score (mother reported) $[3-15]^{5}$ & 10.082 & $(1.750)$ & 9.945 & $(1.671)$ & 0.224 \\
\hline Partner's aggression score (partner reported) $[3-15]^{5}$ & 9.915 & $(1.862)$ & 9.782 & $(1.927)$ & 0.328 \\
\hline \multicolumn{6}{|l|}{ Maternal use of medication } \\
\hline 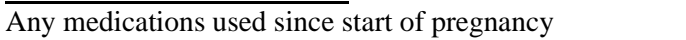 & 0.705 & $(0.456)$ & 0.702 & $(0.458)$ & 0.918 \\
\hline Medication for nausea in first trimester & 0.043 & $(0.202)$ & 0.064 & $(0.245)$ & 0.093 \\
\hline Medication for heartburn in first trimester & 0.071 & $(0.256)$ & 0.042 & $(0.200)$ & 0.070 \\
\hline Medication for vomiting in first trimester & 0.031 & $(0.173)$ & 0.049 & $(0.216)$ & 0.101 \\
\hline Medication for anxiety in first trimester & 0.005 & $(0.068)$ & 0.004 & $(0.061)$ & 0.843 \\
\hline Medication for infection in first trimester & 0.082 & $(0.274)$ & 0.095 & $(0.293)$ & 0.461 \\
\hline Medication for migraine in first trimester & 0.124 & $(0.329)$ & 0.106 & $(0.309)$ & 0.396 \\
\hline Medication for sleeping in first trimester & 0.008 & $(0.087)$ & 0.000 & $(0.000)$ & 0.154 \\
\hline Medication for pain in first trimester & 0.123 & $(0.328)$ & 0.102 & $(0.304)$ & 0.321 \\
\hline Medication for allergies in first trimester & 0.030 & $(0.170)$ & 0.030 & $(0.171)$ & 0.979 \\
\hline Medication for skin condition in first trimester & 0.073 & $(0.260)$ & 0.075 & $(0.265)$ & 0.886 \\
\hline Medication for bleeding in first trimester & 0.006 & $(0.075)$ & 0.000 & $(0.000)$ & 0.221 \\
\hline Medication for depression in first trimester & 0.005 & $(0.069)$ & 0.000 & $(0.000)$ & 0.258 \\
\hline Medication for piles in first trimester & 0.022 & $(0.146)$ & 0.023 & (0.149) & 0.934 \\
\hline Medication for constipation in first trimester & 0.054 & $(0.225)$ & 0.038 & $(0.191)$ & 0.260 \\
\hline Medication for cough in first trimester & 0.052 & $(0.222)$ & 0.064 & $(0.245)$ & 0.388 \\
\hline Medication for other reasons in first trimester & 0.067 & $(0.250)$ & 0.057 & $(0.232)$ & 0.533 \\
\hline Taking iron in first trimester & 0.197 & $(0.397)$ & 0.177 & $(0.382)$ & 0.427 \\
\hline Taking zinc in first trimester & 0.015 & $(0.120)$ & 0.015 & $(0.122)$ & 0.956 \\
\hline Taking calcium in first trimester & 0.032 & $(0.175)$ & 0.045 & $(0.208)$ & 0.222 \\
\hline Taking folic acid in first trimester & 0.086 & $(0.280)$ & 0.094 & $(0.292)$ & 0.645 \\
\hline Taking vitamins in first trimester & 0.160 & $(0.367)$ & 0.198 & $(0.399)$ & 0.107 \\
\hline Taking other supplements or diet foods in first trimester & 0.030 & $(0.170)$ & 0.019 & $(0.138)$ & 0.327 \\
\hline Ever used homeopathic medicine (trimester 1) & 0.103 & $(0.304)$ & 0.102 & $(0.303)$ & 0.933 \\
\hline
\end{tabular}




\begin{tabular}{|c|c|c|c|c|c|}
\hline Taking aspirin in first trimester & 0.042 & $(0.201)$ & 0.053 & $(0.224)$ & 0.396 \\
\hline Taking paracetamol in first trimester & 0.550 & $(0.498)$ & 0.491 & $(0.501)$ & 0.060 \\
\hline Taking codeine or anadin in first trimester & 0.024 & $(0.154)$ & 0.015 & $(0.122)$ & 0.342 \\
\hline Taking sleeping tablets in first trimester & 0.004 & $(0.063)$ & 0.000 & $(0.000)$ & 0.302 \\
\hline Taking tranquiliser in first trimester & 0.003 & $(0.051)$ & 0.008 & $(0.087)$ & 0.141 \\
\hline No. of medications used in first trimester [0-17] & 1.350 & $(1.446)$ & 1.330 & $(1.370)$ & 0.825 \\
\hline Medication for nausea in second trimester & 0.025 & $(0.156)$ & 0.008 & $(0.088)$ & 0.082 \\
\hline Medication for heartburn in second trimester & 0.367 & $(0.482)$ & 0.332 & $(0.472)$ & 0.251 \\
\hline Medication for vomiting in second trimester & 0.016 & $(0.126)$ & 0.004 & $(0.063)$ & 0.125 \\
\hline Medication for anxiety in second trimester & 0.007 & $(0.083)$ & 0.012 & $(0.108)$ & 0.382 \\
\hline Medication for infection in second trimester & 0.107 & $(0.309)$ & 0.090 & $(0.287)$ & 0.389 \\
\hline Medication for migraine in second trimester & 0.077 & $(0.267)$ & 0.070 & $(0.256)$ & 0.692 \\
\hline Medication for sleeping disorder in second trimester & 0.032 & $(0.177)$ & 0.031 & $(0.174)$ & 0.925 \\
\hline Medication for pain in second trimester & 0.155 & $(0.362)$ & 0.117 & $(0.322)$ & 0.105 \\
\hline Medication for allergies in second trimester & 0.046 & $(0.211)$ & 0.035 & $(0.185)$ & 0.400 \\
\hline Medication for skin condition in second trimester & 0.108 & $(0.311)$ & 0.145 & $(0.352)$ & 0.070 \\
\hline Medication for bleeding in second trimester & 0.003 & $(0.058)$ & 0.000 & $(0.000)$ & 0.352 \\
\hline Medication for depression in second trimester & 0.007 & $(0.081)$ & 0.004 & $(0.063)$ & 0.606 \\
\hline Medication for piles in second trimester & 0.077 & $(0.266)$ & 0.090 & $(0.287)$ & 0.450 \\
\hline Medication for constipation in second trimester & 0.070 & $(0.255)$ & 0.063 & $(0.243)$ & 0.650 \\
\hline Medication for cough in second trimester & 0.076 & $(0.266)$ & 0.094 & $(0.292)$ & 0.313 \\
\hline Medication for other reason in second trimester & 0.107 & $(0.309)$ & 0.094 & $(0.292)$ & 0.514 \\
\hline Taken iron in last second trimester & 0.426 & $(0.494)$ & 0.422 & $(0.495)$ & 0.907 \\
\hline Taken zinc in last second trimester & 0.013 & $(0.115)$ & 0.012 & $(0.108)$ & 0.812 \\
\hline Taken calcium in last second trimester & 0.032 & $(0.175)$ & 0.035 & $(0.185)$ & 0.751 \\
\hline Taken folic acid in second trimester & 0.193 & $(0.395)$ & 0.191 & $(0.394)$ & 0.947 \\
\hline Taken vitamins in second trimester & 0.114 & $(0.318)$ & 0.117 & $(0.322)$ & 0.873 \\
\hline Taken other supplements in second trimester & 0.026 & (0.159) & 0.027 & $(0.163)$ & 0.904 \\
\hline Ever use homeopathic medicine (trimester 2) & 0.156 & $(0.363)$ & 0.162 & $(0.369)$ & 0.788 \\
\hline Taken aspirin use in second trimester & 0.028 & $(0.166)$ & 0.027 & $(0.164)$ & 0.942 \\
\hline Taken paracetamol in second trimester & 0.434 & $(0.496)$ & 0.361 & $(0.481)$ & 0.022 \\
\hline Taken codein or anadin in second trimester & 0.017 & $(0.130)$ & 0.024 & $(0.152)$ & 0.459 \\
\hline Taken sleeping pill in second trimester & 0.007 & $(0.086)$ & 0.012 & $(0.108)$ & 0.431 \\
\hline Taken tranquilizer in second trimester & 0.002 & $(0.041)$ & 0.004 & $(0.063)$ & 0.412 \\
\hline No. of medications used in second trimester [0-11] & 1.661 & $(1.568)$ & 1.673 & $(1.542)$ & 0.906 \\
\hline Taken sleeping pill since birth (measured at 8 month) & 0.015 & $(0.120)$ & 0.004 & $(0.064)$ & 0.176 \\
\hline Taken cannabis since birth (measured at 8 month) & 0.030 & $(0.169)$ & 0.025 & $(0.155)$ & 0.652 \\
\hline Taken tranquilliser since birth (measured at 8 month) & 0.007 & $(0.082)$ & 0.008 & $(0.090)$ & 0.804 \\
\hline Taken anti-depressant since birth (meas. at 8 month) & 0.043 & $(0.204)$ & 0.029 & $(0.167)$ & 0.271 \\
\hline Taken hormone tablet since birth (meas. at 8 month) & 0.009 & $(0.092)$ & 0.016 & $(0.127)$ & 0.210 \\
\hline Taken antibiotic since birth (measured at 8 month) & 0.267 & $(0.442)$ & 0.246 & $(0.432)$ & 0.469 \\
\hline Taken painkiller since birth (measured at 8 month) & 0.818 & $(0.386)$ & 0.803 & $(0.398)$ & 0.555 \\
\hline Taken amphetamine since birth (measured at 8 month) & 0.005 & $(0.071)$ & 0.004 & $(0.064)$ & 0.833 \\
\hline Taken the pill since birth (measured at 8 month) & 0.515 & $(0.500)$ & 0.516 & $(0.501)$ & 0.958 \\
\hline Taken opiate or cocaine since birth (meas. at 8 month) & 0.002 & $(0.045)$ & 0.000 & $(0.000)$ & 0.486 \\
\hline Taken anticonvulsant since birth (measured at 8 month) & 0.003 & $(0.051)$ & 0.004 & $(0.064)$ & 0.672 \\
\hline Taken steroid since birth (measured at 8 month) & 0.017 & $(0.128)$ & 0.008 & $(0.090)$ & 0.303 \\
\hline Taken iron since birth (measured at 8 month) & 0.208 & $(0.406)$ & 0.225 & $(0.419)$ & 0.526 \\
\hline Taken vitamin since birth (measured at 8 month) & 0.254 & $(0.435)$ & 0.254 & $(0.436)$ & 0.999 \\
\hline Taken other substance since birth (meas. at 8 month) & 0.184 & $(0.387)$ & 0.168 & $(0.375)$ & 0.532 \\
\hline \multicolumn{6}{|l|}{ Parental substance use } \\
\hline Mother smoked pre-pregnancy & 0.299 & $(0.458)$ & 0.270 & $(0.445)$ & 0.310 \\
\hline Mother ever smoked & 0.567 & $(0.495)$ & 0.523 & $(0.500)$ & 0.164 \\
\hline Father ever smoked & 0.763 & $(0.425)$ & 0.744 & $(0.437)$ & 0.483 \\
\hline Partner smokes (at 18 weeks gest) & 0.341 & $(0.474)$ & 0.346 & $(0.477)$ & 0.855 \\
\hline Partner's number of cigarettes (at 8 months) [0-60] & 3.712 & (7.698) & 3.846 & (7.598) & 0.794 \\
\hline Mother smoked cannabis during pregnancy & 0.023 & $(0.149)$ & 0.019 & $(0.138)$ & 0.726 \\
\hline Mother smoked cannabis in 6 mths prior to pregnancy & 0.043 & $(0.204)$ & 0.039 & $(0.194)$ & 0.735 \\
\hline Mother used amphetamine during pregnancy & 0.001 & $(0.028)$ & 0.004 & $(0.062)$ & 0.125 \\
\hline Mother used barbiturate during pregnancy & 0.000 & $(0.020)$ & 0.000 & $(0.000)$ & 0.745 \\
\hline Mother used crack during pregnancy & 0.000 & $(0.000)$ & 0.000 & $(0.000)$ & - \\
\hline Mother used cocaine during pregnancy & 0.001 & $(0.025)$ & 0.000 & $(0.000)$ & 0.690 \\
\hline Mother used heroin during pregnancy & 0.000 & $(0.014)$ & 0.000 & $(0.000)$ & 0.819 \\
\hline Mother used methadone during pregnancy & 0.000 & $(0.014)$ & 0.000 & $(0.000)$ & 0.818 \\
\hline Mother used ecstasy during pregnancy & 0.003 & $(0.051)$ & 0.000 & $(0.000)$ & 0.700 \\
\hline Mother used other drug during pregnancy & 0.002 & $(0.040)$ & 0.004 & $(0.062)$ & 0.402 \\
\hline
\end{tabular}




\begin{tabular}{|c|c|c|c|c|c|}
\hline Mother used hard drugs during pregnancy & 0.003 & $(0.058)$ & 0.008 & $(0.087)$ & 0.270 \\
\hline Partner smoked cannabis in 6 mths prior to pregnancy & 0.117 & $(0.322)$ & 0.104 & $(0.307)$ & 0.654 \\
\hline Partner smoked cannabis in first trimester & 0.095 & $(0.294)$ & 0.090 & $(0.288)$ & 0.843 \\
\hline Partner used amphetamine in first trimester & 0.006 & $(0.080)$ & 0.000 & $(0.000)$ & 0.235 \\
\hline Partner used barbiturate in first trimester & 0.001 & $(0.036)$ & 0.000 & $(0.000)$ & 0.596 \\
\hline Partner used crack in first trimester & 0.001 & $(0.028)$ & 0.000 & $(0.000)$ & 0.682 \\
\hline Partner used cocaine in first trimester & 0.002 & $(0.046)$ & 0.000 & $(0.000)$ & 0.502 \\
\hline Partner used heroin in first trimester & 0.001 & $(0.032)$ & 0.000 & $(0.000)$ & 0.636 \\
\hline Partner used methadone in first trimester & 0.001 & $(0.032)$ & 0.000 & $(0.000)$ & 0.636 \\
\hline Partner used ecstasy in first trimester & 0.005 & $(0.073)$ & 0.000 & $(0.000)$ & 0.613 \\
\hline Partner used other in first trimester & 0.010 & $(0.098)$ & 0.015 & $(0.120)$ & 0.490 \\
\hline Partner used hard drugs in first trimester & 0.015 & $(0.123)$ & 0.014 & $(0.117)$ & 0.871 \\
\hline Mother used ganja in last 2 months of pregnancy & 0.018 & $(0.132)$ & 0.013 & $(0.112)$ & 0.560 \\
\hline Mother used ganja since birth (measured at 8 weeks) & 0.026 & $(0.158)$ & 0.013 & (0.112) & 0.210 \\
\hline Mother used hard drugs in last 2 months of pregnancy & 0.001 & $(0.033)$ & 0.000 & $(0.000)$ & 0.606 \\
\hline Mother used hard drugs since birth (meas. at 8 weeks) & 0.003 & $(0.057)$ & 0.008 & $(0.090)$ & 0.208 \\
\hline \multicolumn{6}{|l|}{ Mother's use of chemicals during pregnancy } \\
\hline$\overline{\text { Disinfectant }}$ & 0.874 & $(0.332)$ & 0.841 & $(0.366)$ & 0.117 \\
\hline Bleach & 0.845 & $(0.362)$ & 0.841 & $(0.366)$ & 0.872 \\
\hline Window cleaner & 0.621 & $(0.485)$ & 0.601 & $(0.491)$ & 0.521 \\
\hline Carpet cleaner & 0.376 & $(0.484)$ & 0.358 & $(0.480)$ & 0.548 \\
\hline Oven or drain cleaner & 0.416 & $(0.493)$ & 0.380 & $(0.486)$ & 0.244 \\
\hline Dry cleaning fluid & 0.059 & $(0.235)$ & 0.063 & $(0.243)$ & 0.790 \\
\hline Turps or white spirit & 0.217 & $(0.412)$ & 0.188 & $(0.392)$ & 0.261 \\
\hline Paint stripper & 0.058 & $(0.234)$ & 0.048 & $(0.214)$ & 0.481 \\
\hline House paint or varnish & 0.326 & $(0.469)$ & 0.277 & $(0.448)$ & 0.094 \\
\hline Weed killer & 0.076 & $(0.264)$ & 0.063 & $(0.243)$ & 0.433 \\
\hline Pesticide & 0.276 & $(0.447)$ & 0.255 & $(0.436)$ & 0.450 \\
\hline Aerosol or spray & 0.823 & $(0.382)$ & 0.815 & $(0.389)$ & 0.754 \\
\hline Hair dye or bleach & 0.163 & $(0.370)$ & 0.144 & $(0.352)$ & 0.396 \\
\hline Hair removal cream & 0.110 & $(0.312)$ & 0.100 & $(0.300)$ & 0.607 \\
\hline Air freshener & 0.697 & $(0.460)$ & 0.657 & $(0.476)$ & 0.165 \\
\hline Use of other chemicals & 0.061 & $(0.240)$ & 0.066 & $(0.249)$ & 0.736 \\
\hline Electrical mixer & 0.539 & $(0.499)$ & 0.551 & $(0.498)$ & 0.695 \\
\hline Hoover use & 0.966 & $(0.181)$ & 0.958 & $(0.200)$ & 0.507 \\
\hline Floor polisher & 0.056 & $(0.230)$ & 0.023 & $(0.149)$ & 0.020 \\
\hline Electrical iron & 0.964 & $(0.186)$ & 0.951 & $(0.216)$ & 0.270 \\
\hline Electrical hair appliance & 0.876 & $(0.330)$ & 0.879 & $(0.326)$ & 0.867 \\
\hline Electrical typewriter & 0.161 & $(0.368)$ & 0.204 & $(0.404)$ & 0.069 \\
\hline Photocopier or fax & 0.407 & $(0.491)$ & 0.453 & $(0.499)$ & 0.142 \\
\hline PC or VDU & 0.409 & $(0.492)$ & 0.479 & $(0.501)$ & 0.024 \\
\hline Power tool & 0.059 & $(0.235)$ & 0.045 & $(0.208)$ & 0.361 \\
\hline Sunbed or lamp & 0.015 & $(0.121)$ & 0.019 & $(0.136)$ & 0.601 \\
\hline Microwave & 0.777 & $(0.417)$ & 0.767 & $(0.423)$ & 0.719 \\
\hline Other electrical equipment & 0.099 & $(0.299)$ & 0.083 & $(0.276)$ & 0.391 \\
\hline Dental amalgam & 0.013 & $(0.112)$ & 0.015 & $(0.121)$ & 0.780 \\
\hline Ceramic or enamel & 0.019 & $(0.135)$ & 0.015 & $(0.121)$ & 0.648 \\
\hline Dry cleaning & 0.021 & $(0.143)$ & 0.033 & $(0.179)$ & 0.178 \\
\hline Electroplating & 0.001 & $(0.028)$ & 0.000 & $(0.000)$ & 0.642 \\
\hline Glue & 0.258 & $(0.438)$ & 0.283 & $(0.451)$ & 0.359 \\
\hline Leather working & 0.004 & $(0.061)$ & 0.000 & $(0.000)$ & 0.310 \\
\hline Fabric and textile & 0.167 & $(0.373)$ & 0.169 & $(0.376)$ & 0.936 \\
\hline Dye & 0.043 & $(0.203)$ & 0.026 & $(0.159)$ & 0.163 \\
\hline Insecticide & 0.112 & $(0.316)$ & 0.110 & $(0.314)$ & 0.918 \\
\hline Plastics & 0.039 & (0.194) & 0.022 & $(0.147)$ & 0.155 \\
\hline Metal cleaner & 0.219 & $(0.414)$ & 0.191 & (0.394) & 0.275 \\
\hline Petrol & 0.390 & $(0.488)$ & 0.375 & $(0.485)$ & 0.629 \\
\hline Paint & 0.287 & $(0.453)$ & 0.246 & $(0.432)$ & 0.145 \\
\hline Photo chemical & 0.015 & $(0.121)$ & 0.018 & $(0.135)$ & 0.650 \\
\hline ELEC wiring & 0.031 & $(0.173)$ & 0.029 & (0.169) & 0.893 \\
\hline Machining & 0.046 & $(0.210)$ & 0.048 & $(0.214)$ & 0.903 \\
\hline Soldering & 0.006 & $(0.077)$ & 0.004 & $(0.061)$ & 0.629 \\
\hline Radiation & 0.025 & $(0.158)$ & 0.029 & (0.169) & 0.690 \\
\hline
\end{tabular}




\begin{tabular}{|c|c|c|c|c|c|}
\hline \multicolumn{6}{|l|}{ Social support } \\
\hline 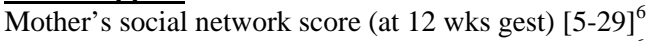 & 23.615 & $(3.690)$ & 23.605 & $(4.047)$ & 0.965 \\
\hline Partner's social network score (at 18 wks gest) [1-29] & 22.503 & (3.890) & 22.605 & (3.880) & 0.706 \\
\hline Mother's social support score (at 12 wks gest) $[0-30]^{6}$ & 19.963 & $(4.914)$ & 20.358 & $(5.115)$ & 0.223 \\
\hline Partner's social support score (at 18 wks gest) $[1-30]^{6}$ & 17.930 & (4.859) & 18.205 & $(4.889)$ & 0.415 \\
\hline \multicolumn{6}{|l|}{ Neighbourhood characteristics } \\
\hline$\overline{\text { Mother thinks neighbourhood is a good place to live }}$ & 0.933 & $(0.251)$ & 0.928 & $(0.259)$ & 0.770 \\
\hline Partner thinks neighbourhood is a good place to live & 0.932 & $(0.251)$ & 0.918 & $(0.275)$ & 0.440 \\
\hline Mother: People in neighbourhood visit & 0.550 & $(0.498)$ & 0.587 & $(0.493)$ & 0.234 \\
\hline Mother: People in neighbourhood argue with mother & 0.044 & $(0.204)$ & 0.026 & $(0.159)$ & 0.164 \\
\hline Mother: People in neighbourhood look after children & 0.202 & $(0.401)$ & 0.238 & $(0.427)$ & 0.151 \\
\hline Mother: People in neighbourhood keep to themselves & 0.822 & $(0.382)$ & 0.807 & $(0.396)$ & 0.520 \\
\hline Mother visits others in neighbourhood & 0.496 & $(0.500)$ & 0.524 & $(0.500)$ & 0.368 \\
\hline Mother argues with people in neighbourhood & 0.037 & $(0.189)$ & 0.022 & $(0.148)$ & 0.208 \\
\hline Mother looks after neighbours’ children & 0.216 & $(0.411)$ & 0.257 & $(0.438)$ & 0.113 \\
\hline Mother keeps to herself & 0.807 & $(0.394)$ & 0.792 & $(0.407)$ & 0.526 \\
\hline Partner: People in neighbourhood visit & 0.516 & $(0.500)$ & 0.549 & $(0.499)$ & 0.370 \\
\hline Partner: People in neighbourhood argue with mother & 0.051 & $(0.221)$ & 0.031 & $(0.174)$ & 0.206 \\
\hline Partner: People in neighbourhood look after children & 0.211 & $(0.408)$ & 0.313 & $(0.465)$ & 0.001 \\
\hline Partner: People in neighbourhood keep to themselves & 0.881 & $(0.324)$ & 0.870 & $(0.337)$ & 0.673 \\
\hline Partner visits others in neighbourhood & 0.378 & $(0.485)$ & 0.421 & $(0.495)$ & 0.229 \\
\hline Partner argues with people in neighbourhood & 0.041 & $(0.199)$ & 0.036 & $(0.187)$ & 0.725 \\
\hline Partner looks after neighbours' children & 0.155 & $(0.362)$ & 0.179 & $(0.384)$ & 0.387 \\
\hline Partner keeps to himself & 0.871 & $(0.335)$ & 0.845 & $(0.363)$ & 0.293 \\
\hline Mother is worried about possible burglary & 0.845 & $(0.361)$ & 0.863 & $(0.345)$ & 0.454 \\
\hline Mother is worried about possible mugging/robbery & 0.655 & $(0.475)$ & 0.664 & $(0.473)$ & 0.758 \\
\hline Mother is worried about possible sex assault & 0.640 & $(0.480)$ & 0.656 & $(0.476)$ & 0.597 \\
\hline Mother is worried about possible vandalism to home & 0.700 & $(0.458)$ & 0.714 & $(0.453)$ & 0.627 \\
\hline Partner is worried about possible burglary & 0.871 & $(0.335)$ & 0.896 & $(0.306)$ & 0.322 \\
\hline Partner is worried about possible mugging/robbery & 0.496 & $(0.500)$ & 0.537 & $(0.500)$ & 0.274 \\
\hline Partner is worried about possible sex assault & 0.226 & $(0.418)$ & 0.212 & $(0.410)$ & 0.655 \\
\hline Partner is worried about possible vandalism to home & 0.737 & $(0.441)$ & 0.773 & $(0.420)$ & 0.258 \\
\hline Mother thinks neighbourhood is lively & 0.569 & $(0.495)$ & 0.553 & $(0.498)$ & 0.604 \\
\hline Mother thinks neighbourhood is friendly & 0.932 & $(0.252)$ & 0.940 & $(0.238)$ & 0.624 \\
\hline Mother thinks neighbourhood is noisy & 0.511 & $(0.500)$ & 0.515 & $(0.501)$ & 0.903 \\
\hline Mother thinks neighbourhood is clean & 0.915 & $(0.278)$ & 0.914 & $(0.282)$ & 0.918 \\
\hline Mother thinks neighbourhood is attractive & 0.833 & $(0.373)$ & 0.827 & $(0.379)$ & 0.797 \\
\hline Mother thinks neighbourhood is polluted or dirty & 0.285 & $(0.451)$ & 0.274 & $(0.447)$ & 0.712 \\
\hline Partner thinks neighbourhood is lively & 0.319 & $(0.467)$ & 0.231 & $(0.439)$ & 0.507 \\
\hline Partner thinks neighbourhood is friendly & 0.881 & $(0.324)$ & 0.846 & $(0.376)$ & 0.704 \\
\hline Partner thinks neighbourhood is noisy & 0.244 & $(0.430)$ & 0.231 & $(0.439)$ & 0.913 \\
\hline Partner thinks neighbourhood is clean & 0.825 & $(0.381)$ & 0.769 & $(0.439)$ & 0.612 \\
\hline Partner thinks neighbourhood is attractive & 0.710 & $(0.455)$ & 0.538 & $(0.519)$ & 0.190 \\
\hline Partner thinks neighbourhood is polluted or dirty & 0.132 & $(0.339)$ & 0.231 & $(0.439)$ & 0.314 \\
\hline
\end{tabular}

Notes: All variables are measured during pregnancy, unless otherwise stated. All variables are binary unless otherwise stated, indicating the range of the values, e.g. [0-30]. ${ }^{1}$ The educational indicators are: less than ordinary (O) level (ref), Olevel only, advanced (A) level that permits higher educational study, and university degree. The social class variables use the standard (reversed, so that higher values correspond to higher social classes) UK classification of social class based on occupation (professional, managerial/technical, non-manual skilled, manual skilled, semi-skilled and unskilled). Family income is an average of two observations (when the child is aged 3 and 4) and is in 1995 prices. It is adjusted for family size and composition (equalised) using the OECD equivalence scale to allow for a comparison of incomes for all households. EPDS and CCEI refer to the mother's Edinburgh Postnatal Depression Score and the Crown-Crisp Experimental Index. EPDS indicates to what extent the mother is at risk of perinatal depression; CCEI captures a broader definition of mental health, measuring general anxiety, depression and somaticism. Higher scores mean the mother is more affected. ${ }^{2}$ Mother's diet is measured at 32 weeks gestation; partner's diet is measured at 18 weeks gestation. 'Attitude to breastfeeding', 'attitude to fatherhood', and 'work and parenthood' are derived from multiple questions, with higher scores indicating more positive attitudes. ${ }^{4}$ The self-perceived change and feel good scores relate to physical, emotional and behavioural changes during early pregnancy, with higher scores indicating more positive changes. ${ }^{5}$ The partner's affection (aggression) scores are derived from multiple questions, where higher scores indicate less affection (aggression). ${ }^{6}$ The social network and social support scores are derived from multiple questions, where higher scores indicate a larger network and more support. 


\section{Appendix C: Parental responsive investments}

Table C1: Potential parental investments in response to child development

\begin{tabular}{|c|c|c|c|c|c|}
\hline & $\begin{array}{c}\text { (1) } \\
\text { Coefficient on } \\
\text { average no. of } \\
\text { units during } \\
\text { pregnancy } \\
\end{array}$ & $\begin{array}{c}\text { Standard } \\
\text { error }\end{array}$ & Mean & $\begin{array}{l}\text { First stage } \\
\text { F-statistic }\end{array}$ & (5) \\
\hline \multicolumn{6}{|l|}{ Child diet and nutrition } \\
\hline$\overline{\text { Baby has fruit juice (4 weeks) }}$ & 0.004 & $(0.042)$ & 0.125 & 14.651 & 2620 \\
\hline Baby has vitamins (4 weeks) & 0.004 & $(0.034)$ & 0.071 & 14.651 & 2620 \\
\hline Baby has glucose solution (4 weeks) & 0.010 & $(0.011)$ & 0.006 & 14.651 & 2620 \\
\hline Baby has cereal (4 weeks) & 0.008 & $(0.023)$ & 0.019 & 14.651 & 2620 \\
\hline Baby has other diet supplements (4 weeks) & -0.013 & $(0.041)$ & 0.100 & 14.651 & 2620 \\
\hline Child had formula (6 months) & $0.149 * *$ & $(0.070)$ & 0.825 & 13.790 & 2546 \\
\hline Child had follow-on milk (6m) & -0.075 & $(0.049)$ & 0.093 & 13.790 & 2546 \\
\hline Child had soya milk (6m) & 0.007 & $(0.024)$ & 0.029 & 13.790 & 2546 \\
\hline Child had goats milk (6m) & 0.001 & $(0.001)$ & 0.001 & 13.790 & 2546 \\
\hline Child had hypo-allergenic formula (6m) & -0.011 & $(0.013)$ & 0.002 & 13.790 & 2546 \\
\hline Child had cows' milk (6m) & -0.079 & $(0.060)$ & 0.198 & 13.790 & 2546 \\
\hline Child had plain baby rice (6m) & -0.033 & $(0.039)$ & 0.887 & 13.790 & 2546 \\
\hline Child had flavoured baby rice $(6 \mathrm{~m})$ & 0.032 & $(0.064)$ & 0.382 & 13.790 & 2546 \\
\hline Child had other cereal (6m) & 0.024 & $(0.051)$ & 0.818 & 13.790 & 2546 \\
\hline Child had sweetened rusks (6m) & -0.023 & $(0.059)$ & 0.225 & 13.790 & 2546 \\
\hline Child had plain rusks $(6 \mathrm{~m})$ & -0.017 & $(0.065)$ & 0.612 & 13.790 & 2546 \\
\hline Child had bread or toast (at 6m) & -0.022 & $(0.065)$ & 0.375 & 13.790 & 2546 \\
\hline Child had biscuits (6m) & -0.011 & $(0.057)$ & 0.223 & 13.790 & 2546 \\
\hline Child had prepared savoury meat (6m) & 0.066 & $(0.054)$ & 0.832 & 13.790 & 2546 \\
\hline Child had prepared savoury fish (6m) & -0.102 & $(0.072)$ & 0.359 & 13.790 & 2546 \\
\hline Child had prepared savoury veg (6m) & -0.033 & $(0.039)$ & 0.898 & 13.790 & 2546 \\
\hline Child had prepared fruit pudding (6m) & 0.011 & $(0.043)$ & 0.873 & 13.790 & 2546 \\
\hline Child had prepared milk pudding (6m) & -0.036 & $(0.065)$ & 0.583 & 13.790 & 2546 \\
\hline Child had home cooked egg $(6 \mathrm{~m})$ & -0.022 & $(0.047)$ & 0.145 & 13.790 & 2546 \\
\hline Child had home cooked meat (6m) & 0.031 & $(0.067)$ & 0.479 & 13.790 & 2546 \\
\hline Child had home cooked fish (6m) & -0.090 & $(0.068)$ & 0.303 & 13.790 & 2546 \\
\hline Child had home cooked potatoes (6m) & -0.037 & $(0.039)$ & 0.883 & 13.790 & 2546 \\
\hline Child had home cooked veg $(6 \mathrm{~m})$ & -0.058 & $(0.047)$ & 0.816 & 13.790 & 2546 \\
\hline Child had home-made fruit puddings (6m) & -0.035 & $(0.068)$ & 0.463 & 13.803 & 2539 \\
\hline Child had home-made milk puddings (6m) & -0.055 & $(0.059)$ & 0.189 & 13.790 & 2546 \\
\hline Child had coca cola or pepsi $(6 \mathrm{~m})$ & -0.001 & $(0.012)$ & 0.011 & 13.790 & 2546 \\
\hline Child had other fizzy drink (6m) & $0.014^{*}$ & $(0.007)$ & 0.008 & 13.790 & 2546 \\
\hline Child had apple juice $(6 \mathrm{~m})$ & 0.016 & $(0.059)$ & 0.246 & 13.790 & 2546 \\
\hline Child had a little alcohol $(6 \mathrm{~m})$ & 0.005 & $(0.015)$ & 0.024 & 13.790 & 2546 \\
\hline Child had blackcurrant/rosehip syrup (6m) & -0.068 & $(0.068)$ & 0.344 & 13.790 & 2546 \\
\hline Child had other fruit drink $(6 \mathrm{~m})$ & 0.028 & $(0.067)$ & 0.557 & 13.790 & 2546 \\
\hline Child had herbal drink $(6 \mathrm{~m})$ & $-0.138 *$ & $(0.072)$ & 0.495 & 13.790 & 2546 \\
\hline Child had gripe water $(6 \mathrm{~m})$ & 0.033 & $(0.067)$ & 0.542 & 13.790 & 2546 \\
\hline Child had tea (6m) & 0.042 & $(0.029)$ & 0.072 & 13.790 & 2546 \\
\hline Child had coffee $(6 \mathrm{~m})$ & $0.021 * *$ & $(0.010)$ & 0.010 & 13.790 & 2546 \\
\hline Child had raw fruit $(6 \mathrm{~m})$ & -0.047 & $(0.067)$ & 0.418 & 13.790 & 2546 \\
\hline Child had crisps (6m) & -0.027 & $(0.028)$ & 0.022 & 13.790 & 2546 \\
\hline Child had chocolates (6m) & 0.011 & $(0.054)$ & 0.207 & 13.790 & 2546 \\
\hline Child had sweets $(6 \mathrm{~m})$ & 0.005 & $(0.007)$ & 0.012 & 13.790 & 2546 \\
\hline Child had raw veg $(6 \mathrm{~m})$ & -0.092 & $(0.061)$ & 0.167 & 13.790 & 2546 \\
\hline Child had packet soup (15m) & -0.060 & $(0.038)$ & 0.082 & 22.616 & 2482 \\
\hline Child had canned soup (15m) & 0.019 & $(0.057)$ & 0.429 & 23.377 & 2489 \\
\hline Child had liver (15m) & 0.018 & $(0.048)$ & 0.198 & 22.857 & 2490 \\
\hline Child had kidney (15m) & 0.014 & $(0.026)$ & 0.067 & 23.050 & 2489 \\
\hline Child had shell fish (15m) & 0.025 & $(0.030)$ & 0.089 & 22.752 & 2491 \\
\hline Child had baked beans $(15 \mathrm{~m})$ & 0.011 & $(0.030)$ & 0.927 & 22.662 & 2495 \\
\hline Child had green peas $(15 \mathrm{~m})$ & 0.021 & $(0.029)$ & 0.938 & 22.637 & 2494 \\
\hline Child had other legumes (15m) & $-0.102 *$ & $(0.061)$ & 0.270 & 22.069 & 2476 \\
\hline Child had yoghurt (15m) & -0.005 & $(0.017)$ & 0.965 & 21.959 & 2488 \\
\hline Child had fig $(15 \mathrm{~m})$ & -0.008 & $(0.025)$ & 0.040 & 21.574 & 2474 \\
\hline
\end{tabular}




\begin{tabular}{|c|c|c|c|c|c|}
\hline Child had raw apple (15m) & -0.020 & $(0.039)$ & 0.833 & 22.754 & 2485 \\
\hline Child had other raw fruit (15m) & -0.019 & $(0.018)$ & 0.965 & 22.002 & 2488 \\
\hline Child had raw carrot (15m) & -0.029 & $(0.058)$ & 0.454 & 22.798 & 2483 \\
\hline Child had other raw vegetables (15m) & 0.003 & $(0.039)$ & 0.171 & 23.304 & 2316 \\
\hline Child had nuts (15m) & -0.000 & $(0.036)$ & 0.082 & 22.161 & 2483 \\
\hline Child had crisps (15m) & -0.050 & $(0.054)$ & 0.637 & 22.108 & 2485 \\
\hline Child had other savoury snacks (15m) & 0.003 & $(0.055)$ & 0.672 & 22.242 & 2476 \\
\hline Child had chocolate $(15 \mathrm{~m})$ & 0.081 & $(0.052)$ & 0.841 & 22.011 & 2486 \\
\hline Child had mints (15m) & 0.004 & $(0.027)$ & 0.041 & 22.383 & 2478 \\
\hline Child had sweets (15m) & -0.053 & $(0.057)$ & 0.302 & 22.748 & 2480 \\
\hline Child ever had gravy or soy sauce (15m) & 0.059 & $(0.051)$ & 0.805 & 22.553 & 2484 \\
\hline Child ever had salt (15m) & 0.035 & $(0.043)$ & 0.229 & 22.663 & 2485 \\
\hline Child ever had herbs (15m) & -0.029 & $(0.058)$ & 0.430 & 22.604 & 2467 \\
\hline Child ever had spices (15m) & 0.002 & $(0.043)$ & 0.188 & 22.605 & 2482 \\
\hline Child ever had tomato ketchup (15m) & 0.020 & $(0.050)$ & 0.275 & 22.244 & 2484 \\
\hline Child ever had other sauce (15m) & -0.007 & $(0.037)$ & 0.117 & 22.723 & 2338 \\
\hline Child ever had sugar (15m) & -0.012 & $(0.053)$ & 0.275 & 21.705 & 2467 \\
\hline Child ever had smoked or cured food (15m) & 0.057 & $(0.058)$ & 0.410 & 22.573 & 2490 \\
\hline Child ever had microwave meal (15m) & $0.050 * *$ & $(0.023)$ & 0.064 & 22.609 & 2489 \\
\hline Child ever had BBQ food (15m) & 0.052 & $(0.039)$ & 0.144 & 22.381 & 2488 \\
\hline Child ever had sports drink (15m) & $0.011 * * *$ & $(0.003)$ & 0.012 & 22.376 & 2492 \\
\hline No. of meals a day (6m) [ranging from 1-4] & -0.008 & $(0.057)$ & 2.903 & 13.775 & 2539 \\
\hline No. of meals a day (38m) [ranging from 1-4] & -0.025 & $(0.029)$ & 2.944 & 12.080 & 2324 \\
\hline Feeding difficulties (6m) & 0.072 & $(0.066)$ & 0.353 & 13.226 & 2528 \\
\hline Cereal added to child's bottle (6m) & -0.018 & $(0.020)$ & 0.022 & 14.223 & 2506 \\
\hline Sugar added to child's food/bottle (6m) & 0.012 & $(0.034)$ & 0.071 & 13.558 & 2532 \\
\hline Child uses dummy (6m) & 0.105 & $(0.071)$ & 0.463 & 13.790 & 2546 \\
\hline \multicolumn{6}{|l|}{ Immunisation and other treatment } \\
\hline Began to immunise baby at 4weeks & 0.019 & $(0.025)$ & 0.044 & 14.241 & 2608 \\
\hline BCG (tuberculosis) immunisation (6m) & -0.018 & $(0.018)$ & 0.008 & 13.790 & 2546 \\
\hline DTP immun. incl. whooping cough (6m) & -0.026 & $(0.038)$ & 0.916 & 13.790 & 2546 \\
\hline DT immun. excl. whooping cough (6m) & -0.020 & $(0.029)$ & 0.044 & 13.790 & 2546 \\
\hline Polio immunisation (6m) & 0.061 & $(0.055)$ & 0.829 & 13.790 & 2546 \\
\hline Hib (meningitis) immunisation (6m) & -0.006 & $(0.056)$ & 0.239 & 13.790 & 2546 \\
\hline Fluoride treatment $(6 \mathrm{~m})$ & -0.017 & $(0.021)$ & 0.013 & 10.560 & 2307 \\
\hline Child has vitamins (24m) & 0.054 & $(0.056)$ & 0.246 & 11.543 & 2383 \\
\hline Child has vitamins (38m) & -0.027 & $(0.061)$ & 0.291 & 12.476 & 2364 \\
\hline \multicolumn{6}{|l|}{ (Night-time) interactions ${ }^{1}$} \\
\hline Partner ever feeds baby at night (4w) & -0.009 & $(0.063)$ & 0.668 & 13.894 & 2561 \\
\hline Feed baby when wakes at night (4w) & 0.014 & $(0.019)$ & 0.988 & 14.704 & 2581 \\
\hline Give baby water when wakes at night (4w) & $0.107 * *$ & $(0.047)$ & 0.139 & 14.704 & 2581 \\
\hline Cuddle baby when wakes at night (4w) & -0.019 & $(0.036)$ & 0.886 & 14.704 & 2581 \\
\hline Give baby dummy when wakes at night (4w) & 0.070 & $(0.066)$ & 0.405 & 14.704 & 2581 \\
\hline Baby to mother's bed when wakes (4w) & 0.034 & $(0.062)$ & 0.668 & 14.704 & 2581 \\
\hline Nappy change when wakes at night (4w) & 0.009 & $(0.025)$ & 0.966 & 14.704 & 2581 \\
\hline Other activity when baby wakes (4w) & -0.001 & $(0.024)$ & 0.040 & 14.704 & 2581 \\
\hline Ever wake baby for feed (4w) & 0.005 & $(0.054)$ & 0.764 & 14.793 & 2599 \\
\hline Give baby milk when wakes at night (6m) & -0.075 & $(0.068)$ & 0.557 & 13.331 & 2362 \\
\hline Give baby other drink when wakes (6m) & $0.158 * *$ & $(0.070)$ & 0.307 & 13.331 & 2362 \\
\hline Cuddle baby when wakes at night (6m) & 0.078 & $(0.063)$ & 0.748 & 13.331 & 2362 \\
\hline Give baby dummy when wakes at night (6m) & 0.107 & $(0.069)$ & 0.429 & 13.331 & 2362 \\
\hline Baby to mum's bed when wakes $(6 \mathrm{~m})$ & 0.014 & $(0.066)$ & 0.487 & 13.331 & 2362 \\
\hline Nappy change when wakes at night (6m) & $0.136^{*}$ & $(0.072)$ & 0.644 & 13.331 & 2362 \\
\hline Other activity when baby wakes $(6 \mathrm{~m})$ & 0.029 & $(0.036)$ & 0.111 & 13.331 & 2362 \\
\hline Partner interaction score $(42 m)[0-36]$ & -0.464 & $(0.816)$ & 21.778 & 10.989 & 2223 \\
\hline Mother interaction score (42m) [0-36] & -0.172 & $(0.589)$ & 28.966 & 12.812 & 2328 \\
\hline Other person interaction score $(42 \mathrm{~m})$ [0-36] & -0.754 & $(0.749)$ & 18.219 & 25.219 & 1102 \\
\hline \multicolumn{6}{|l|}{ Doctor and dentist visits } \\
\hline Child uses toothbrush (15m) & 0.010 & $(0.028)$ & 0.953 & 22.580 & 2483 \\
\hline Child uses toothbrush (24m) & 0.005 & $(0.008)$ & 0.997 & 11.160 & 2376 \\
\hline Child uses toothbrush (38m) & $-0.034 * *$ & $(0.014)$ & 0.978 & 12.476 & 2364 \\
\hline Child uses toothpaste (15m) & -0.025 & $(0.038)$ & 0.896 & 22.429 & 2482 \\
\hline Child uses toothpaste (24m) & 0.027 & $(0.023)$ & 0.989 & 10.782 & 2373 \\
\hline Child uses toothpaste (38m) & $-0.026 * *$ & $(0.011)$ & 0.979 & 12.476 & 2364 \\
\hline
\end{tabular}




\begin{tabular}{|c|c|c|c|c|c|}
\hline Child ever visited dentist (38m) & $-0.118 * *$ & $(0.048)$ & 0.829 & 12.476 & 2364 \\
\hline Mother took baby to health clinic (4w) & -0.051 & $(0.059)$ & 0.689 & 14.337 & 2593 \\
\hline Doctor called to home for child (6m) & -0.000 & $(0.060)$ & 0.271 & 13.353 & 2534 \\
\hline Doctor called to home for child (18m) & $0.128^{*}$ & $(0.075)$ & 0.378 & 11.722 & 2474 \\
\hline Doctor called to home for child (30m) & $0.126 *$ & $(0.067)$ & 0.280 & 14.059 & 2373 \\
\hline Specialist checked child (24m) & 0.020 & $(0.052)$ & 0.188 & 12.694 & 2358 \\
\hline Child had surgery visit (30m) & -0.015 & $(0.055)$ & 0.814 & 13.079 & 2364 \\
\hline Child had routine check with doctor (30m) & -0.037 & $(0.055)$ & 0.172 & 12.726 & 2332 \\
\hline \multicolumn{6}{|l|}{ Parenting and teaching scores ${ }^{2}$} \\
\hline Child's activity score (6m) [0-20] & -0.067 & $(0.330)$ & 14.480 & 13.804 & 2543 \\
\hline Child's activity score (30m) [0-29] & 0.032 & $(0.424)$ & 18.589 & 14.381 & 2392 \\
\hline Child's activity score (42m) [0-28] & 0.172 & $(0.364)$ & 18.724 & 12.818 & 2324 \\
\hline Mother's parenting score (6m) [0-12] & -0.135 & $(0.193)$ & 10.542 & 13.668 & 2539 \\
\hline Mother's parenting score (18m) [6-51] & -0.254 & $(0.572)$ & 40.860 & 13.025 & 2481 \\
\hline Mother's parenting score (24m) [20-40] & 0.462 & $(0.394)$ & 34.547 & 10.632 & 2324 \\
\hline Mother's parenting score (38m) [4-30] & -0.291 & $(0.405)$ & 25.250 & 12.614 & 2356 \\
\hline Partner's parenting score (6m) [10-30] & 0.311 & $(0.496)$ & 23.599 & 14.612 & 2493 \\
\hline Partner's parenting score (18m) [0-40] & 1.057 & $(0.944)$ & 24.486 & 11.804 & 2406 \\
\hline Partner's parenting score (38m) [0-30] & -0.097 & $(0.700)$ & 21.447 & 11.186 & 2248 \\
\hline Mother's teaching score $(30 \mathrm{~m})[0-8]$ & -0.007 & $(0.159)$ & 6.637 & 14.167 & 2380 \\
\hline Mother's teaching score (42m) [0-8] & 0.190 & $(0.179)$ & 6.993 & 12.817 & 2325 \\
\hline Child's toy score (24m) [5-36] & -0.532 & $(0.497)$ & 23.512 & 9.978 & 2317 \\
\hline Child's toy score (42m) [1-9] & -0.097 & $(0.090)$ & 8.180 & 12.817 & 2325 \\
\hline Maternal care score $(18 m)[0-24]$ & 0.196 & $(0.683)$ & 20.044 & 15.367 & 2655 \\
\hline Maternal overprotective score (18m) [0-20] & -0.342 & $(0.553)$ & 6.288 & 15.367 & 2655 \\
\hline Maternal enjoyment score (8m) [0-15] & -0.254 & $(0.230)$ & 13.243 & 13.240 & 2506 \\
\hline Maternal confidence score (8m) [4-18] & -0.033 & $(0.249)$ & 15.088 & 13.240 & 2506 \\
\hline Maternal bonding score (8m) [4-33] & -0.286 & $(0.401)$ & 28.331 & 13.240 & 2506 \\
\hline \multicolumn{6}{|l|}{ Time spent doing different activities } \\
\hline TV is on for most of the day (30m) & 0.033 & $(0.066)$ & 0.463 & 14.043 & 2224 \\
\hline TV is on for most of the day (42m) & 0.052 & $(0.083)$ & 0.475 & 9.271 & 2166 \\
\hline Hours p/wk spent in car (38m) [0-14] & -0.084 & $(0.211)$ & 3.928 & 12.854 & 2331 \\
\hline Hours p/wk spent outdoors $(38 \mathrm{~m})[0-14]$ & 0.811 & $(0.500)$ & 9.652 & 12.394 & 2319 \\
\hline Hours p/wk spent watching TV (38m)[0-14] & -0.181 & $(0.488)$ & 7.487 & 12.872 & 2327 \\
\hline Hours p/wk spent w/ other kids $(38 \mathrm{~m})[0-14]$ & 0.009 & $(0.464)$ & 11.668 & 12.411 & 2312 \\
\hline Mother has nights out each week (8m) & -0.010 & $(0.052)$ & 0.196 & 12.954 & 2417 \\
\hline \multicolumn{6}{|l|}{ Mother worried that child may: } \\
\hline Get accident $(18 \mathrm{~m})$ & 0.093 & $(0.065)$ & 0.717 & 13.032 & 2477 \\
\hline Get meningitis (18m) & 0.057 & $(0.065)$ & 0.639 & 13.019 & 2472 \\
\hline Get asthma (18m) & 0.073 & $(0.065)$ & 0.350 & 11.574 & 2429 \\
\hline Get fits $(18 \mathrm{~m})$ & 0.005 & $(0.049)$ & 0.162 & 12.996 & 2470 \\
\hline Be mentally handicapped (18m) & 0.011 & $(0.030)$ & 0.052 & 13.020 & 2471 \\
\hline Get AIDS (18m) & -0.005 & $(0.035)$ & 0.098 & 12.818 & 2470 \\
\hline Worried about any aspect of behaviour (42m) & $-0.123 *$ & $(0.063)$ & 0.194 & 13.224 & 2259 \\
\hline \multicolumn{6}{|l|}{ Household characteristics $^{3}$} \\
\hline Other children in house (6m) & -0.003 & $(0.067)$ & 0.540 & 13.178 & 2529 \\
\hline Other children in house (18m) & -0.077 & $(0.070)$ & 0.574 & 12.343 & 2471 \\
\hline Older children in house (18m) & -0.038 & $(0.068)$ & 0.538 & 12.285 & 2468 \\
\hline Younger children in house (18) & -0.042 & $(0.035)$ & 0.047 & 12.441 & 2456 \\
\hline Total number of hh members (8m) [1-14] & -0.117 & $(0.143)$ & 3.793 & 13.131 & 2461 \\
\hline Financial difficulties score (8m) [0-15] & -0.147 & $(0.467)$ & 2.752 & 13.348 & 2497 \\
\hline \multicolumn{6}{|l|}{ Child care } \\
\hline Expect to use partner (at 32 wks gest) & $0.075^{*}$ & $(0.041)$ & 0.163 & 15.699 & 2670 \\
\hline Expect to use family (at 32 wks gest) & 0.051 & $(0.049)$ & 0.188 & 15.469 & 2661 \\
\hline Expect to use child minder (at 32 wks gest) & -0.004 & $(0.039)$ & 0.116 & 15.314 & 2648 \\
\hline Expect to use nanny (at 32 wks gest) & -0.017 & $(0.024)$ & 0.038 & 14.801 & 2647 \\
\hline Expect to use nursery (at 32 wks gest) & 0.028 & $(0.028)$ & 0.046 & 15.386 & 2620 \\
\hline Expect to use other (at 32 wks gest) & -0.015 & $(0.016)$ & 0.017 & 15.465 & 2663 \\
\hline Partner regularly looks after child (15m) & 0.032 & $(0.050)$ & 0.778 & 21.799 & 2473 \\
\hline Grandparent regularly looks after child (15m) & $0.103^{*}$ & $(0.057)$ & 0.443 & 21.799 & 2473 \\
\hline Other relative reg. looks after child $(15 \mathrm{~m})$ & -0.014 & $(0.034)$ & 0.099 & 21.799 & 2473 \\
\hline Friend regularly looks after child (15m) & -0.056 & $(0.043)$ & 0.097 & 21.799 & 2473 \\
\hline
\end{tabular}




\begin{tabular}{|c|c|c|c|c|c|}
\hline Child minder regularly looks after child (15m) & 0.010 & $(0.039)$ & 0.142 & 21.799 & 2473 \\
\hline Nanny regularly looks after child (15m) & -0.022 & $(0.030)$ & 0.062 & 21.799 & 2473 \\
\hline Nursery regularly looks after child (15m) & $0.056 * *$ & $(0.024)$ & 0.061 & 21.799 & 2473 \\
\hline Someone else reg. looks after child (15m) & 0.020 & $(0.016)$ & 0.017 & 21.799 & 2473 \\
\hline Partner regularly looks after child (24m) & 0.062 & $(0.064)$ & 0.720 & 11.060 & 2363 \\
\hline Grandparent regularly looks after child (24m) & $0.171 * *$ & $(0.081)$ & 0.447 & 11.060 & 2363 \\
\hline Other relative reg. looks after child (24m) & 0.021 & $(0.042)$ & 0.116 & 11.060 & 2363 \\
\hline Friend regularly looks after child (24m) & -0.001 & $(0.047)$ & 0.140 & 11.060 & 2363 \\
\hline Child minder regularly looks after child (24m) & -0.011 & $(0.051)$ & 0.147 & 11.060 & 2363 \\
\hline Nanny regularly looks after child (24m) & 0.019 & $(0.035)$ & 0.066 & 11.060 & 2363 \\
\hline Nursery regularly look after child (24m) & 0.041 & $(0.043)$ & 0.101 & 11.060 & 2363 \\
\hline Other person regularly looks after child (24m) & 0.017 & $(0.019)$ & 0.012 & 11.060 & 2363 \\
\hline Partner regularly looks after child (38m) & 0.009 & $(0.057)$ & 0.766 & 12.476 & 2364 \\
\hline Grandparents regularly look after child (38m) & $0.136 *$ & $(0.071)$ & 0.429 & 12.476 & 2364 \\
\hline Other relative reg. looks after child (38m) & -0.038 & $(0.044)$ & 0.094 & 12.476 & 2364 \\
\hline Friend regularly looks after child (38m) & -0.016 & $(0.043)$ & 0.122 & 12.476 & 2364 \\
\hline Child minder regularly looks after child (38m) & -0.083 & $(0.051)$ & 0.094 & 12.476 & 2364 \\
\hline Nanny regularly looks after child (38m) & 0.041 & $(0.033)$ & 0.073 & 12.476 & 2364 \\
\hline Nursery regularly looks after child (38m) & 0.052 & $(0.067)$ & 0.359 & 12.476 & 2364 \\
\hline Other person regularly looks after child (38m) & -0.111 & $(0.072)$ & 0.319 & 12.476 & 2364 \\
\hline Number of types of child care (38m) [0-6] & -0.010 & $(0.157)$ & 2.255 & 12.476 & 2364 \\
\hline \multicolumn{6}{|l|}{$\underline{\text { Social support }}^{4}$} \\
\hline Mother's social support score (8w) [0-30] & 0.334 & $(0.646)$ & 20.374 & 15.599 & 2578 \\
\hline Partner's social support score (8w) [0-30] & -0.647 & $(0.607)$ & 19.422 & 20.743 & 1991 \\
\hline Mother's social help score (8w) [0-24] & -0.696 & $(0.522)$ & 16.306 & 15.596 & 2577 \\
\hline Partner's social help at home (8w) [0-27] & $-1.384 * *$ & $(0.621)$ & 15.298 & 21.418 & 1998 \\
\hline Partner's social help with child (8w) [0-35] & 0.871 & $(0.802)$ & 20.669 & 21.418 & 1998 \\
\hline
\end{tabular}

Notes: All variables are measured after the child is born, unless otherwise stated. All variables are binary unless otherwise stated, indicating the range of the variable, e.g. [0-30]. The coefficients (column 1) and standard errors (column 2) denote the estimates from an IV regression of the effect of alcohol exposure in utero on the outcome of interested listed in the first column, where the mother's $A D H 1 B$ is used as the instrument. Column 3 shows the mean of the outcome of interest, column 4 shows the first-stage $F$-statistic, and column 5 shows the sample size for each analysis. All 'score-variables' are derived from multiple questions. ${ }^{1}$ The interaction scores indicate the frequency and type of interactions with the child, with higher scores indicating more interactions. ${ }^{2}$ The activity scores measure activities such as going to the park, supermarket, visiting friends, etc., with higher scores indicating more activity. The parenting scores measure activities such as reading stories, eating together, cuddling, slapping, singing to the child, etc., where higher scores indicate better parenting. The teaching scores capture activities such as teaching numbers, rhymes, shapes, politeness, etc., where higher scores indicate more teaching. The toy scores capture the number and types of toys the child has, such as push/pull, co-ordination toys, lego, books, etc., where higher scores indicate more toys. The maternal care and overprotective scores measure the relationship between the mother and her mother (e.g. whether the mother's mother was friendly, cold, controlling, affectionate, etc.). The maternal enjoyment, confidence and bonding scores capture whether the mother enjoys looking after, is confident, and bonds with her baby. ${ }^{3}$ The financial difficulties score measures how difficult it is to afford food, clothing, heating, rent, etc. ${ }^{4}$ The social support score measures the extent of support available to the mother and partner (including emotional support, sharing happiness, relying on each other, etc.). The social help scores measure the extent to which the mother and partner receive help with the baby, doing shopping, cleaning, cooking, washing, etc. 


\section{Appendix D: Robustness checks}

Table D1: Robustness checks on use of covariates, IV estimates with Key Stage 1 as the outcome variable and the number of alcoholic units consumed as the treatment variable.

\begin{tabular}{|c|c|c|c|c|}
\hline & $\begin{array}{c}\text { (1) } \\
\text { Coefficient on } \\
\text { average no. } \\
\text { units during } \\
\text { pregnancy } \\
\end{array}$ & $\begin{array}{l}(2) \\
\text { Standard } \\
\text { error }\end{array}$ & $\begin{array}{l}\text { (3) } \\
\text { First stage } \\
\text { F-statistic }\end{array}$ & (4) \\
\hline \multicolumn{5}{|l|}{ Panel A: Controlling for additional alcohol-related covariates } \\
\hline 1: Replicates the results from Table 5 & $-0.245^{* *}$ & $(0.114)$ & 16.366 & 2433 \\
\hline 2: Includes maternal smoking during pregnancy as covariate & $-0.242 * *$ & $(0.114)$ & 15.909 & 2431 \\
\hline 3: Excludes child $A D H 1 B$ (i.e. only the principal components) & $-0.182 * *$ & $(0.084)$ & 33.526 & 2433 \\
\hline $\begin{array}{l}\text { 4: Includes binary indicators for maternal post-natal alcohol } \\
\text { intake when the child was } 8,21,33 \text {, and } 47 \text { months old }\end{array}$ & -0.204 & $(0.138)$ & 7.922 & 1861 \\
\hline $\begin{array}{l}\text { 5: Includes binary indicators for the child's own alcohol intake } \\
\text { at } 157,166 \text {, and } 185 \text { months }\end{array}$ & -0.140 & $(0.119)$ & 11.816 & 1125 \\
\hline 6: Includes mother’s partner’s and parents' alcohol consumption & $-0.232 * *$ & $(0.113)$ & 14.216 & 2035 \\
\hline \multicolumn{5}{|l|}{ Panel B: Controlling for covariates specified in Appendix B } \\
\hline 7: Includes all ‘standard’ covariates & $-0.217^{*}$ & $(0.122)$ & 10.856 & 1551 \\
\hline $\begin{array}{l}\text { 8: Same as model (7), but using (single) multivariate imputation } \\
\text { for missing values on the covariate to obtain the same sample } \\
\text { size as the original specification }\end{array}$ & $-0.273^{* *}$ & $(0.128)$ & 11.030 & 2433 \\
\hline 9: Includes mother’s tea, coffee and milk intake, 8 wks gestation & $-0.299 * *$ & $(0.150)$ & 11.373 & 2345 \\
\hline 10: Includes mother’s diet and nutrition, 32 weeks gestation & $-0.198 *$ & $(0.105)$ & 14.975 & 2241 \\
\hline 11: Includes mother's attitude to parenting & $-0.209 *$ & $(0.121)$ & 12.881 & 2254 \\
\hline 12: Includes mother's religious believes & $-0.234 * *$ & $(0.118)$ & 14.168 & 2385 \\
\hline 13: Includes household characteristics & $-0.319 * *$ & $(0.130)$ & 12.888 & 2292 \\
\hline 14: Includes variables related to the mother's pregnancy & -0.221 & $(0.142)$ & 7.479 & 1914 \\
\hline 15: Includes mother’s physical health during pregnancy & $-0.294 *$ & $(0.153)$ & 9.274 & 1273 \\
\hline 16: Includes mothers' physical activity during pregnancy & $-0.211 * *$ & $(0.095)$ & 28.892 & 2280 \\
\hline 17: Includes mother's mental health during pregnancy & -0.160 & $(0.116)$ & 12.127 & 2200 \\
\hline 18: Includes mother's use of medication during pregnancy & $-0.206 * *$ & $(0.100)$ & 15.147 & 2246 \\
\hline 19: Includes mother’s substance use during pregnancy & $-0.199 *$ & $(0.113)$ & 12.940 & 2096 \\
\hline 20: Includes mother's use of chemicals & $-0.183 *$ & $(0.101)$ & 16.751 & 2426 \\
\hline 21: Includes mother’s social support network & $-0.225^{*}$ & $(0.117)$ & 14.856 & 2296 \\
\hline 22: Includes mother's perception of neighbourhood & $-0.222 * *$ & $(0.108)$ & 16.577 & 2339 \\
\hline
\end{tabular}


Tables and Figures

Figure 1: The Metabolism of Alcohol

ADH: Alcohol dehydrogenase

ALDH: Aldehyde dehydrogenase

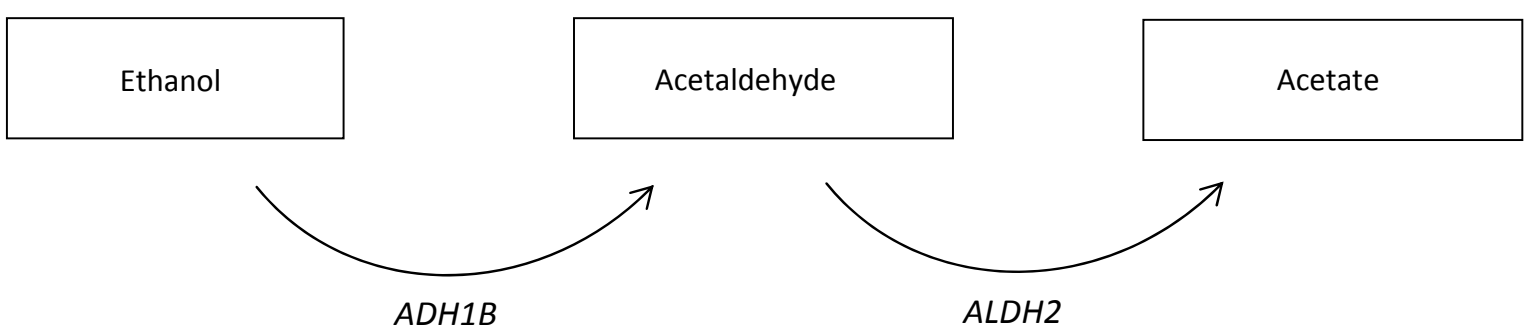

Figure 2: Weight functions

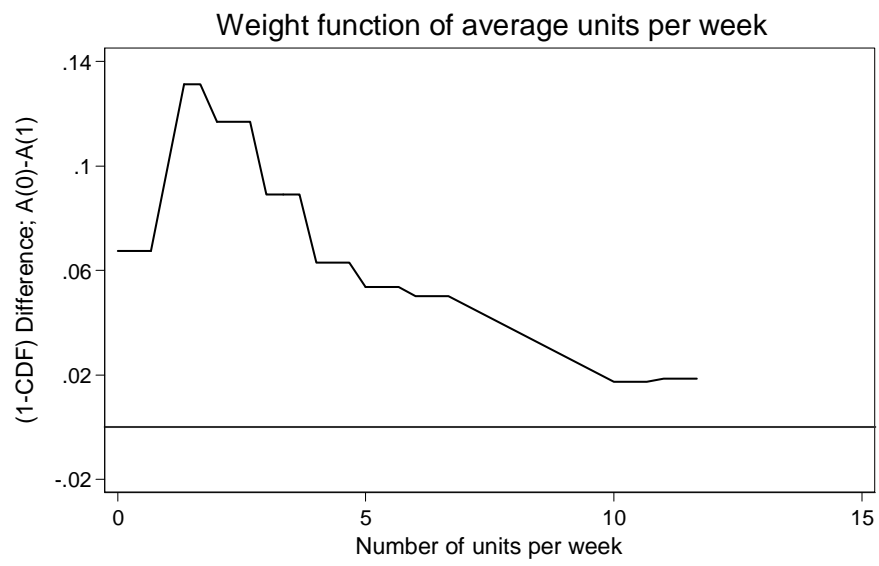

Figure 3: The effect of low-to-moderate and heavy drinking on the child's KS1 score

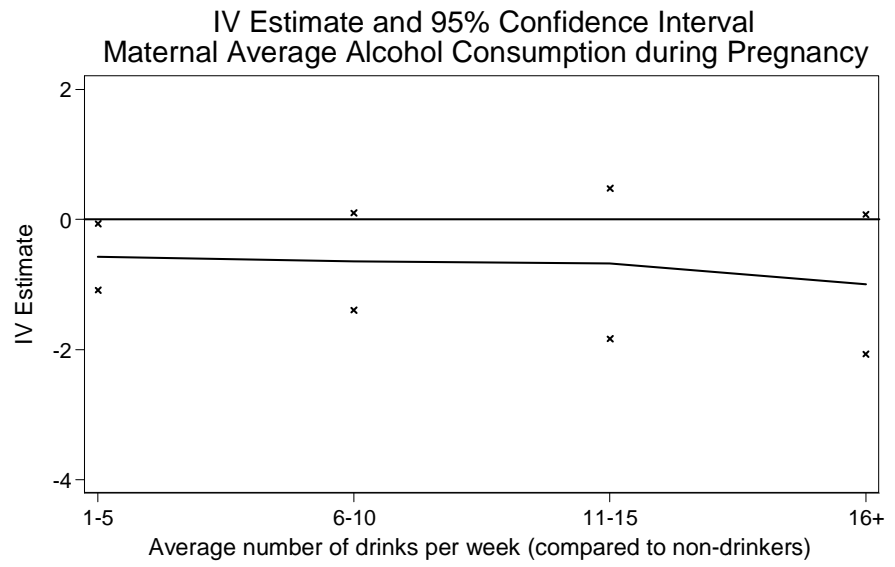

Note: The 95\% confidence intervals are presented as two points above and below the estimate. 
Table 1: Descriptive statistics, mean and standard deviation of variables of interest

\begin{tabular}{|c|c|c|c|c|}
\hline & $\begin{array}{c}\text { (1) } \\
\text { Full sample } \\
\text { Mean (std dev) }\end{array}$ & $\begin{array}{c}\text { (2) } \\
\text { Homozygous for the } \\
A D H 1 B \text { common allele } \\
\text { Mean (std dev) }\end{array}$ & $\begin{array}{c}\text { (3) } \\
\text { Carrying at least one } \\
A D H 1 B \text { rare allele } \\
\text { Mean (std dev) } \\
\end{array}$ & $\begin{array}{c}\text { (4) } \\
\text { t-test } \\
p \text {-value } \\
\end{array}$ \\
\hline \multicolumn{5}{|c|}{ Panel A: Any alcohol consumption } \\
\hline $\begin{array}{l}\text { Any alcohol (binary) } \\
N\end{array}$ & $\begin{array}{c}0.627 \quad(0.484) \\
4201\end{array}$ & $\begin{array}{c}0.633(0.482) \\
3990\end{array}$ & $\begin{array}{l}0.507 \quad(0.501) \\
211\end{array}$ & 0.001 \\
\hline \multicolumn{5}{|c|}{ Panel B: Pattern and duration } \\
\hline $\begin{array}{l}\text { Bingeing (trimester 2) } \\
N\end{array}$ & $\begin{array}{c}0.167 \quad(0.373) \\
4714\end{array}$ & $\begin{array}{c}0.170 \quad(0.375) \\
4482\end{array}$ & $\begin{array}{c}0.112 \\
232\end{array}$ & 0.022 \\
\hline $\begin{array}{l}\text { Length of exposure } \\
N\end{array}$ & $\begin{array}{c}0.971 \quad(1.165) \\
2880\end{array}$ & $\begin{array}{c}0.991 \quad(1.172) \\
2733\end{array}$ & ${ }_{147}^{0.592}(0.963)$ & $<0.001$ \\
\hline \multicolumn{5}{|c|}{ Panel C: Average alcohol consumption } \\
\hline $\begin{array}{l}\text { No. of units } \mathrm{p} / \mathrm{w} \\
{[\min -\max ]} \\
N\end{array}$ & $\begin{array}{c}1.503 \quad(2.980) \\
{\left[\begin{array}{ll}0 & 35\end{array}\right]} \\
2781\end{array}$ & $\begin{array}{c}1.549 \quad(3.031) \\
{\left[\begin{array}{ll}0 & 35\end{array}\right]} \\
2639\end{array}$ & $\begin{array}{c}0.646 \quad(1.583) \\
{\left[\begin{array}{ll}0 & 11\end{array}\right]} \\
142\end{array}$ & $<0.001$ \\
\hline $\begin{array}{l}\text { No. of units of wine } \\
{[\min -\max ]} \\
N\end{array}$ & $\begin{array}{c}0.565 \quad(1.388) \\
{\left[\begin{array}{ll}0 & 17\end{array}\right]} \\
2116\end{array}$ & $\begin{array}{c}0.584 \quad(1.421) \\
{\left[\begin{array}{ll}0 & 17\end{array}\right]} \\
1991\end{array}$ & $\begin{array}{c}0.261 \quad(0.608) \\
{\left[\begin{array}{ll}0 & 3\end{array}\right]} \\
125\end{array}$ & 0.012 \\
\hline $\begin{array}{l}\text { No. of units of beer } \\
{[\text { min - max }]} \\
N\end{array}$ & $\begin{array}{c}0.377 \quad(1.543) \\
{\left[\begin{array}{ll}0 & 35\end{array}\right]} \\
1803\end{array}$ & $\begin{array}{c}0.395 \quad(1.582) \\
{\left[\begin{array}{ll}0 & 35\end{array}\right]} \\
1697\end{array}$ & $\begin{array}{c}0.101 \quad(0.552) \\
{\left[\begin{array}{ll}0 & 5\end{array}\right]} \\
106\end{array}$ & 0.057 \\
\hline Standard deviations & Between & Between & Between & \\
\hline $\begin{array}{l}\text { All alcohol } \\
\text { Wine } \\
\text { Beer }\end{array}$ & $\begin{array}{ll}3.318 & 1.881 \\
1.796 & 1.143 \\
1.966 & 1.268\end{array}$ & $\begin{array}{ll}3.370 & 1.911 \\
1.818 & 1.153 \\
2.004 & 1.288\end{array}$ & $\begin{array}{ll}1.975 & 1.177 \\
1.285 & 0.930 \\
0.988 & 0.809\end{array}$ & \\
\hline
\end{tabular}

\footnotetext{
Note: The $p$-value is based on a test of equality between the mean for the homozygotes for the common allele and those carrying at least one rare allele. 'Any alcohol' is a binary variable indicating whether the foetus was exposed to any alcohol in utero. 'Length of exposure' ranges from zero to three trimesters. The average number of units of wine is calculated among women who either indicate to drink no beer, spirits or other alcoholic drinks, or who did not report their beer, spirit or other alcoholic consumption (i.e. have missing values for beer, spirit and other alcoholic drinks). Similarly, the average number of units of beer is calculated among women who either indicate to drink no wine, spirits or other alcoholic drinks, or who did not report their wine, spirit or other alcoholic consumption. Therefore, the sample sizes of the number of units of wine and beer do not add up to the total number of units. Indeed, some mothers may report to drink alcohol, but do not define which drink they consumed.
} 
Table 2: OLS regressions of child academic achievement on maternal prenatal alcohol consumption

\begin{tabular}{|c|c|c|c|c|c|}
\hline & $\begin{array}{c}\text { Entry } \\
\text { Assessment }\end{array}$ & KS1, age 7 & KS2, age 11 & KS3, age 14 & KS4, age 16 \\
\hline \multicolumn{6}{|l|}{ Panel A: Any alcohol intake } \\
\hline Any alcohol intake & $\begin{array}{c}0.054 \\
(0.039)\end{array}$ & $\begin{array}{l}-0.037 \\
(0.033)\end{array}$ & $\begin{array}{c}0.026 \\
(0.034)\end{array}$ & $\begin{array}{c}0.026 \\
(0.037)\end{array}$ & $\begin{array}{l}-0.033 \\
(0.035)\end{array}$ \\
\hline$N$ & 2614 & 3319 & 3132 & 2872 & 3201 \\
\hline \multicolumn{6}{|c|}{ Panel B: Pattern and duration } \\
\hline Bingeing & $\begin{array}{c}-0.107 * * \\
(0.045)\end{array}$ & $\begin{array}{c}-0.210^{* * *} \\
(0.038)\end{array}$ & $\begin{array}{c}-0.159 * * * \\
(0.040)\end{array}$ & $\begin{array}{c}-0.225^{* * *} \\
(0.041)\end{array}$ & $\begin{array}{c}-0.235^{* * *} \\
(0.040)\end{array}$ \\
\hline$N$ & 3238 & 4088 & 3868 & 3572 & 3955 \\
\hline Length of exposure & $\begin{array}{c}0.061 * * * \\
(0.019)\end{array}$ & $\begin{array}{l}0.028^{*} \\
(0.015)\end{array}$ & $\begin{array}{c}0.053 * * * \\
(0.015)\end{array}$ & $\begin{array}{c}0.046 * * * \\
(0.017)\end{array}$ & $\begin{array}{c}0.044 * * * \\
(0.016)\end{array}$ \\
\hline$N$ & 1982 & 2518 & 2372 & 2179 & 2428 \\
\hline \multicolumn{6}{|c|}{ Panel C: Average alcohol intake } \\
\hline Average units of alcohol & $\begin{array}{c}0.010 \\
(0.007)\end{array}$ & $\begin{array}{l}-0.010^{*} \\
(0.006)\end{array}$ & $\begin{array}{c}-0.002 \\
(0.007)\end{array}$ & $\begin{array}{c}-0.006 \\
(0.007)\end{array}$ & $\begin{array}{l}-0.005 \\
(0.006)\end{array}$ \\
\hline$N$ & 1922 & 2433 & 2293 & 2106 & 2345 \\
\hline Average units of wine & $\begin{array}{c}0.064 * * * \\
(0.016)\end{array}$ & $\begin{array}{c}0.033^{* *} \\
(0.014)\end{array}$ & $\begin{array}{c}0.053^{* * *} \\
(0.013)\end{array}$ & $\begin{array}{c}0.052 * * * \\
(0.017)\end{array}$ & $\begin{array}{c}0.041^{* * *} \\
(0.014)\end{array}$ \\
\hline$N$ & 1473 & 1862 & 1747 & 1600 & 1795 \\
\hline Average units of beer & $\begin{array}{l}-0.015 \\
(0.019)\end{array}$ & $\begin{array}{c}-0.044^{* * *} \\
(0.016)\end{array}$ & $\begin{array}{c}-0.039 * \\
(0.022)\end{array}$ & $\begin{array}{c}-0.061^{* * *} \\
(0.015)\end{array}$ & $\begin{array}{c}-0.049 * * * \\
(0.015)\end{array}$ \\
\hline$N$ & 1275 & 1569 & 1475 & 1381 & 1521 \\
\hline
\end{tabular}

Notes: The table presents the correlations between academic achievement shown in the columns and the measures of alcohol exposure shown in the rows. All estimates come from separate regressions and control for ancestry-informative principal components and the child's $A D H 1 B$. Robust standard errors are in parentheses. ${ }^{*} \mathrm{p}<0.10,{ }^{* *} \mathrm{p}<0.05,{ }^{* * *} \mathrm{p}<0.01$. 
Table 3: The correlation between alcohol consumption and background characteristics

\begin{tabular}{|c|c|c|c|c|c|c|}
\hline & $\begin{array}{c}(1) \\
\text { Any alcohol } \\
\text { intake }\end{array}$ & $\begin{array}{c}(2) \\
\text { Binge } \\
\text { drinking }\end{array}$ & $\begin{array}{c}\text { (3) } \\
\text { Length of } \\
\text { exposure }\end{array}$ & $\begin{array}{c}\text { (4) } \\
\text { Average no. } \\
\text { of units of } \\
\text { alcohol }\end{array}$ & $\begin{array}{l}\text { (5) } \\
\text { Average no. } \\
\text { of units of } \\
\text { wine }\end{array}$ & $\begin{array}{l}\text { (6) } \\
\text { Average no. } \\
\text { of units of } \\
\text { beer }\end{array}$ \\
\hline \multicolumn{7}{|l|}{ Covariates } \\
\hline Child's $A D H 1 B$ & $\begin{array}{c}-0.116^{* * * *} \\
(0.038)\end{array}$ & $\begin{array}{c}-0.026 \\
(0.024)\end{array}$ & $\begin{array}{c}-0.325^{* * *} \\
(0.090)\end{array}$ & $\begin{array}{c}-0.637 * * * \\
(0.203)\end{array}$ & $\begin{array}{c}-0.260 * * \\
(0.132)\end{array}$ & $\begin{array}{c}-0.269 * * \\
(0.108)\end{array}$ \\
\hline Girl & $\begin{array}{c}-0.031^{*} \\
(0.016)\end{array}$ & $\begin{array}{c}-0.006 \\
(0.011)\end{array}$ & $\begin{array}{l}-0.047 \\
(0.043)\end{array}$ & $\begin{array}{c}-0.121 \\
(0.113)\end{array}$ & $\begin{array}{c}0.019 \\
(0.066)\end{array}$ & $\begin{array}{c}-0.080 \\
(0.065)\end{array}$ \\
\hline Mother's age & $\begin{array}{c}0.008^{* * *} \\
(0.002)\end{array}$ & $\begin{array}{c}0.001 \\
(0.001)\end{array}$ & $\begin{array}{c}0.034 * * * \\
(0.005)\end{array}$ & $\begin{array}{c}0.068 * * * \\
(0.014)\end{array}$ & $\begin{array}{c}0.073 * * * \\
(0.008)\end{array}$ & $\begin{array}{l}0.016^{*} \\
(0.008)\end{array}$ \\
\hline Older siblings & $\begin{array}{c}0.032 * * * \\
(0.011)\end{array}$ & $\begin{array}{c}0.031^{* * *} \\
(0.008)\end{array}$ & $\begin{array}{c}0.041 \\
(0.030)\end{array}$ & $\begin{array}{c}0.214^{* * *} \\
(0.080)\end{array}$ & $\begin{array}{c}0.107 * * \\
(0.047)\end{array}$ & $\begin{array}{c}0.114^{* *} \\
(0.052)\end{array}$ \\
\hline Younger siblings & $\begin{array}{c}-0.006 \\
(0.038)\end{array}$ & $\begin{array}{c}0.021 \\
(0.028)\end{array}$ & $\begin{array}{c}0.062 \\
(0.107)\end{array}$ & $\begin{array}{c}0.152 \\
(0.298)\end{array}$ & $\begin{array}{c}0.250 \\
(0.200)\end{array}$ & $\begin{array}{c}0.097 \\
(0.194)\end{array}$ \\
\hline Father's education & $\begin{array}{c}0.035 * * * \\
(0.008)\end{array}$ & $\begin{array}{c}-0.024^{* * *} \\
(0.005)\end{array}$ & $\begin{array}{c}0.163 * * * \\
(0.021)\end{array}$ & $\begin{array}{c}0.169 * * * \\
(0.059)\end{array}$ & $\begin{array}{c}0.260 * * * \\
(0.035)\end{array}$ & $\begin{array}{l}-0.027 \\
(0.035)\end{array}$ \\
\hline Mother's education & $\begin{array}{c}0.026 * * * \\
(0.009)\end{array}$ & $\begin{array}{c}-0.039 * * * \\
(0.006)\end{array}$ & $\begin{array}{c}0.148 * * * \\
(0.025)\end{array}$ & $\begin{array}{c}0.043 \\
(0.068)\end{array}$ & $\begin{array}{c}0.249 * * * \\
(0.039)\end{array}$ & $\begin{array}{c}-0.141^{* * *} \\
(0.042)\end{array}$ \\
\hline Father's social class & $\begin{array}{c}0.027 * * * \\
(0.006)\end{array}$ & $\begin{array}{c}-0.021 * * * \\
(0.004)\end{array}$ & $\begin{array}{c}0.103 * * * \\
(0.017)\end{array}$ & $\begin{array}{c}0.098 * * \\
(0.040)\end{array}$ & $\begin{array}{c}0.176 * * * \\
(0.024)\end{array}$ & $\begin{array}{l}-0.017 \\
(0.023)\end{array}$ \\
\hline Ln(income) & $\begin{array}{c}0.063 * * * \\
(0.018)\end{array}$ & $\begin{array}{c}-0.062 * * * \\
(0.013)\end{array}$ & $\begin{array}{c}0.359 * * * \\
(0.049)\end{array}$ & $\begin{array}{c}0.158 \\
(0.137)\end{array}$ & $\begin{array}{c}0.466 * * * \\
(0.075)\end{array}$ & $\begin{array}{l}-0.118 \\
(0.078)\end{array}$ \\
\hline Mother employed & $\begin{array}{c}0.056^{* * *} \\
(0.017)\end{array}$ & $\begin{array}{c}0.004 \\
(0.011)\end{array}$ & $\begin{array}{c}0.193 * * * \\
(0.046)\end{array}$ & $\begin{array}{c}0.128 \\
(0.112)\end{array}$ & $\begin{array}{c}0.214^{* * *} \\
(0.071)\end{array}$ & $\begin{array}{c}0.025 \\
(0.063)\end{array}$ \\
\hline Father employed & $\begin{array}{c}0.016 \\
(0.027)\end{array}$ & $\begin{array}{c}-0.065^{* * *} \\
(0.019)\end{array}$ & $\begin{array}{c}0.148 * * \\
(0.070)\end{array}$ & $\begin{array}{c}-0.196 \\
(0.241)\end{array}$ & $\begin{array}{c}0.291^{* * * *} \\
(0.096)\end{array}$ & $\begin{array}{c}-0.434^{* *} \\
(0.189)\end{array}$ \\
\hline CCEI & $\begin{array}{c}0.005^{* * *} \\
(0.001)\end{array}$ & $\begin{array}{c}0.006^{* * * *} \\
(0.001)\end{array}$ & $\begin{array}{c}0.007 * * \\
(0.003)\end{array}$ & $\begin{array}{c}0.036^{* * * *} \\
(0.011)\end{array}$ & $\begin{array}{c}0.008 \\
(0.005)\end{array}$ & $\begin{array}{c}0.020 * * * \\
(0.007)\end{array}$ \\
\hline EPDS & $\begin{array}{c}0.008 * * * \\
(0.002)\end{array}$ & $\begin{array}{c}0.009 * * * \\
(0.001)\end{array}$ & $\begin{array}{c}0.010 * * \\
(0.005)\end{array}$ & $\begin{array}{c}0.058 * * * \\
(0.017)\end{array}$ & $\begin{array}{c}0.017 * * \\
(0.008)\end{array}$ & $\begin{array}{c}0.031 * * * \\
(0.010)\end{array}$ \\
\hline Smoke (Trimester 1) & $\begin{array}{c}0.084 * * * \\
(0.021)\end{array}$ & $\begin{array}{c}0.163 * * * \\
(0.018)\end{array}$ & $\begin{array}{l}0.108^{*} \\
(0.061)\end{array}$ & $\begin{array}{c}1.004 * * * \\
(0.236)\end{array}$ & $\begin{array}{c}0.010 \\
(0.104)\end{array}$ & $\begin{array}{c}0.775^{* * * *} \\
(0.153)\end{array}$ \\
\hline
\end{tabular}

Notes: The coefficient estimates are obtained from separate regressions of the alcohol exposure of interest (denoted in the columns) on each of the covariates in column 1 . Robust standard errors are in parentheses, ${ }^{*} \mathrm{p}<0.10,{ }^{* *} \mathrm{p}<0.05,{ }^{* * *} \mathrm{p}<0.01$. 
Table 4: First Stage IV results

\begin{tabular}{|c|c|c|c|c|c|c|}
\hline & $\begin{array}{c}\text { (1) } \\
\text { Any alcohol } \\
\text { intake }\end{array}$ & $\begin{array}{c}\text { (2) } \\
\text { Binge } \\
\text { drinking }\end{array}$ & $\begin{array}{c}\text { (3) } \\
\text { Length of } \\
\text { exposure }\end{array}$ & $\begin{array}{c}\text { (4) } \\
\text { Average no. } \\
\text { of units of } \\
\text { alcohol } \\
\end{array}$ & $\begin{array}{l}\text { (5) } \\
\text { Average no. of } \\
\text { units of wine }\end{array}$ & $\begin{array}{c}\text { (6) } \\
\text { Average } \\
\text { no. of units } \\
\text { of beer } \\
\end{array}$ \\
\hline \multicolumn{7}{|c|}{ Sample for Entry Assessment } \\
\hline$A D H 1 B$ & $\begin{array}{c}-0.131 * * \\
(0.051)\end{array}$ & $\begin{array}{c}-0.062 * * \\
(0.028)\end{array}$ & $\begin{array}{c}-0.327 * * * \\
(0.113)\end{array}$ & $\begin{array}{c}-0.818^{* * *} \\
(0.189)\end{array}$ & $\begin{array}{c}-0.325^{* *} \\
(0.128)\end{array}$ & $\begin{array}{c}-0.245^{* * *} \\
(0.063)\end{array}$ \\
\hline First stage $F$-statistic & 6.62 & 4.95 & 8.32 & 18.74 & 6.40 & 15.17 \\
\hline$N$ & 2614 & 3238 & 1982 & 1922 & 1473 & 1275 \\
\hline \multicolumn{7}{|l|}{ Sample for Key Stage 1} \\
\hline$A D H 1 B$ & $\begin{array}{c}-0.131^{* * *} \\
(0.046)\end{array}$ & $\begin{array}{c}-0.061 * * \\
(0.025)\end{array}$ & $\begin{array}{c}-0.364 * * * \\
(0.108)\end{array}$ & $\begin{array}{c}-0.822 * * * \\
(0.203)\end{array}$ & $\begin{array}{c}-0.396^{* * *} \\
(0.115)\end{array}$ & $\begin{array}{c}-0.239 * * * \\
(0.051)\end{array}$ \\
\hline First stage $F$-statistic & 8.18 & 5.90 & 11.48 & 16.37 & 11.90 & 21.54 \\
\hline$N$ & 3319 & 4088 & 2518 & 2433 & 1862 & 1569 \\
\hline \multicolumn{7}{|l|}{ Sample for Key Stage 2} \\
\hline$A D H 1 B$ & $\begin{array}{c}-0.147 * * * \\
(0.048)\end{array}$ & $\begin{array}{c}-0.070 * * * \\
(0.025)\end{array}$ & $\begin{array}{c}-0.375^{* * *} \\
(0.106)\end{array}$ & $\begin{array}{c}-0.859 * * * \\
(0.189)\end{array}$ & $\begin{array}{c}-0.417 * * * \\
(0.111)\end{array}$ & $\begin{array}{c}-0.241 * * * \\
(0.049)\end{array}$ \\
\hline First stage $F$-statistic & 9.52 & 7.79 & 12.51 & 20.66 & 13.98 & 24.76 \\
\hline$N$ & 3132 & 3868 & 2372 & 2293 & 1747 & 1475 \\
\hline \multicolumn{7}{|l|}{ Sample for Key Stage 3} \\
\hline$A D H 1 B$ & $\begin{array}{c}-0.108^{* *} \\
(0.050)\end{array}$ & $\begin{array}{c}-0.071 * * * \\
(0.026)\end{array}$ & $\begin{array}{c}-0.282 * * \\
(0.118)\end{array}$ & $\begin{array}{c}-0.773 * * * \\
(0.208)\end{array}$ & $\begin{array}{c}-0.338^{* * *} \\
(0.131)\end{array}$ & $\begin{array}{c}-0.265^{* * *} \\
(0.058)\end{array}$ \\
\hline First stage $F$-statistic & 4.61 & 7.31 & 5.74 & 13.84 & 6.69 & 20.57 \\
\hline$N$ & 2872 & 3572 & 2179 & 2106 & 1600 & 1381 \\
\hline \multicolumn{7}{|l|}{ Sample for Key Stage 4} \\
\hline$A D H 1 B$ & $\begin{array}{c}-0.147 * * * \\
(0.047)\end{array}$ & $\begin{array}{c}-0.067 * * * \\
(0.025)\end{array}$ & $\begin{array}{c}-0.379 * * * \\
(0.105)\end{array}$ & $\begin{array}{c}-0.857 * * * \\
(0.180)\end{array}$ & $\begin{array}{c}-0.391^{* * *} \\
(0.107)\end{array}$ & $\begin{array}{c}-0.254 * * * \\
(0.049)\end{array}$ \\
\hline First stage $F$-statistic & 9.96 & 7.41 & 12.97 & 22.77 & 13.26 & 26.46 \\
\hline$N$ & 3201 & 3955 & 2428 & 2345 & 1795 & 1521 \\
\hline
\end{tabular}

Notes: All estimates come from separate regressions and control for ancestry-informative principal components and the child's $A D H 1 B$. Robust standard errors in parentheses. * $\mathrm{p}<0.10, * * \mathrm{p}<0.05, * * * \mathrm{p}<0.01$. 
Table 5: Second Stage IV results

\begin{tabular}{ccccc}
$(1)$ & $(2)$ & $(3)$ & $(4)$ & $(5)$ \\
Entry & KS1, age 7 & KS2, age 11 & KS3, age 14 & KS4, age 16 \\
Assessment & & & & \\
\hline
\end{tabular}

\section{Panel A: Anv alcohol intake}

Any alcohol intake

95\% Confidence intervals

$N$

Panel B: Pattern and duration

-0.685
$[-4.45,0.84]$
2614

$-1.372 \dagger$

$[-4.85,-0.24]$

3319

$[-4.59,-0.43]$

3132

$-1.724$

$[-18.6,-0.23]$

2872

$-1.557 \dagger$

[-4.57, -0.47]

3201

\section{Bingeing}

95\% Confidence intervals

N

Length of exposure

95\% Confidence intervals

N

Panel C: Average alcohol intake

Average units of alcohol

95\% Confidence intervals N

Average units of wine 95\% Confidence intervals $N$

Average units of beer 95\% Confidence intervals N

$\begin{array}{ccccc}-1.782 & -2.623 \dagger & -2.855 \dagger & -2.618 \dagger & -3.134 \dagger \\ {[-13.8,1.51]} & {[-12.7,-0.46]} & {[-9.68,-0.84]} & {[-9.84,-0.58]} & {[-11.1,-1.06]} \\ 3238 & 4088 & 3868 & 3572 & 3955 \\ & & & & \\ -0.486 & -0.591 \dagger & -0.693 \dagger & -0.665 & -0.610 \dagger \\ {[-2.21,0.13]} & {[-1.67,-0.14]} & {[-1.81,-0.20]} & {[-3.74,0.01]} & {[-1.64,-0.13]} \\ 1982 & 2518 & 2372 & 2179 & 2428\end{array}$

$[-0.57,0.06]$

1922

$-0.245 \dagger$

$[-0.57,-0.05]$

2433

$-0.298+$

$-0.232$

$-0.274 \dagger$

[-0.64, -0.08]

2293

$[-0.63,0.02]$

2106

$[-0.60,-0.06]$

$-0.480$

$[-2.95,0.21]$

1473

$-0.554 \dagger$

$-0.657 \dagger$

$[-1.60,-0.10]$

1862

$-0.520$

[-1.66, -0.17]

1747

$[-2.24,0.14]$

1600

2345

$-0.895$

[-2.53, 0.09]

$-1.061 \dagger$

$-1.462 \dagger$

$[-2.39,-0.25]$

1569

[-2.96, -0.54]

$-1.176 \dagger$

1475

$[-2.54,-0.35]$

1381
$-0.621 \dagger$

1795

$-1.105 \dagger$

$[-2.40,-0.22]$

1521
[-1.68, -0.10]

Notes: All estimates come from separate regressions and control for ancestry-informative principal components and the child's $A D H 1 B$. Weak-instrument robust $95 \%$ confidence bounds in square brackets. $\dagger \mathrm{p}<0.05$ using weak-instrument robust 95\% confidence bounds. 
Table 6: Reduced form estimates - academic achievement regressed on mother's and/or offspring $A D H 1 B$

$\begin{array}{ccccc}(1) & (2) & (3) & (4) & (5) \\ \text { Entry } & \text { KS1, age 7 } & \text { KS2, age 11 } & \text { KS3, age 14 } & \text { KS4, age 16 } \\ \text { Assessment } & & & & \end{array}$

Panel A: Separate regressions

$\begin{array}{lccccc}\text { Maternal } A D H 1 B(\mathrm{rs} 1229984) & 0.030 & 0.159 * * & 0.180^{* * *} & 0.142^{*} & 0.214^{* * * *} \\ & (0.086) & (0.068) & (0.068) & (0.074) & (0.069) \\ N & 2564 & 3255 & 3067 & 2812 & 3138 \\ & & & & & \\ \text { Offspring } A D H 1 B(\mathrm{rs} 1229984) & -0.146^{*} & 0.011 & -0.007 & -0.011 & 0.040 \\ N & (0.088) & (0.071) & (0.080) & (0.078) & (0.065) \\ N & 2564 & 3255 & 3067 & 2812 & 3138\end{array}$

Panel B: Including both genotypes simultaneously

\begin{tabular}{|c|c|c|c|c|c|}
\hline Maternal $A D H 1 B$ (rs1229984) & $\begin{array}{c}0.118 \\
(0.096)\end{array}$ & $\begin{array}{c}0.198 * * * \\
(0.075)\end{array}$ & $\begin{array}{c}0.239 * * * \\
(0.082)\end{array}$ & $\begin{array}{c}0.192 * * \\
(0.085)\end{array}$ & $\begin{array}{c}0.250 * * * \\
(0.079)\end{array}$ \\
\hline Offspring $A D H 1 B$ (rs1229984) & $\begin{array}{c}-0.202^{* *} \\
(0.098)\end{array}$ & $\begin{array}{l}-0.082 \\
(0.079)\end{array}$ & $\begin{array}{l}-0.122 \\
(0.093)\end{array}$ & $\begin{array}{c}-0.103 \\
(0.089)\end{array}$ & $\begin{array}{l}-0.075 \\
(0.074)\end{array}$ \\
\hline$N$ & 2564 & 3255 & 3067 & 2812 & 3138 \\
\hline
\end{tabular}

Notes: All estimates come from separate regressions that control for ten ancestry-informative principal components. Robust standard errors in parentheses, ${ }^{*} \mathrm{p}<0.10,{ }^{* *} \mathrm{p}<0.05$, *** $\mathrm{p}<0.01$. 
Table 7: Subgroup analysis, number of alcoholic units

\begin{tabular}{|c|c|c|c|c|c|}
\hline & $\begin{array}{c}(1) \\
\text { Entry } \\
\text { Assessment } \\
\end{array}$ & $\begin{array}{c}\text { (2) } \\
\text { KS1, age } 7\end{array}$ & $\begin{array}{c}\text { (3) } \\
\text { KS2, age } 11\end{array}$ & $\begin{array}{c}\text { (4) } \\
\text { KS3, age } 14\end{array}$ & $\begin{array}{c}\text { (5) } \\
\text { KS4, age } 16\end{array}$ \\
\hline \multicolumn{6}{|l|}{ By gender } \\
\hline Boys & $\begin{array}{l}-0.167 \\
(0.170)\end{array}$ & $\begin{array}{c}-0.278 * * \\
(0.128)\end{array}$ & $\begin{array}{l}-0.217 \\
(0.133)\end{array}$ & $\begin{array}{l}-0.240 * \\
(0.141)\end{array}$ & $\begin{array}{c}-0.390 * * \\
(0.168)\end{array}$ \\
\hline First stage F-statistic & 12.832 & 15.681 & 15.618 & 12.007 & 15.307 \\
\hline$N$ & 1000 & 1239 & 1151 & 1060 & 1188 \\
\hline Girls & $\begin{array}{l}-0.182 \\
(0.212)\end{array}$ & $\begin{array}{l}-0.185 \\
(0.207)\end{array}$ & $\begin{array}{l}-0.438 \\
(0.274)\end{array}$ & $\begin{array}{l}-0.180 \\
(0.310)\end{array}$ & $\begin{array}{l}-0.087 \\
(0.192)\end{array}$ \\
\hline First stage F-statistic & 7.838 & 4.200 & 7.533 & 3.740 & 9.415 \\
\hline$N$ & 922 & 1194 & 1142 & 1046 & 1157 \\
\hline \multicolumn{6}{|l|}{ By mother's age at birth } \\
\hline Mothers aged 27 or less & $\begin{array}{c}0.150 \\
(0.239)\end{array}$ & $\begin{array}{c}-0.233 \\
(0.227)\end{array}$ & $\begin{array}{l}-0.420 \\
(0.307)\end{array}$ & $\begin{array}{c}-0.412 \\
(0.291)\end{array}$ & $\begin{array}{l}-0.174 \\
(0.221)\end{array}$ \\
\hline First stage F-statistic & 5.362 & 6.317 & 5.141 & 4.864 & 7.030 \\
\hline$N$ & 789 & 962 & 909 & 867 & 928 \\
\hline Mothers aged over 27 & $\begin{array}{c}-0.424 * * \\
(0.185)\end{array}$ & $\begin{array}{c}-0.265^{* *} \\
(0.126)\end{array}$ & $\begin{array}{c}-0.261^{* *} \\
(0.129)\end{array}$ & $\begin{array}{l}-0.158 \\
(0.162)\end{array}$ & $\begin{array}{c}-0.326^{* *} \\
(0.141)\end{array}$ \\
\hline First stage F-statistic & 11.197 & 9.545 & 13.909 & 7.712 & 13.849 \\
\hline$N$ & 1133 & 1471 & 1384 & 1239 & 1417 \\
\hline \multicolumn{6}{|l|}{ By social class } \\
\hline Low social class & $\begin{array}{l}-0.221 \\
(0.213)\end{array}$ & $\begin{array}{l}-0.255^{*} \\
(0.144)\end{array}$ & $\begin{array}{c}-0.440 * * \\
(0.204)\end{array}$ & $\begin{array}{l}-0.305^{*} \\
(0.172)\end{array}$ & $\begin{array}{l}-0.293^{*} \\
(0.176)\end{array}$ \\
\hline First stage F-statistic & 7.232 & 9.245 & 10.037 & 7.951 & 9.939 \\
\hline$N$ & 817 & 977 & 941 & 889 & 952 \\
\hline High social class & $\begin{array}{l}-0.262 \\
(0.237)\end{array}$ & $\begin{array}{l}-0.303^{*} \\
(0.180)\end{array}$ & $\begin{array}{l}-0.184 \\
(0.164)\end{array}$ & $\begin{array}{l}-0.184 \\
(0.240)\end{array}$ & $\begin{array}{l}-0.258 \\
(0.178)\end{array}$ \\
\hline First stage F-statistic & 8.050 & 6.593 & 9.273 & 5.496 & 11.589 \\
\hline$N$ & 1010 & 1346 & 1254 & 1118 & 1287 \\
\hline \multicolumn{6}{|l|}{ By maternal educational level } \\
\hline Low education & $\begin{array}{l}-0.188 \\
(0.313)\end{array}$ & $\begin{array}{l}-0.279 \\
(0.209)\end{array}$ & $\begin{array}{l}-0.507 \\
(0.310)\end{array}$ & $\begin{array}{l}-0.232 \\
(0.230)\end{array}$ & $\begin{array}{c}-0.433^{*} \\
(0.257)\end{array}$ \\
\hline First stage F-statistic & 3.422 & 5.770 & 4.878 & 4.241 & 6.395 \\
\hline$N$ & 1231 & 1478 & 1414 & 1353 & 1444 \\
\hline High education & $\begin{array}{l}-0.156 \\
(0.126)\end{array}$ & $\begin{array}{l}-0.140 \\
(0.105)\end{array}$ & $\begin{array}{l}-0.060 \\
(0.086)\end{array}$ & $\begin{array}{l}-0.106 \\
(0.114)\end{array}$ & $\begin{array}{l}-0.051 \\
(0.100)\end{array}$ \\
\hline First stage F-statistic & 20.346 & 10.947 & 20.855 & 11.266 & 21.018 \\
\hline$N$ & 688 & 952 & 876 & 750 & 898 \\
\hline \multicolumn{6}{|l|}{ By income } \\
\hline Low income (less than median) & $\begin{array}{l}-0.404 \\
(0.272)\end{array}$ & $\begin{array}{l}-0.319 \\
(0.195)\end{array}$ & $\begin{array}{l}-0.405 \\
(0.260)\end{array}$ & $\begin{array}{l}-0.258 \\
(0.271)\end{array}$ & $\begin{array}{l}-0.321 \\
(0.212)\end{array}$ \\
\hline First stage F-statistic & 6.580 & 8.471 & 7.814 & 4.602 & 8.437 \\
\hline$N$ & 853 & 1027 & 978 & 939 & 1005 \\
\hline High income (more than median) & $\begin{array}{c}0.007 \\
(0.199)\end{array}$ & $\begin{array}{l}-0.081 \\
(0.131)\end{array}$ & $\begin{array}{l}-0.104 \\
(0.110)\end{array}$ & $\begin{array}{l}-0.087 \\
(0.139)\end{array}$ & $\begin{array}{l}-0.061 \\
(0.136)\end{array}$ \\
\hline First stage F-statistic & 7.161 & 5.263 & 8.165 & 4.775 & 9.427 \\
\hline$N$ & 820 & 1090 & 1020 & 883 & 1040 \\
\hline
\end{tabular}

Notes: All estimates come from separate regressions where the treatment of interest is the number of alcoholic units consumed. All analyses control for ancestry-informative principal components and the child's $A D H 1 B$. Robust standard errors in parentheses. Low social class indicates non-skilled, semi-skilled or skilled manual occupations; High social class indicates skilled non-manual, managerial or professional occupations. Low education denotes O-level or less, high education indicates A-level or university degree. ${ }^{*} \mathrm{p}<0.10, * * \mathrm{p}<0.05, * * * \mathrm{p}<0.01$. 